\title{
Si-based polymer-derived ceramics for energy conversion and storage
}

\author{
Qingbo WEN ${ }^{a, \dagger}$, Fangmu $\mathrm{QU}^{c, \dagger}$, Zhaoju YU $\mathrm{U}^{b, *}$, \\ Magdalena GRACZYK-ZAJAC ${ }^{c, d^{*}}$, Xiang XIONG ${ }^{a}$, Ralf RIEDEL ${ }^{c}$ \\ ${ }^{a}$ State Key Laboratory of Powder Metallurgy, Central South University, Changsha 410083, China \\ ${ }^{b}$ College of Materials, Key Laboratory of High-Performance Ceramic Fibers (Xiamen University), \\ Ministry of Education, Xiamen 361005, China \\ ${ }^{c}$ Technische Universität Darmstadt, Institut für Materialwissenschaft, Otto-Berndt-Straße 3, \\ D-64287, Darmstadt, Germany \\ ${ }^{d}$ EnBW Energie Baden-Württemberg AG, Durlacher Allee 93, 76131 Karlsruhe, Germany
}

Received: September 30, 2021; Revised: December 5, 2021; Accepted: December 7, 2021

(c) The Author(s) 2021.

\begin{abstract}
Since the 1960s, a new class of Si-based advanced ceramics called polymer-derived ceramics (PDCs) has been widely reported because of their unique capabilities to produce various ceramic materials (e.g., ceramic fibers, ceramic matrix composites, foams, films, and coatings) and their versatile applications. Particularly, due to their promising structural and functional properties for energy conversion and storage, the applications of PDCs in these fields have attracted much attention in recent years. This review highlights the recent progress in the PDC field with the focus on energy conversion and storage applications. Firstly, a brief introduction of the Si-based polymer-derived ceramics in terms of synthesis, processing, and microstructure characterization is provided, followed by a summary of PDCs used in energy conversion systems (mainly in gas turbine engines), including fundamentals and material issues, ceramic matrix composites, ceramic fibers, thermal and environmental barrier coatings, as well as high-temperature sensors. Subsequently, applications of PDCs in the field of energy storage are reviewed with a strong focus on anode materials for lithium and sodium ion batteries. The possible applications of the PDCs in Li-S batteries, supercapacitors, and fuel cells are discussed as well. Finally, a summary of the reported applications and perspectives for future research with PDCs are presented.
\end{abstract}

Keywords: polymer-derived ceramics (PDCs); high-temperature resistance; structural properties; electrochemical properties; microstructure

\section{Introduction}

In the modern society, energy is necessary for almost

$\uparrow$ Qingbo Wen and Fangmu Qu contributed equally to this work.

* Corresponding authors.

E-mail: Z. Yu, zhaojuyu@xmu.edu.cn;

M. Graczyk-Zajac, m.graczyk-zajac@enbw.com every activity of our life from household tasks, transportation, and entertainment, to architecture, agriculture, and manufacturing [1]. Because of a global development of human beings' society, energy use and production is predicted to increase by $60 \%$ from 2010 to 2040 [1,2]. The first law of thermodynamics states that energy can be neither created nor destroyed but only converted from one form to another. Therefore, 
strictly speaking, energy production (e.g., power generation and solar energy harvesting) is energy conversion. The traditional energy conversion systems (e.g., steam turbine engines, gas/combustion turbine engines) mainly use fossil fuels as energy sources, which however leads to serious pollutant emissions and global warming. Thus, in recent years, clean and sustainable energy conversion systems have been widely developed, such as hydroelectric power generators, wind turbine generators (wind mills), solar cells, and fuel cells. It is well known that the power plants using steam and/or gas turbine engines can be operated continuously and therefore can be well integrated into the electric grids. However, for most of the sustainable energy conversion systems, the intermittency feature strongly limits their integration into the electric grids and large-scale applications. In order to solve this problem, energy storage systems, such as novel secondary batteries and super capacitors with long life and high charge/discharge efficiency, are urgently demanded.

In the last 100 years, energy conversion and storage systems have experienced a large revolution with the development of materials which possess dramatically improved structural and functional properties. One good example is the increasing application of advanced ceramics despite that most of the time, these "hidden champions" cannot be seen by the end users and consumers [1]. Advanced ceramics (e.g., $\mathrm{SiC}_{\mathrm{C}} \mathrm{Si}_{3} \mathrm{~N}_{4}$ ) is a class of inorganic and nonmetallic polycrystalline materials, which provide a good combination of high strength, high hardness, outstanding oxidation resistance, as well as excellent thermal stability and chemical durability. Importantly, their properties and performance can be tailored and optimized via modifying the chemical/phase compositions and microstructure. Therefore, advanced ceramics have been broadly used in energy conversion and storage devices [1].

In the early 1960s, a new class of advanced ceramics produced via pyrolysis of organosilicon polymers has been developed, namely polymer-derived ceramics (PDCs) [3,4]. Because of their unique capabilities to produce ceramic fibers $[5,6]$, films/ coatings [7-10], foams [11], nanocomposites [12-15], ceramic matrix composites (CMCs) [16-19] and for additive manufacturing [20,21], PDCs have been extensively investigated for more than 50 years and have received increasing attention in recent years [5,22-37]. Generally, the preparation of silicon-based PDCs requires 3 steps: (1) synthesis of Si-containing preceramic polymers; (2) shaping and crosslinking $\left(100-400{ }^{\circ} \mathrm{C}\right)$; (3) polymer-to-ceramic transformation $\left(400-1400{ }^{\circ} \mathrm{C}\right)$ [35,38]. After polymer-to-ceramic transformation, the PDCs are generally amorphous. When annealed at higher temperatures $\left(\geqslant 1400{ }^{\circ} \mathrm{C}\right)$, they will transform into (poly)crystalline ceramics. The general temperature range for processing of PDCs is shown in Fig. 1.

It has been widely reported that the chemical and phase composition as well as microstructure of the PDCs are strongly determined by the molecular structure of the preceramic polymer [41-47]. The molecular structure design and polymer-to-ceramic transformation enable facile fabrication of Si-based ternary (e.g., SiOC [48-52], SiCN [53-57], SiHfC [12], SiTaC [58]), quaternary (e.g., SiCNO [59-62], SiBCO [63-65], SiAlCO [66-69], SiAlCN [70-73], SiBCN [31,74-77],

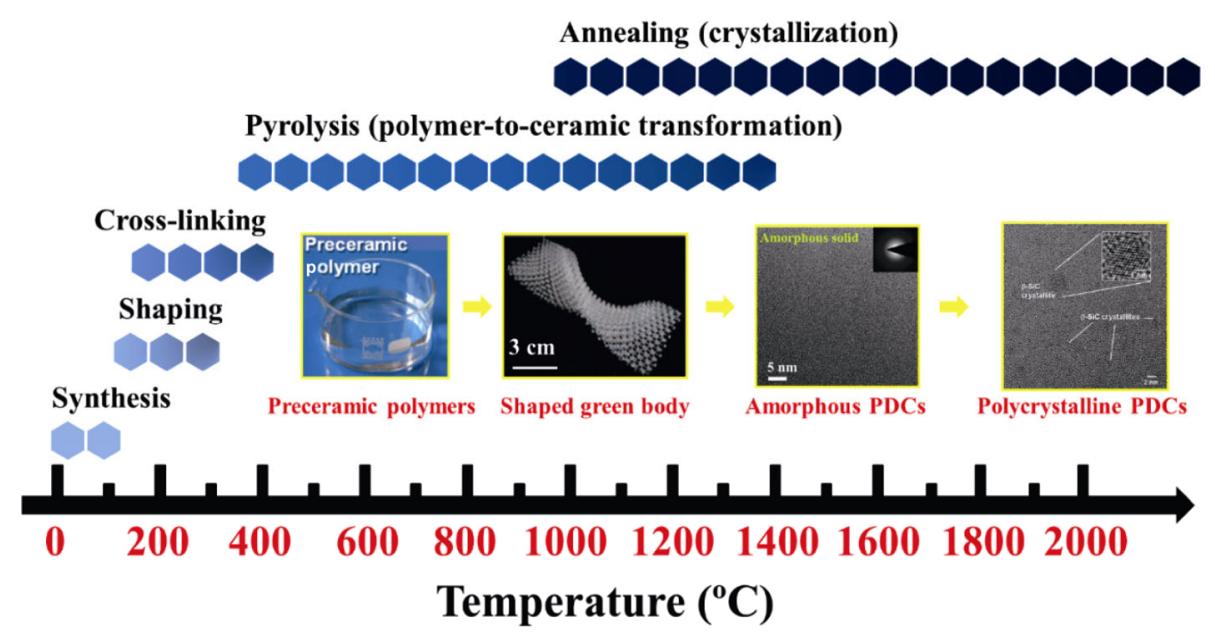

Fig. 1 General processes involved in the producing of polymer-derived ceramics. Reproduced with permission from Ref. [36], (C) Elsevier Ltd. 2019; Ref. [39], C Acta Materialia Inc. 2017; Ref. [40], (C) Elsevier Ltd. 2016. 
SiHfTaC [78]), as well as pentanary (e.g., SiHfCNO [79,80], SiHfBCN [81-84]) ceramics, which are difficult to produce using other methods $[35,36,85]$. Owing to their tunable structures/compositions, excellent high-temperature stabilities as well as their capabilities for being shaped via various processing techniques (e.g., fiber drawing [5,25,86,87], dip- or spin-coating [9,88-91], freeze casting [50,92-94], additive manufacturing (3D printing) [20,21,95-98], and warm pressing [32,99-102]), PDCs can be conveniently used in plenty of technological key fields, such as high-temperature structural applications (e.g., thermal/environmental barrier coatings [9,103-105]), ceramic matrix composites [19,82,106,107], joining/ adhesive materials $[108,109]$, anode materials used in lithium/sodium ion batteries [110-117], porous electrode used for supercapacitors [118-120], electromagnetic absorbing and shielding applications [121-125], micro-electromechanical systems (MEMS) [126-131], photoluminescent applications [132-135], tribological applications (e.g., brakes for motorbikes) [136-140], sensing materials [141-144], and biomedical components [145-147]. Detailed information with respect to the application of PDCs can be found in various review articles and books [30,35,127,148-154].

As mentioned above, advanced technologies for energy conversion and storage become increasingly important for our daily life and for the future of human beings. Therefore, the applications of PDCs in energy conversion and storage have attracted much attention in recent years as well [110-115]. However, no review articles regarding the applications of PDCs in the areas of energy conversion and storage have been published. Therefore, this review will focus on recent progress of PDCs in energy conversion and storage applications in order to provide a comprehensive summary of the PDCs used in this field and to facilitate their further development. Firstly, synthesis of the preceramic polymers, polymer-to-ceramic transformation, and microstructure characterization of the silicon-based PDCs will be briefly introduced. Then, applications of PDCs in energy conversion and energy storage will be systematically summarized. The correlation between the microstructure and associated properties will be comprehensively highlighted in this part as well. Finally, the perspectives of PDCs in the field of energy conversion and storage will be discussed. Actually, a few Si-free PDCs have also been reported in the last few years, such as the polymer-derived $\mathrm{BCN}$
[155-157], BN [158-162], $\mathrm{ZrO}_{2}$ [163], as well as transition metal nitrides [164-166], carbides [167-172], and borides [173-175]. In order to be more exalted, the present review mainly focuses on Si-based PDCs.

\section{Si-based polymer-derived ceramics}

\section{1 Synthesis of preceramic polymers}

Polymer-derived ceramics mean that the ceramics are produced from polymers, which differentiates them from those fabricated via the traditional powder technological route. However, not all polymers can be used as preceramic precursors. Typically, they are thermosetting polymers and should meet some requirements for practical applications: (1) high molecular weight with low volatilization during pyrolysis; (2) no uncontrolled polymerization (e.g., gelation or crosslinking) for storage; (3) good solubility or suitable rheological properties for shaping; (4) presence of functional groups for further reaction or modification; (5) defined molecular structure for the synthesis of stoichiometric ceramic compositions (e.g., $\left.\mathrm{SiC}, \mathrm{Si}_{3} \mathrm{~N}_{4}\right)[38,85]$.

In the last 50 years, numbers of Si-based preceramic polymers with different molecular structures have been synthesized [35]. As shown in Fig. 2, organochlorosilanes are always used as the starting materials to synthesize different silicon-based polymers. For instance, the polycarbosilanes, polysiloxanes, and polysilazanes are synthesized via reactions of organochlorosilanes with $\mathrm{Na} / \mathrm{K}$, water, and ammonia, respectively. Poly(silylcarbodiimides) are synthesized via reactions between organochlorosilanes and bis(trimethylsilyl)carbodiimide. For the well-known $\mathrm{SiBCN}$ ceramics, at least two different approaches can be used (i.e., starting from monomers or chemical modification of polysilazanes or poly(silylcarbodiimides)) to synthesize the preceramic polymers (i.e., polyborosilazane or polyborosilylcarbodiimide). The chemical modification basically relies on hydroboration reactions between B-H groups of the modifiers (e.g., $\mathrm{BH}_{3} \cdot \mathrm{SMe}_{2}$ ) and unsaturated carbon bonds of the hydrocarbon side group (e.g., vinyl or allyl groups) as well as on dehydrocoupling reactions between $\mathrm{B}-\mathrm{H}$ and $\mathrm{N}-\mathrm{H}$ bonds on the backbone of the polymers [31,176-179]. For more detailed synthesis routes, please refer to previously reported review articles [35,85,179-185]. 


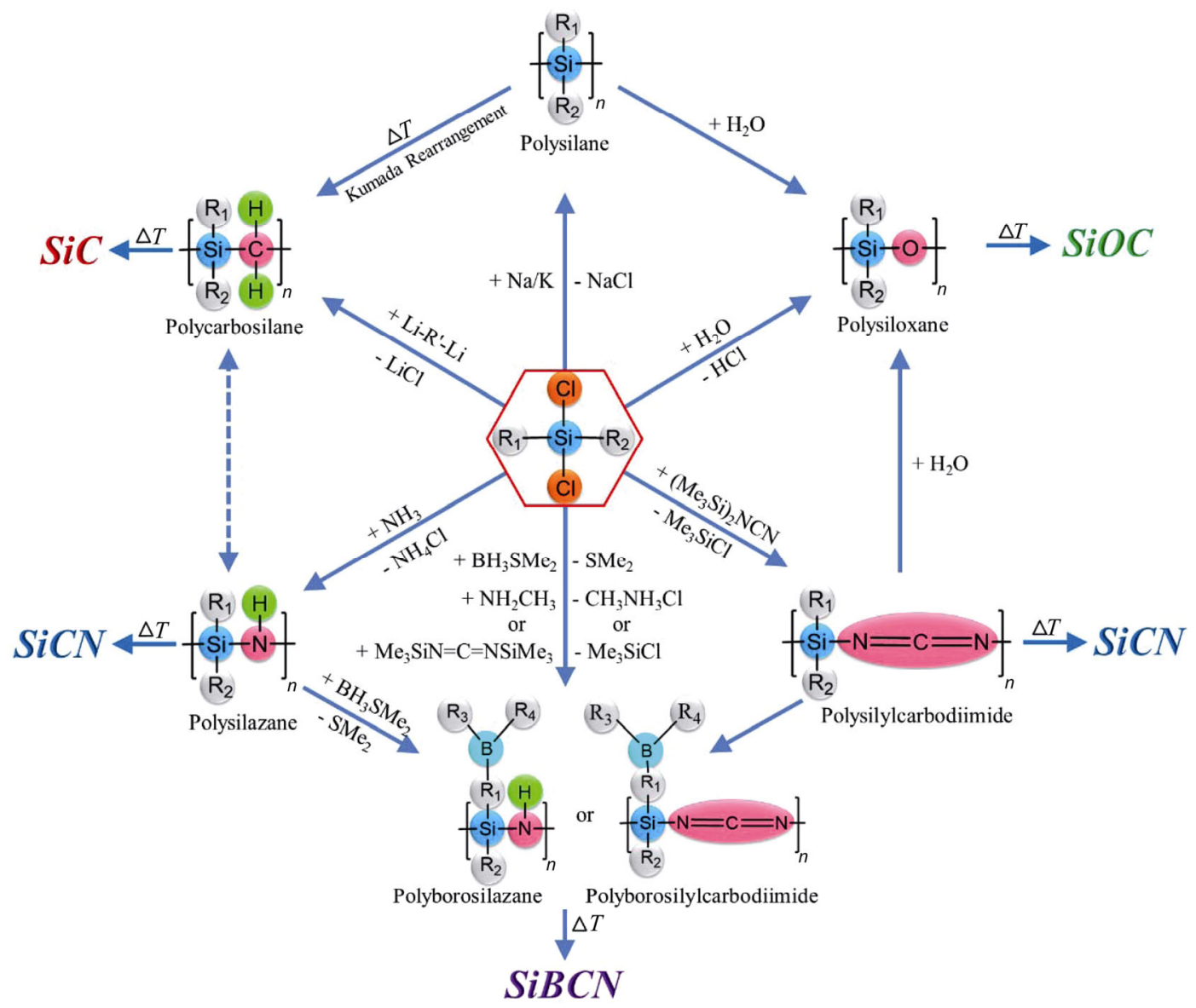

Fig. 2 Synthetic routes for typical Si-based polymers and associated ceramics from organochlorosilanes. $R_{1}-R_{4}$ represent organic groups or hydrogen attached to silicon of the polymer backbone. Reproduced with permission from Ref. [36], (C) Elsevier Ltd. 2019.

\section{2 Crosslinking}

Before transformation into ceramics, there is an important step, in which the preceramic polymers are converted into infusible organic/inorganic materials, namely crosslinking. This is a crucial step because it not only retains the shape of the precursors but also increases the ceramic yield due to the formation of a continuous network within the infusible precursors [186,187]. Based on molecular structure of the polymers and requirements of the resultant ceramics, different initiation mechanisms of the crosslinking process can be utilized [35]. Thermal crosslinking is usually employed $\left(200-400{ }^{\circ} \mathrm{C}\right)$ when the chemical and phase compositions of final ceramics must be controlled. This is because, under this condition, no additional elements are introduced. The thermal crosslinking capability comes from the condensation or addition reactions which occur between the functional groups on the preceramic polymers (e.g., $\mathrm{Si}-\mathrm{OH}, \mathrm{Si}-\mathrm{H}$,
$\mathrm{N}-\mathrm{H}$, and allyl/vinyl substituents) [35,183]. As reported, during the thermal crosslinking process, four major reactions are generally involved, namely, polymerization (e.g., vinyl or allyl groups), hydrosilylation (e.g., $\mathrm{Si}-\mathrm{H} /$ vinyl groups), transamination (i.e., evolution of amines, ammonia, or oligomeric silazanes), and dehydrocoupling (e.g., $\mathrm{Si}-\mathrm{H} / \mathrm{Si}-\mathrm{H}$ or $\mathrm{Si}-\mathrm{H} / \mathrm{N}-\mathrm{H}$ groups) $[12,36,81,99,183,188-190]$. As a function of temperature, the reaction activities are in the order of hydrosilylation $>$ dehydrocoupling $>$ transamination $>$ vinyl group polymerization [188]. Furthermore, in order to reduce the crosslinking temperature, some catalysts (e.g., dicumyl peroxide, transition metal ions) can be used [12,131,191]. Moreover, the crosslinking activity can be also initiated using other methods, such as oxygen [6,25,192-196], electron-beam [150,196-198], UV light [126,199-202], laser beam (3D printing) [21,203-211], or other reactive gases (e.g., $\mathrm{NH}_{3}, \mathrm{NO}_{2}$ ) [212-215], reactive plasma (based on $\mathrm{NH}_{3}, \mathrm{CH}_{4}, \mathrm{O}_{2}, \mathrm{SiH}_{4}$, or $\mathrm{BH}_{3}$ gas) 
[216,217], or even via highly alkaline solutions [218]. Most of these methods are able to start the crosslinking behavior at room temperature.

\section{3 Polymer-to-ceramic transformation}

After crosslinking, the next step of the synthesis of PDCs is the polymer-to-ceramic transformation, i.e., ceramization. The ceramization process occurs during pyrolysis at temperatures from 400 to $1400{ }^{\circ} \mathrm{C}$ (Fig. 1) [38]. As shown in Fig. 2, after ceramization, the poly(organosiloxanes), poly(organocarbosilanes), poly(organoborosilazane), as well as poly(organosilazanes)/ poly(organosilylcarbodiimides) are transformed into amorphous $\mathrm{SiOC}, \mathrm{SiC}, \mathrm{SiBCN}$, and $\mathrm{SiCN}$ ceramics, respectively. During polymer-to-ceramic transformation, different atmospheres, inert or reactive gases, are used. Interestingly, the atmosphere strongly affects the ceramic yield as well as the chemical/phase composition of the resultant ceramics [35]. For example, in PDCs, free carbon always exists in the ceramic matrix because of the presence of hydrocarbon groups on the polymers [36]. It is hard to avoid free carbon in PDCs if using argon or nitrogen as protective gas, whereas free carbon can be reduced or even completely removed when pyrolysis is performed in $\mathrm{H}_{2}$ [40,219221]. Moreover, in addition to the generally used pyrolysis method [35], the ceramization process can be achieved through rapid thermal annealing [222], plasma spraying [223], laser pyrolysis [224-229], flash pyrolysis [230], microwave pyrolysis [231,232], and ion irradiation [233-237]. The ion irradiation is a nonthermal ceramization process which occurs by elimination of hydrogen atoms via cleavage of $\mathrm{C}-\mathrm{H}$ bonds [235,236,238-240].

\section{4 Microstructure}

The microstructure of PDCs has been comprehensively characterized by using various techniques that can provide the average/integral information of the microstructures (e.g., X-ray diffraction (XRD), small-angle X-ray scattering (SAXS), magic-angle spinning nuclear magnetic resonance (MAS-NMR), Fourier transform infrared spectroscopy (FT-IR), Raman spectroscopy and small-angle neutron scattering (SANS)) or local information at the nanometer scale (e.g., scanning electron microscopy (SEM), transmission electron microscopy (TEM), electron energy loss spectroscopy (EELS), and energy-filtered transmission electron microscopy (EF-TEM)) [35,36]. Furthermore, theoretical simulations have also been employed to investigate the microstructures of PDCs [241-246] and numbers of modes have been developed to understand the relationship between microstructure and properties [54,241,243,247].

Silicon oxycarbide (SiOC) and silicon carbonitride $(\mathrm{SiCN})$ are two typical polymer-derived ceramics which possess unique microstructures hard to be observed in other ceramic materials [54]. The SiOC is generally amorphous with $\mathrm{Si}$ atoms tetrahedrally coordinated by $\mathrm{O}$ and $\mathrm{C}$ atoms $[49,54,248,249]$. Thus, within the $\mathrm{SiOC}$ ceramics, $\mathrm{SiC}_{4}, \mathrm{SiC}_{3} \mathrm{O}, \mathrm{SiC}_{2} \mathrm{O}_{2}$, and $\mathrm{SiO}_{4}$ tetrahedral units with "Si-O/-C" mixed bonds can be clearly detected $[54,250]$. A classic model (see Model 1 in Fig. 3) for the microstructure of the SiOC ceramics has been proposed in 2005 [251,252]. According to this model, the SiOC ceramic is constructed by three constituents: (1) the clusters of silica tetrahedra that form the heart of the nanodomains; (2) the graphene cage-like network that encases the silica nanodomains, and (3) the monolayer of $\mathrm{SiC}_{x} \mathrm{O}_{4-x}$ mixed bonds $(0 \leqslant x \leqslant 4)$ that interconnect the silica nanodomains with the graphene network. This model is consistent with the experimentally determined data including MAS-NMR and SAXS results as well as the mechanical properties (e.g., unique viscoelastic behavior and high creep resistance) of the SiOC ceramics.

In addition, another model (see Model 2 in Fig. 3) with two continuous interpenetrating phases (i.e., silica-rich phase and free carbon) and a carbon-rich $\mathrm{SiO}_{x} \mathrm{C}_{4-x}$ interface (Fig. 3(b)) was also proposed [36]. However, according to the experimental results, Model 2 was ruled out in Saha et al.'s work because it cannot interpret the unique creep and viscoelastic behavior of the SiOC ceramics [251,252]. Interestingly, based on the high-resolution ${ }^{29} \mathrm{Si}$ NMR spin-lattice relaxation studies, Widgeon et al. found that the SiOC ceramics consist of a continuous mass fractal backbone of corner-shared $\mathrm{SiC}_{x} \mathrm{O}_{4-x}$ tetrahedral units with "voids" occupied by free carbon nanodomains. Obviously, this is more consistent with Model 2 (Fig. 3(b)) [36,250]. In this model, the oxygen-rich $\mathrm{SiC}_{x} \mathrm{O}_{4-x}$ units (i.e., $x<$ 2) locate at the interior of the backbone with a mass fractal dimension of $\sim 2.5$, and the carbon-rich units (i.e., $x \geqslant 2$ ) occupy the interface between the backbone and the free carbon nanodomains with a slightly lower dimensionality (2.1-2.3) [250,253]. Moreover, for the carbon-rich SiOC ceramics, the 
(a)

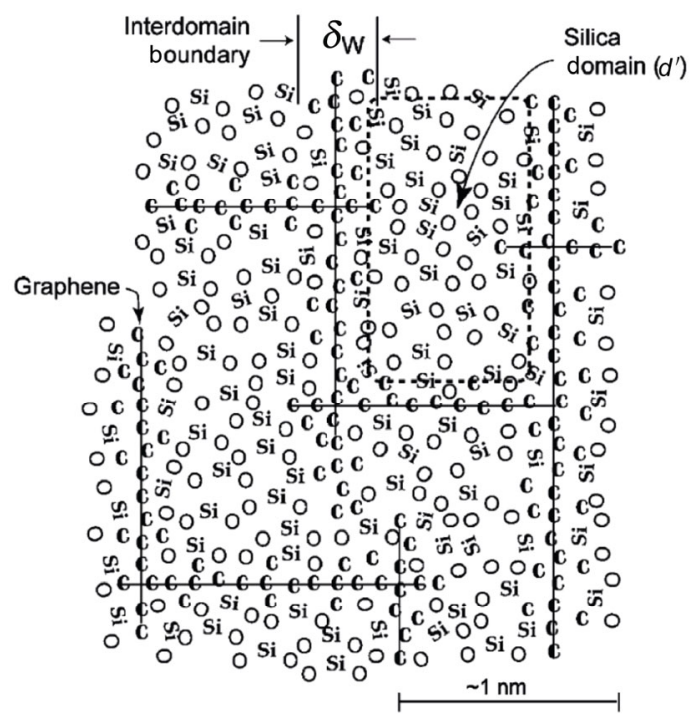

Model 1

(b)

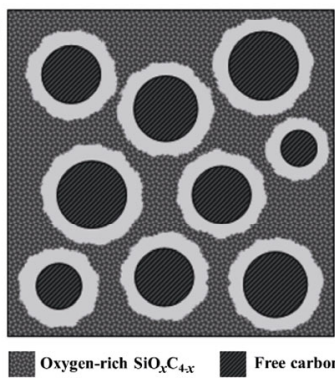

(c)

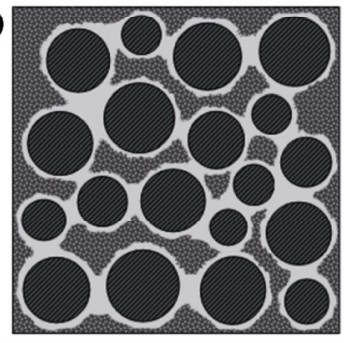

Carbon-rich Sio $_{x} C_{+x}$

\section{Model 2}

Fig. 3 Two proposed models illustrating the microstructure of polymer-derived SiOC ceramics: (a) a classic model illustrating a microstructure with clusters of silica tetrahedra, monolayer of $\mathrm{SiC}_{x} \mathrm{O}_{4-x}$ mixed bonds and graphene cage-like network that encases the silica nanodomains; (b) Model 2 with isolated carbon-rich $\mathrm{SiO}_{x} \mathrm{C}_{4-x}$ interface and (c) Model 2 with interconnected carbon-rich $\mathrm{SiO}_{x} \mathrm{C}_{4-x}$ interface in carbon rich $\mathrm{SiOC}$ ceramics. Reproduced with permission from Ref. [36], (C) Elsevier Ltd. 2019.

carbon-rich $\mathrm{SiO}_{x} \mathrm{C}_{4-x}$ interface can be interpenetrated as well, which can be illustrated by Model 2 (right) (Fig. 3(c)) [250]. Accordingly, the microstructure of SiOC ceramics is rather complicated. It varies and strongly depends on the molecular structure and composition of the preceramic polymers.

The microstructure of amorphous SiCN ceramics is strongly determined by the molecular structures of the preceramic polymers. The main difference between amorphous $\mathrm{SiCN}$ ceramics is whether there are $\mathrm{Si}-\mathrm{C} / \mathrm{N}$ mixed bonds (i.e., the presence of $\mathrm{SiC}_{x} \mathrm{~N}_{y}$ units) in the ceramic matrix or not. Within the ceramic matrix of polysilazane-derived $\mathrm{SiCN}$ ceramics, the tetrahedrally coordinated $\mathrm{Si}$ atoms are bonded to either $\mathrm{N}$ or $\mathrm{C}$ or a mixture of $\mathrm{C}$ and $\mathrm{N}$ (i.e., $\mathrm{SiC}_{x} \mathrm{~N}_{y}$ ), forming $\mathrm{SiC}_{4}, \mathrm{SiN}_{4}$, or $\mathrm{SiC}_{x} \mathrm{~N}_{y}$ units, respectively (Fig. 4(a)) [148]. In contrast, no significant concentration of $\mathrm{SiC}_{x} \mathrm{~N}_{4-x}$ mixed bonds can be found in the polysilylcarbodiimide-derived SiCN ceramics [44,178,254,255]. As shown in Fig. 4(b), within the matrix of carbon-rich polysilylcarbodiimidesderived $\mathrm{SiCN}$ ceramics, three amorphous phases including $\mathrm{Si}_{3} \mathrm{~N}_{4}, \mathrm{SiC}$, and free carbon nanodomains can be characterized $[44,256,257]$. The thermal stabilities of the amorphous $\mathrm{SiCN}$ against crystallization are significantly affected by the microstructures. As reported, with an analogous $\mathrm{C} / \mathrm{Si}$ ratio, the amorphous SiCN ceramics obtained from polysilylcarbodiimides crystallize at temperatures $50-100{ }^{\circ} \mathrm{C}$ higher than that derived from polysilazanes [35].

Furthermore, one of the most intriguing characteristics of PDCs is that, the X-ray amorphous PDCs are not strictly amorphous because they contain short-range structural features with the size ranging from 1 to $5 \mathrm{~nm}$, namely nanodomains. The nanodomains are firstly discovered in the $\mathrm{Si}(\mathrm{B}) \mathrm{CN}$ ceramics and then in the SiOC ceramics via small-angle X-ray scattering (SAXS) analysis [247,252,257,258]. The nature of nanodomains was proposed to be the basis for the excellent resistance of PDCs to crystallization even at ultrahigh temperatures $[241,242,252,259]$. Taking the polysilazanederived $\mathrm{SiCN}$ ceramics as an example, the characteristic nanodomain microstructures are schematically illustrated in Fig. 5 [260,261]. In the amorphous Si-containing phase, the silicon atoms are tetrahedrally coordinated by $\mathrm{C}$ or $\mathrm{N}$ atoms via $\mathrm{sp}^{3}$-hybridization, forming several different nanodomains with $\mathrm{SiC}_{4}, \mathrm{SiN}_{4}$, or $\mathrm{SiC}_{x} \mathrm{~N}_{4-x}$ $(0 \leqslant x \leqslant 4)$ units. Within the free carbon nanodomains, the $\mathrm{C}$ atoms are bonded to each other through $\mathrm{sp}^{2}$-hybridization, forming the basic structural unit (BSU) of free carbon [148,262,263].

When the amorphous PDCs are subjected to elevated temperature conditions $\left(\geqslant 1400{ }^{\circ} \mathrm{C}\right)$, they will undergo further phase separation and crystallization, generally leading to the formation of ceramic (nano)composites with multiple phases [49,264-269]. In addition, the carbothermal reactions between the oxygen- or nitrogen-containing phases (e.g., $\mathrm{SiO}_{x} \mathrm{C}_{y}$, $\mathrm{Si}_{3} \mathrm{~N}_{4}$ ) and free carbon occur significantly when the temperature exceeds $1500{ }^{\circ} \mathrm{C}$, leading to a mass loss of the ceramic materials, generation of new phases, and a reduce of carbon, oxygen, and nitrogen content via releasing of gaseous products (e.g., $\mathrm{CO}, \mathrm{SiO}$, or $\mathrm{N}_{2}$ ) $[12,78,186,269-272]$. 
(a)

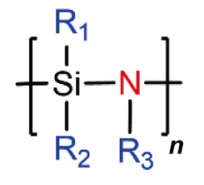

$\stackrel{800-1100}{\circ} \mathrm{C}$

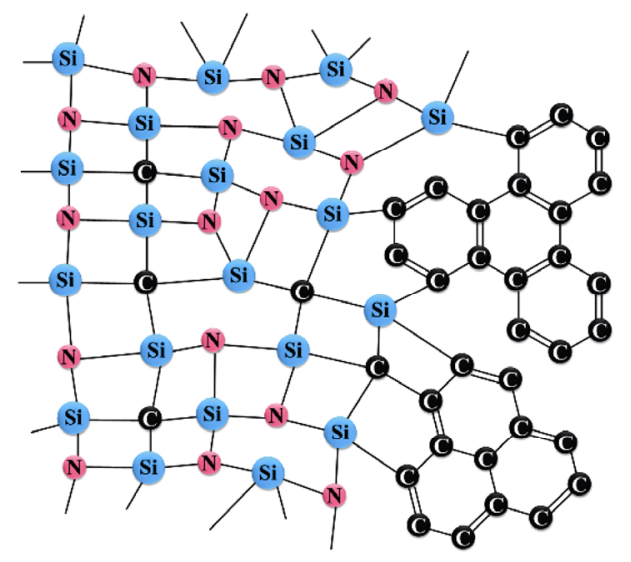

Amorphous $\mathrm{SiC}_{x} \mathrm{~N}_{y}+z \mathrm{C}$

\section{Mixed bonds}

(b)<smiles>[R7]C1([R7])CC1N=C=C=NCC1(C)CC1</smiles>

800-1100 ${ }^{\circ} \mathrm{C}$

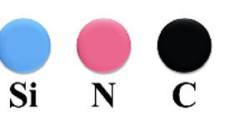

Polysilylcarbodiimides

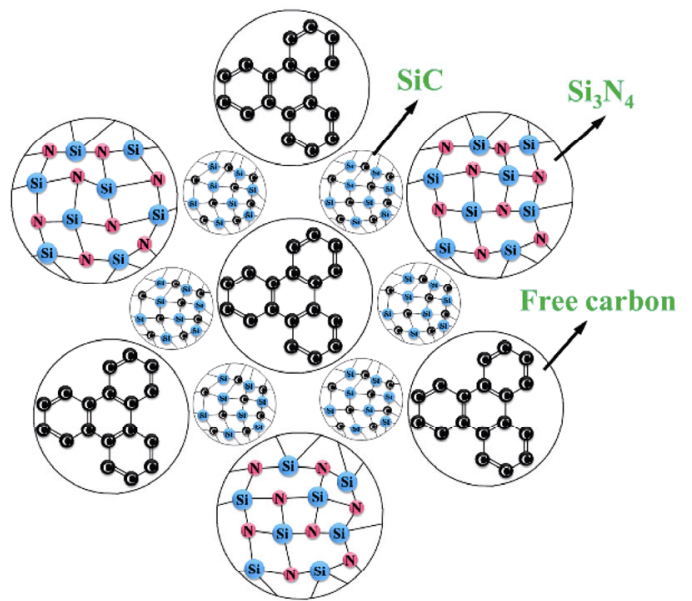

Amorphous $x \mathrm{SiC}_{3} \mathrm{~N}_{4}+y \mathrm{C}+z \mathrm{SiC}$

\section{No mixed bonds}

Fig. 4 Microstructure of amorphous SiCN ceramics derived from two different polymers: (a) polysilazanes, (b) polysilylcarbodiimides. Reproduced with permission from Ref. [36], C Elsevier Ltd. 2019.

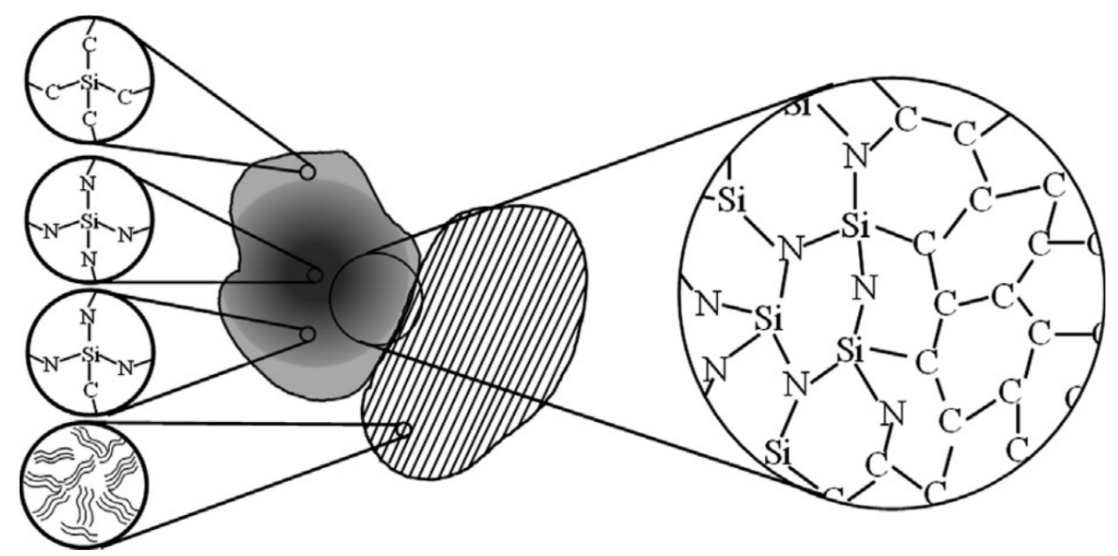

Fig. 5 Proposed nanodomain structural models for SiCN ceramics derived from polysilazane. The dark area is Si-containing phase, and the stripe area is free carbon phase. The atomic structures within these nanodomains are shown schematically in the insets. Reproduced with permission from Ref. [261], (C) Acta Materialia Inc. 2014. 


\section{Polymer-derived ceramics for energy conversion}

\section{1 Fundamentals and material issues}

As mentioned in the introduction, several energy conversion systems (e.g., gas turbine engines, steam turbine engines, wind mills, solar cells, and fuel cells) have been developed based on different energy sources. According to the prediction, gas turbine engines will still play an important role in energy conversion at least till 2050 [1], despite that the application of renewable energy will significantly increase in the following decades. Particularly, gas turbine technology is very important for future worldwide reduction of $\mathrm{CO}_{2}$ emissions in both power generation and aviation sectors, owing to their high efficiency and fuel flexibility [273]. The sustainable energy conversion systems (e.g., solar cells and fuel cells) have been comprehensively highlighted in several review articles and books [274-281]. Therefore, in this review, we mainly focus on the application of polymer-derived ceramics in gas turbine engines.

The gas turbine engine is a type of continuous and internal combustion engine (ICE) that burns gaseous or liquid fuel, and therefore it is also called combustion turbine engine. The gas turbine engines are mainly composed of upstream rotating gas compressors (lowand high-pressure compressors), a combustor, and downstream turbines (low- and high-pressure turbines) on the same shaft as the upstream compressors (Fig. 6(a)). Because the energy of gas turbines can be split into thrust and shaft work based on the specific purpose, they are now setting world standards in two major industrial applications, namely jet engines for the aero industry and the electric power generation. Moreover, the rotating shaft can also provide mechanical power for driving compressors/pumps and ship/train/tank propulsion [273].

For power generation sector, the gas turbine engines are becoming the main technology for conversion of fossil fuels into electricity. As reported in literature, the gas turbines were used to generate $\sim 20 \%$ of the world's electricity, with the sales estimated at around US\$17 billion in 2015 [283]. In the near future, the conventional gas- and oil-fired steam power plants will be replaced by the quite high efficient combined-cycle power plants, in which the rotatory shaft of the gas turbine engine works for a electricity generator, while the exhaust heat is used in an additional steam power plant [273]. In 2018, the combined-cycle mode has been proven to exhibit high efficiency up to $63 \%$ [286].

Within the aviation sector, the gas turbines play an enormously important role in moving cargos and people around the world in a time- and energy-efficient way. As the mainstay of commercial and military aircraft propulsion, the sales of gas turbines in 2015 were estimated at US\$ 39 billion globally, and it was predicted to be around US\$1.07 trillion in 2028 [283]. Generally, the gas turbines used for air transport applications can be classified into three different configurations: (1) turbojet/turbofan (generally called jet engines), (2) turboprop, as well as (3) turboshaft designs [273]. Among the three configurations, jet engines are the most popular use of gas turbines owing to their excellent thrust/weight ratio [1].

As mentioned above, a further improvement in technologies and materials used in the gas turbine engines is highly demanded to improve fuel efficiency and reduce $\mathrm{CO}_{2}$ emissions, in response to the energy crisis and climate change [284,285]. In order to find out the essential factors that affect the fuel efficiency of gas turbines, a simplified gas-turbine cycle (i.e., the so-called Brayton cycle) has been proposed (Fig. 6(b)). A thermodynamic evaluation of the Brayton cycle proves that the efficiency $\eta$ of a Brayton process depends on the pressure ratio $R=P_{2} / P_{1}$ and the ratio of specific heats $\left(k=C_{p} / C_{V}\right)$ at constant pressure $\left(C_{p}\right)$ and constant volume $\left(C_{V}\right)$ :

$$
\eta_{\text {Brayton }}=1-\frac{1}{R^{\frac{k-1}{k}}}
$$

Obviously, higher pressure ratio is the prerequisite of higher efficiency of the gas turbines. The pressure ratio $(R)$ can be described by

$$
R=\left(\frac{T_{2}}{T_{1}}\right)^{\frac{k}{k-1}}=\left(\frac{T_{3}}{T_{4}}\right)^{\frac{k}{k-1}}
$$

Accordingly, the increase of fuel efficiency results in the demand for higher operation temperatures [287]. The specific core power of a gas-turbine engine as a function of gas-inlet temperature is shown in Fig. 6(c) $[283,284]$. The increasingly improved gas-inlet temperature translates into more severe operating conditions.

In the last 100 years, plenty of advanced materials 
(a)

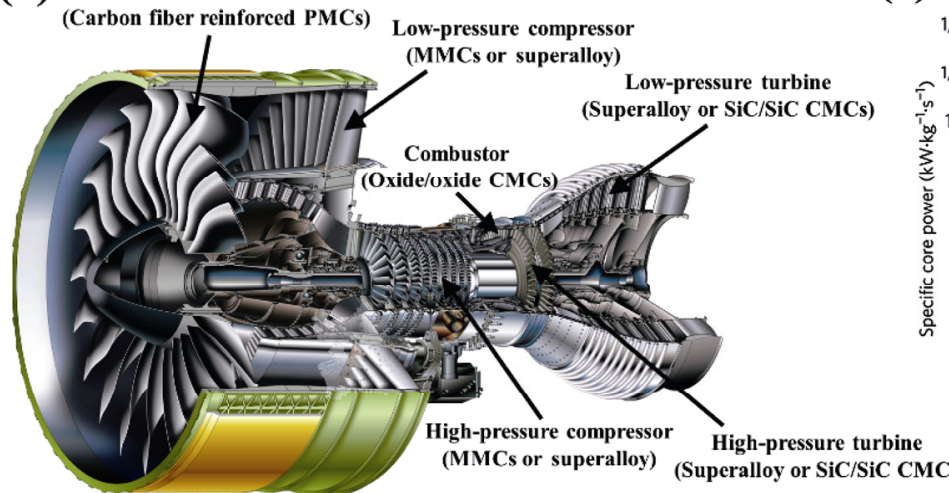

(c)

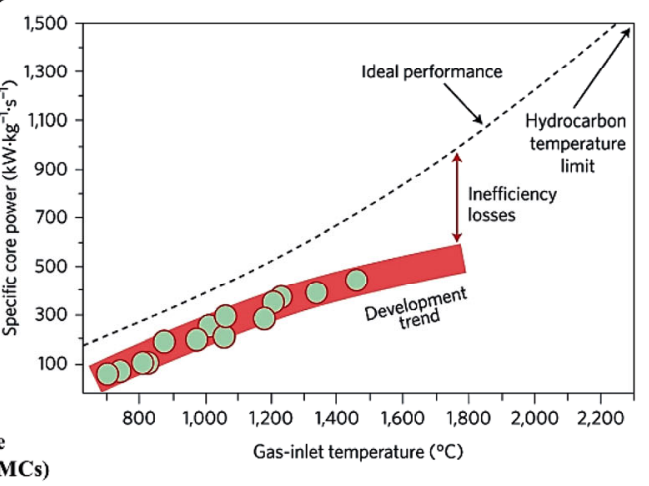

(b)

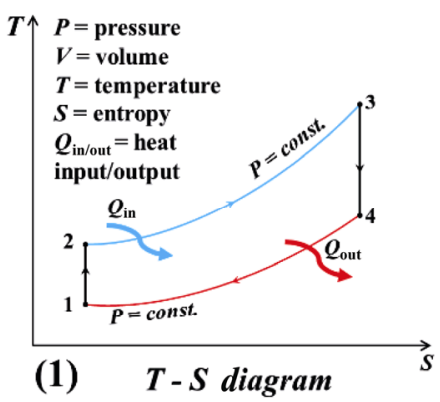

(d)

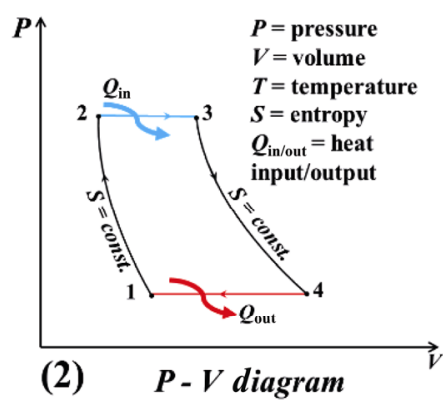

Fig. 6 (a) Cutaway view of GP7200 aircraft engine (retrieved from https://prattwhitney.com/products-and-services/products/ commercial-engines/gp7200) and the potential applications of continuous fiber reinforced composites (PMCs: polymer matrix composites; MMCs: metal matrix composites; CMCs: ceramic matrix composites) [282]. (b) $T-S$ (1) and $P-V$ (2) diagrams of an ideal Brayton cycle. Reproduced with permission from Ref. [1], (C) Elsevier Ltd. 2020. (c) Specific core power of a gas-turbine engine as a function of gas-inlet temperature, and (d) progression and projection of temperature capabilities of Ni-based superalloy (grey), TBCs (green, rough estimates), CMCs (blue, rough estimates), and maximum allowable gas temperatures with cooling (red, rough estimates). Reproduced with permission from Ref. [283], (C) Nature Publishing Group, a division of Macmillan Publishers Limited 2016.

have been used as high-temperature structural materials at the heart of gas turbines, ranging from conventionally casted or directionally solidified high-temperature alloys to nickel-based single-crystal superalloys. Figure 6(d) shows the development of temperature capability of materials used at the heart of the gas turbine engines over the last decades. It clearly shows that high-temperature alloys and thermal barrier coatings, in conjunction with cooling systems, have played a crucial role in the development of gas turbine engines. However, the increasing severity of operating conditions with the gas-inlet temperature higher than $1800{ }^{\circ} \mathrm{C}$ in future turbine engines limits the menu of available materials to very few high-temperature ceramics, mainly ceramic matrix composites (CMCs) protected by environmental barrier coatings (EBCs). Polymer-derived ceramics are one of the best candidates for producing these materials [35]. The following sections will comprehensively summarize the role of PDCs in production of ceramic matrix composites, ceramic fibers, as well as ceramic coatings.

\section{2 Ceramic matrix composites}

Ceramic matrix composites (CMCs) are considered as the most promising candidates for significant enhancement of material capability with respect to (ultra)high temperature applications under harsh environmental conditions and strong mechanical load [288]. As the replacements of Ni-based superalloys in future gas turbine engines, CMCs are capable of handling the highest temperature $\left(\geqslant 1500{ }^{\circ} \mathrm{C}\right)$ even without thermal barrier coatings (Fig. 6(d)) [283]. This feature is in particular of great technological importance for the development of the next-generation gas turbines for stationary and non-stationary energy conversion systems. Typically, the CMCs which have 
the potential to be used for the blades of gas turbine engines in the future consist of a SiC-based ceramic matrix, a continuous $\mathrm{SiC}$ fiber reinforcement, and a moderately weak fiber/matrix interface (e.g., BN and C) $[289,290]$. Carbon fibers are also used to produce $\mathrm{C} / \mathrm{SiC}$ CMCs. However, they are more suitable for hypersonic and rocket engine applications because of their relatively short lifetime caused by the poor oxidation resistance of carbon fibers [283,291]. Oxidebased ceramic matrix exhibits excellent oxidationresistant, but the low strength and creep resistance limit their applications as the core section of the engines [283].

In addition to the excellent high-temperature strength, CMCs are inherently lightweight, with $1 / 3$ of the weight of superalloys, resulting in a high specific strength [291]. This will enable to substantially reduce the fuel consumption and pollution associated with the operation of combustion engines, contributing to further development of environmentally friendly technologies. Moreover, compared with superalloys, the CMCs exhibit better high-temperature oxidation and creep resistance [283,291-293]. Most importantly, CMCs are damage-tolerant and notch-insensitive, which is the inherent disadvantages of monolithic ceramics [294,295]. Because of these superiorities, significant investments have been made in CMCs by the major engine manufacturers, and huge progress has been made in the last decades. For instance, the exhaust-section flaps/seals and afterburners made of CMCs have been used in military engines for years [283]. In the recent demonstration of jet engines, both stationary and rotating CMC components in the hot section have been used $[283,296]$.

Several methods have been developed to prepare CMCs using 2D/3D fiber preforms and ceramic precursors, such as chemical vapor infiltration (CVI), polymer infiltration and pyrolysis (PIP), slurry infiltration (SI), reactive melt infiltration (RMI), or liquid silicon infiltration (LSI), as well as the hybrid of these methods [82,106,298,299]. Preceramic polymers have been used for the fabrication of CMCs in two different aspects: (1) producing ceramic fibers as reinforcement (will be discussed later) $[6,150,300-$ 303]; (2) producing the ceramic matrix via PIP process $[16,17,297,304]$. The procedures of PIP processing to fabricate polymer-derived CMCs are shown in Fig. 7. For producing ceramic matrix, preceramic polymers provide myriad advantages, including lower thermal

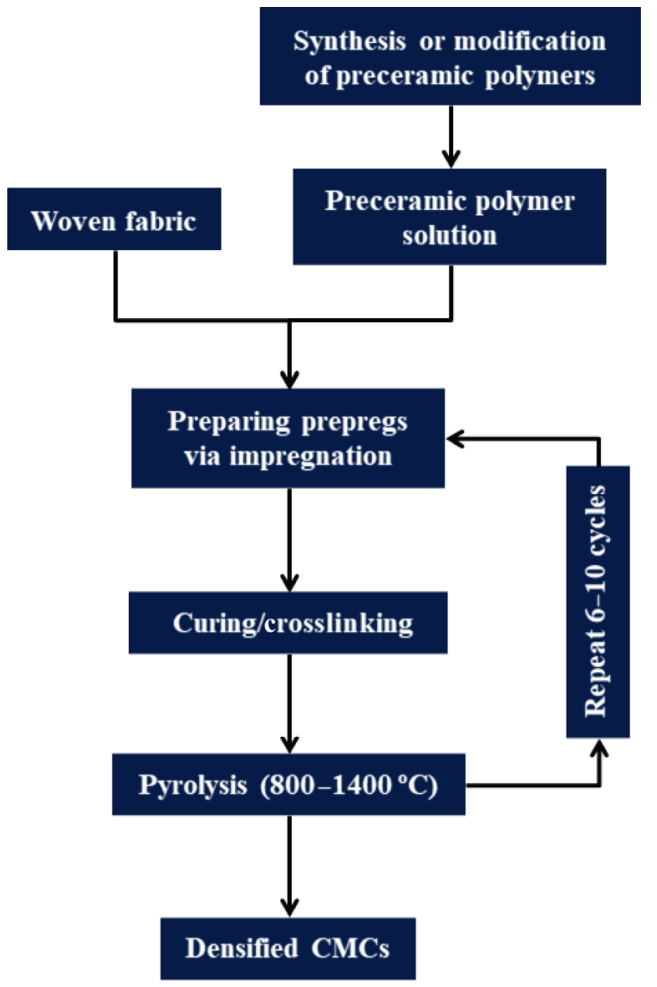

Fig. 7 Flow chart of PIP processing protocol to fabricate polymer-derived CMCs $[17,83,297]$.

treatment temperatures (which is of significant importance for strength retention of ceramic fibers and mechanical properties of the CMCs), deeper infiltration depth, shorter cycle time, better homogeneity, no residue silicon or other metallic elements, as well as the capability for near-net-shape fabricating large and complex parts with simpler and cheaper equipments $[18,19,35,305]$. Importantly, preceramic polymers can be chemically modified by other elements (e.g., B, Ti, $\mathrm{Zr}$, Hf) to fabricate $\mathrm{CMCs}$ with preferable nanostructures and ultra-high temperature resistant ceramics with improved thermal protection performance (e.g., $\mathrm{C}_{\mathrm{f}} / \mathrm{SiHfBCN}$ and $\mathrm{C}_{\mathrm{f}} / \mathrm{SiHfC}$ ) [12,83,102,306-309].

Up to now, several CMCs with different ceramic matrix have been investigated using PIP method for the purpose of structural application in hot section of gas turbine engines, such as $\mathrm{C}_{\mathrm{f}} / \mathrm{SiC}$ [106], $\mathrm{C}_{\mathrm{f}} / \mathrm{SiBCN}$ [107,310-312], $\mathrm{C}_{\mathrm{f}} / \mathrm{SiCN}[82,298,313], \mathrm{C}_{\mathrm{f}} / \mathrm{SiHfBCN}$ [82], $\mathrm{C}_{\mathrm{f}} / \mathrm{SiOC}[314,315], \mathrm{C}_{\mathrm{f}} / \mathrm{SiCON}[18], \mathrm{C}_{\mathrm{f}} / \mathrm{SiBOC}$ [316], $\mathrm{SiC}_{\mathrm{f}} / \mathrm{SiCN}$ [298,317], $\mathrm{SiC}_{\mathrm{f}} / \mathrm{SiC}[318,319]$, and $\mathrm{SiC}_{\mathrm{f}} / \mathrm{SiBCN}$ [320]. These CMCs with polymer-derived ceramic matrix have been demonstrated to exhibit excellent structural properties which are preferable for application in gas turbine engines, such as excellent thermal stability, oxidation resistance, high-temperature 
mechanical properties, as well as creep resistance [321-323]. Jones et al. [321] reported the mechanical properties of PIP-fabricated $\mathrm{SiC}_{\mathrm{f}} / \mathrm{SiC} \mathrm{CMCs}$ containing two different $\mathrm{SiC}$ fibers (namely, CG Nicalon CMC and Hi-Nicalon CMC). As shown in Table 1, $\mathrm{SiC}_{\mathrm{f}} / \mathrm{SiC}$ CMCs exhibit excellent mechanical properties with tensile strength higher than $250 \mathrm{MPa}$ at both room and high temperatures. Compared to CG Nicalon CMC, the Hi-Nicalon CMC shows enhanced tensile strength at high temperatures, which is due to the improved thermal stability of the Hi-Nicalon fibers. Moreover, the authors found out that the Hi-Nicalon CMC exhibits outstanding creep resistance at $1200{ }^{\circ} \mathrm{C}$, despite that the $\mathrm{CG}$ Nicalon $\mathrm{CMC}$ can only perform under moderate stress in air for extended periods at $1100{ }^{\circ} \mathrm{C}$ [321]. $\mathrm{Xu}$ et al. [315] prepared threedimensional carbon-fiber reinforced $\mathrm{SiOC}\left(3 \mathrm{D} \mathrm{C}_{\mathrm{f}} / \mathrm{SiOC}\right)$ composites through PIP processing and investigated their mechanical properties after annealing at 1300-1700 ${ }^{\circ} \mathrm{C}$. The results show that the annealing temperature played a crucial role on the mechanical properties of the $\mathrm{C}_{\mathrm{f}} / \mathrm{SiOC}$ composites. The mechanical properties of the composites vary slightly when the annealing temperature increases from $1200{ }^{\circ} \mathrm{C}$ (flexural strength: $308 \pm 14 \mathrm{MPa}$ ) to $1400{ }^{\circ} \mathrm{C}$ (flexural strength: $303 \pm 10 \mathrm{MPa}$ ). However, when the annealing temperature exceeds $1500{ }^{\circ} \mathrm{C}$, both the flexural strength and modulus decrease remarkably, which is due to the decomposition and volume shrinkage of SiOC matrixes caused by carbothermal reductions [315]. Tian et al. [324] prepared carbon-fiber reinforced SiCN CMCs $\left(\mathrm{C}_{\mathrm{f}} / \mathrm{SiCN}\right)$ via PIP processing using homemade polysilazanes (PSN-T03) as precursors and investigated their high-temperature mechanical properties at 1200 $1500{ }^{\circ} \mathrm{C}$. Interestingly, compared with the mechanical properties at room temperature, the $\mathrm{C}_{\mathrm{f}} / \mathrm{SiCN}$ exhibits enhanced mechanical properties at $1200-1400{ }^{\circ} \mathrm{C}$. The tensile strength of the $\mathrm{C}_{\mathrm{f}} / \mathrm{SiCN}$ composites at room temperature and $1400{ }^{\circ} \mathrm{C}$ are 230 and $350 \mathrm{MPa}$, respectively, and the bending strength are measured to be 380 and $530 \mathrm{MPa}$, respectively. This behavior might be because the testing temperatures are close to the fabrication process temperature, and the internal heat stress was relieved well under the testing condition. Nevertheless, the mechanical properties of the $\mathrm{C}_{\mathrm{f}} / \mathrm{SiCN}$ composites decline rapidly at $1500{ }^{\circ} \mathrm{C}$ due to the carbothermic reduction of the silicon nitride phase [324]. Lee et al. [310] fabricated $\mathrm{C}_{\mathrm{f}} / \mathrm{SiBCN}$ CMCs using a liquid two-component $\mathrm{Si}-\mathrm{B}-\mathrm{C}-\mathrm{N}$ precursor via PIP processing (Fig. 8(a)). The thermogravimetric analysis (TGA) and mechanical tests show that the $\mathrm{C}_{\mathrm{f}} / \mathrm{SiBCN}$ CMCs exhibit excellent high temperature stability (Fig. 8(b)) and mechanical properties (Fig. 8(c)), respectively. The flexural strength of the as-fabricated $\mathrm{C}_{\mathrm{f}} / \mathrm{SiBCN}$ CMCs was $255 \mathrm{MPa}$, and they retained most of their strength up to $1500{ }^{\circ} \mathrm{C}$ (Fig. 8(c)). Moreover, the $\mathrm{C}_{\mathrm{f}} / \mathrm{SiBCN}$ exhibits excellent creep resistance. The results show that the secondary creep occurred up to 60 $\mathrm{h}$ at $1400{ }^{\circ} \mathrm{C}$ with $100 \mathrm{MPa}$ pressure in argon, and the total creep strain was as low as $0.55 \%$ (Fig. $8(\mathrm{~d})$ ). This value is smaller than that of CMCs obtained by chemical vapor infiltration (CVI) (e.g., $\mathrm{C}_{\mathrm{f}} / \mathrm{SiC} 1400{ }^{\circ} \mathrm{C}$, $110 \mathrm{MPa}, 60 \mathrm{~h}: \sim 0.75 \%$ [325] and Hi-Nicalon ${ }^{\mathrm{TM}}$ $\mathrm{SiC}_{\mathrm{f}} / \mathrm{SiC} 1300{ }^{\circ} \mathrm{C}, 90 \mathrm{MPa}, 30 \mathrm{~h}: \sim 0.7 \%$ [326]) which have been reported to offer the best high-temperature properties. Very recently, Yuan et al. [82] prepared a carbon fiber reinforced $\mathrm{C}_{\mathrm{f}} / \mathrm{SiHfBCN}$ CMCs via PIP approach using a Hf- and B-modified polysilazane as precursor. The results prove that incorporation of $\mathrm{Hf}$ and $\mathrm{B}$ into SiCN matrix is able to significantly enhance the hydrothermal corrosion performance of the as-prepared $\mathrm{C}_{\mathrm{f}} / \mathrm{SiHfBCN}$ CMCs.

As discussed above, taking the full advantages of the low temperature processability of preceramic polymers, the PIP approach offers solution to most of the problems associated with other processing methods (e.g., CVI, RMI) for CMCs. However, when employing this approach, one must pay much attention to each processing step, particularly the pyrolysis step. This is because, during polymer-to-ceramic transformation, the decomposition of precursor matrix inevitably leads to shrinkage of the matrix and formation of pores, voids, and micro-cracks. The evolution of gases during pyrolysis may also result in delamination of the green composite. In order to overcome this problem, the first pyrolysis step should be carried out at a slow heating rate. The ceramic matrix may react with the interphase coating/fiber during the repeated PIP process, which can deteriorate the strength of fiber reinforcement as well. In addition, the pyrolysis temperature should be carefully chosen to ensure that the reinforcing fibers do not lose its strength [297,327].

\section{3 Ceramic fibers}

Ceramics fibers, acting as the strengthening and toughening component, are of crucial importance for ceramic-fiber reinforced ceramic matrix composites (CMCs) using gas turbine engines [86]. It is clearly shown in Table 1 that $\mathrm{SiC}_{\mathrm{f}} / \mathrm{SiC} \mathrm{CMCs}$ containing 

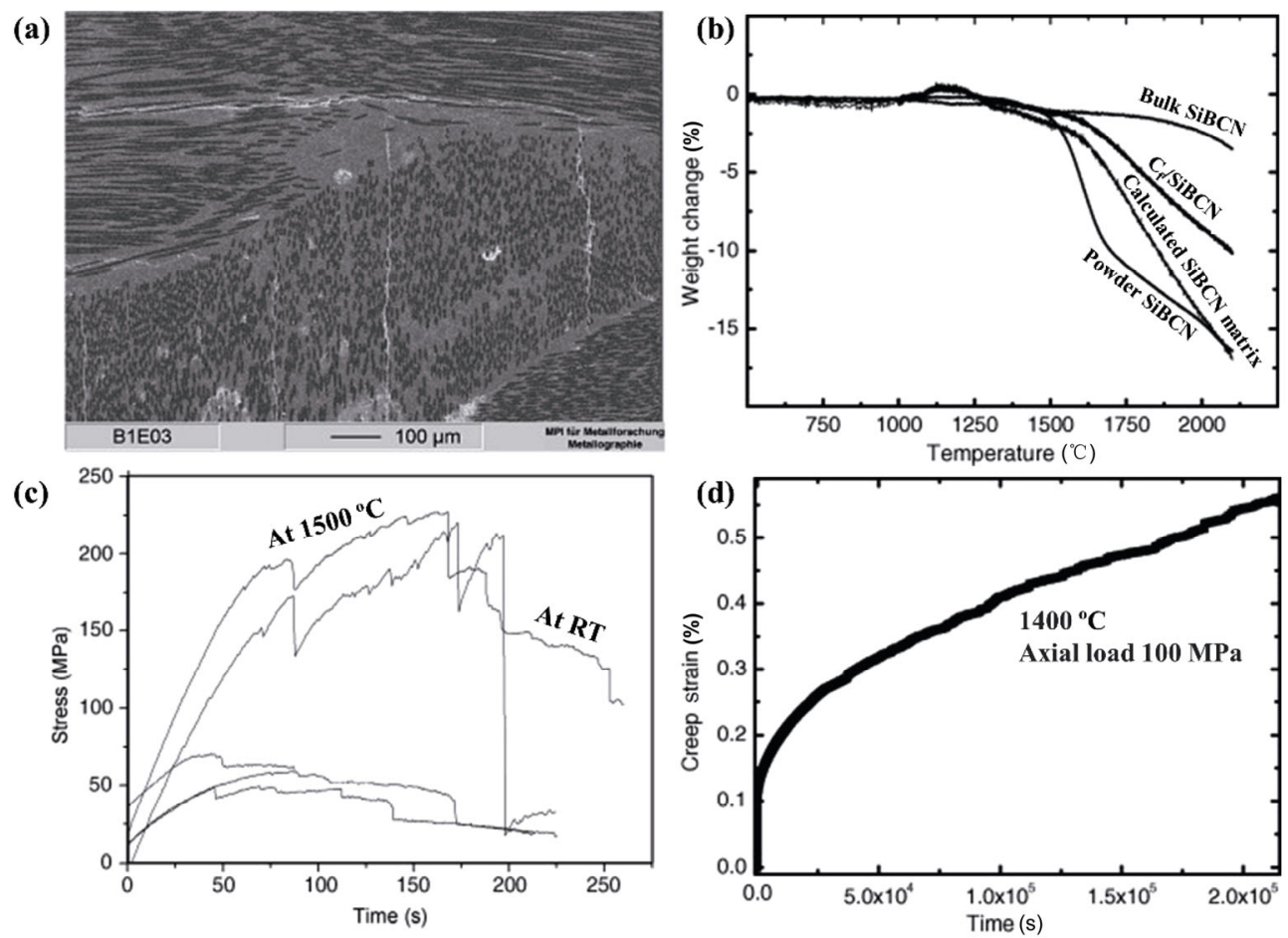

Fig. 8 (a) SEM image of cross-section of the as-prepared $\mathrm{C}_{\mathrm{f}} / \mathrm{SiBCN}$ CMCs; (b) TGA curves of bulk and powdered SiBCN, $\mathrm{C}_{\mathrm{f}} / \mathrm{SiBCN}$ composite, as well as the $\mathrm{SiBCN}$ matrix of the $\mathrm{C}_{\mathrm{f}} / \mathrm{SiBCN}$ composites (calculated based on a matrix content of 59.6 $\mathrm{wt} \%$ ); (c) fracture behavior of the $\mathrm{C}_{\mathrm{f}} / \mathrm{SiBCN}$ composite at room temperature (RT) and $1500{ }^{\circ} \mathrm{C}$; (d) creep strain curve of the as-fabricated $\mathrm{C}_{\mathrm{f}} / \mathrm{SiBCN}$ composite at $1400{ }^{\circ} \mathrm{C}$ in Ar atmosphere with $100 \mathrm{MPa}$ axial load. Reproduced with permission from Ref. [310], C Acta Materialia Inc. 2007.

Table 1 Mechanical properties of typical $\mathrm{SiC}_{\mathrm{f}} / \mathrm{SiC}$ CMCs prepared by PIP processing [19]

\begin{tabular}{ccc}
\hline Temperature $\left({ }^{\circ} \mathrm{C}\right)$ & CG Nicalon CMC & Hi-Nicalon CMC \\
\hline \multicolumn{3}{c}{ Tensile strength $(\mathrm{MPa})$} \\
\hline 20 & 250 & 360 \\
1000 & 265 & 360 \\
1200 & 290 & 347 \\
\hline \multicolumn{3}{c}{ Tensile modulus $(\mathrm{GPa})$} \\
\hline 20 & 95.2 & 120 \\
1000 & 88.4 & 115 \\
1200 & 85 & 100 \\
\hline \multicolumn{3}{c}{ Double notch shear strength $(\mathrm{MPa})$} \\
\hline 1000 & 35 & 37 \\
1200 & 26 & - \\
\hline \multirow{3}{*}{ Compression strength $(\mathrm{MPa})$} \\
\hline 20 & 431 & - \\
\hline
\end{tabular}

different SiC fibers exhibit totally different mechanical properties at both room and high temperatures. As mentioned above, the other important application of preceramic polymers for fabrication of CMCs is producing ceramic fibers. Actually, the potential of polymer-derived ceramics (PDCs) for materials science was not recognized until people produced small-diameter ceramic fibers via spinning and pyrolysis of polyorganosilicon precursors in the $1970 \mathrm{~s}$ $[5,22-27,36]$. Up to now, ceramic fibers are the most successful commercial application of PDCs. SiC fiber reinforced CMCs have been widely used in exhaust flaps, seals of jet engines and have been introduced in heat-resistant parts of the new GE LEAP jet engines for passenger planes $[36,150,196]$.

Typical manufacturing steps and important parameters for a controllable processing of ceramic fibers from preceramic precursors are shown in Fig. 9 [86]. The viscoelasticity, melting point, and thermal stability of preceramic polymers, the curing methods, ceramic yield, as well as thermal treatment methods are critical factors for the successful fabrication of high-performance ceramic fibers. During the last 50 years, numbers of ceramic fibers have been developed via PDC route, such as $\mathrm{SiC}(\mathrm{O})$ [212], Si-Ti-C-O [328], Si-Zr-C-O [328,329], SiCN [86], SiOC [87], SiBN [330,331], 


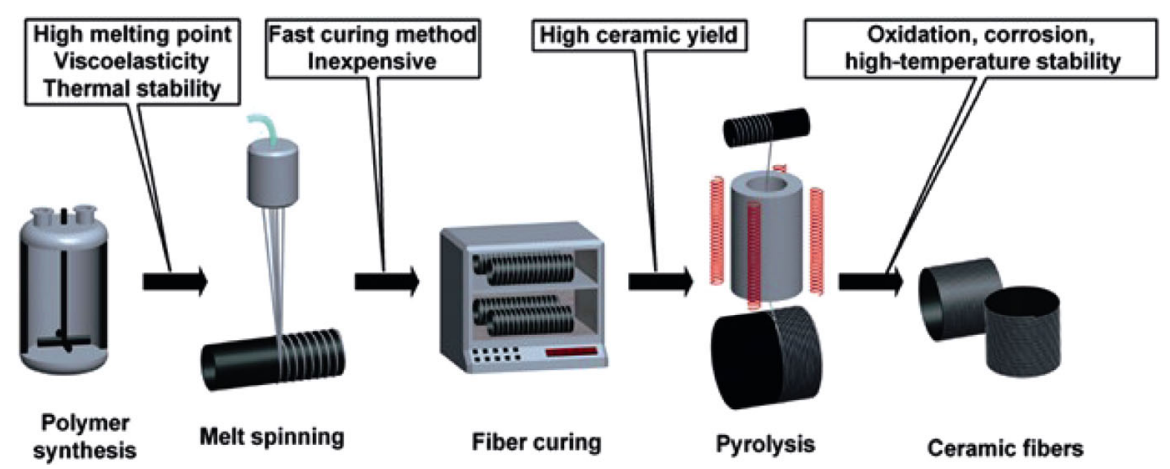

Fig. 9 Manufacturing procedures for polymer-derived ceramic fibers. Reproduced with permission from Ref. [86], C) WILEY-VCH Verlag GmbH \& Co. KGaA, Weinheim 2014.

SiBCN [74], SiBOC [302,332] fibers. The fracture surface of typical ceramic fibers, namely $\mathrm{SiC}$ fiber (Hi-Nicalon) and $\mathrm{SiCN}$ fiber (derived from polyorganosilazane named ABSE), is shown in Fig. 10. The chemical composition, properties, commercial availability, and price of these fibers are summarized in Table 2. So far, only a handful of ceramic fibers for use in CMCs have reached the market, and all of them are SiC-based fibers. Therefore, here we briefly introduce SiC fibers.

As reported in literature, SiC-based ceramic fibers can be classified into three generations according to their oxygen content and $\mathrm{C} / \mathrm{Si}$ atomic ratio $[150,196]$. The first-generation fibers are $\mathrm{Si}-\mathrm{C}-\mathrm{O}$ (Nicalon) fibers and $\mathrm{Si}-\mathrm{Ti}-\mathrm{C}-\mathrm{O}$ (Tyranno Lox M) fibers which were fabricated in the 1980s. However, the maximum working temperature of the first-generation fibers cannot be higher than $1100{ }^{\circ} \mathrm{C}$ because their strength starts degrading significantly at temperatures above $1300{ }^{\circ} \mathrm{C}$. This is due to the presence of large amount of oxygen $(>10 \mathrm{wt} \%)$ and free carbon (the $\mathrm{C} / \mathrm{Si}$ ratio is around 1.3-1.4) within the ceramic fibers, which leads to carbothermal reaction at temperatures higher than $1300{ }^{\circ} \mathrm{C}$. The first-generation fibers have a very high oxygen content because the preceramic precursor is crosslinked in air in the temperature range from 145 to $200{ }^{\circ} \mathrm{C}$ by forming $\mathrm{Si}-\mathrm{O}-\mathrm{Si}$ linkages (i.e., oxygen curing) [150]. The typical second-generation fibers are Hi-Nicalon SiC fibers [150]. For the second-generation fibers, the curing process has been changed into electron beam irradiation curing in helium atmosphere. As a result, the oxygen content of the fibers is significantly reduced (less than $1 \mathrm{wt} \%$ ), leading to a dramatically enhanced high-temperature stability and strength. The strength retention temperature of these fibers was improved up to $1500{ }^{\circ} \mathrm{C}$. However, the creep resistance of the second-generation fibers is limited to a maximum of $1150{ }^{\circ} \mathrm{C}$. This can be attributed to the polycrystalline feature of the fibers which is caused by the relatively high free carbon content (the $\mathrm{C} / \mathrm{Si}$ ratio is around 1.4). It should be noted that the cost of irradiation curing process is actually too expensive for commercial application of the ceramic fibers. Therefore, the oxygen curing process used for the first-generation fibers is also used for the second-generation fibers (e.g., Tyranno ZM fibers). The difference is that, in order to enhance the thermal stability, the metal element grafted to the PCS polymer was changed (i.e., the titanium
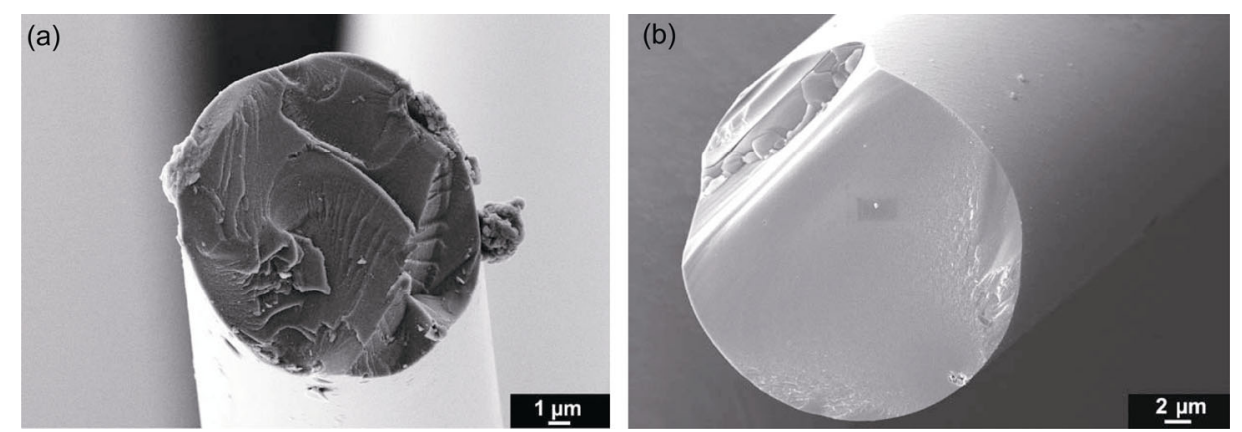

Fig. 10 Fracture surface of typical ceramic fibers derived from preceramic polymers: (a) Hi-Nicalon; (b) ABSE-derived SiCN fiber. Reproduced with permission from Ref. [86], (C) WILEY-VCH Verlag GmbH \& Co. KGaA, Weinheim 2014. 


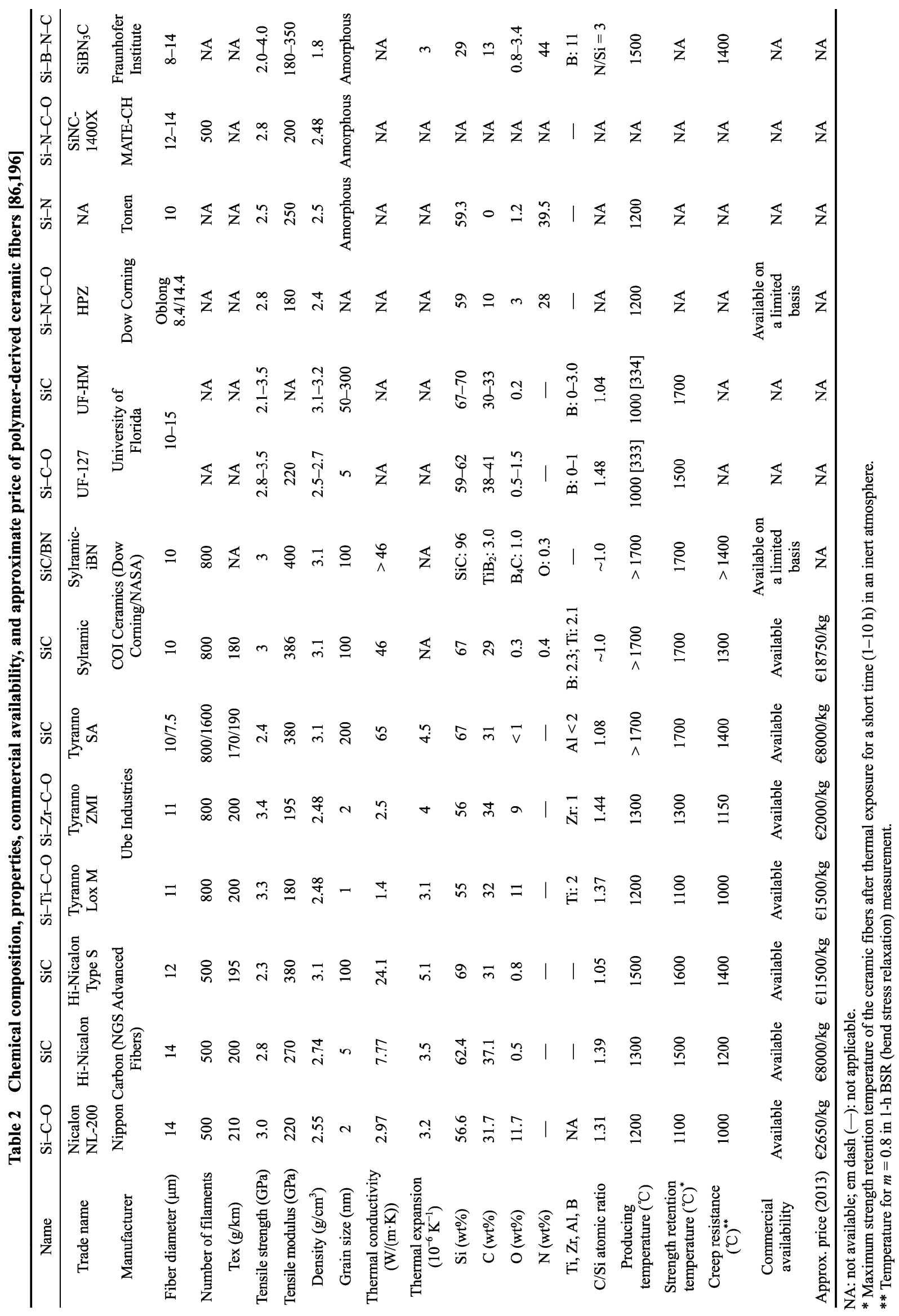


was replaced by zirconium). Hi-Nicalon Type S, Tyranno SA, and Sylramic TM fibers are typical thirdgeneration $\mathrm{SiC}$ fibers. The chemical composition of the third-generation $\mathrm{SiC}$ fibers must meet two requirements: (1) with $\mathrm{C} / \mathrm{Si}$ ratio near to 1 and (2) with rather low oxygen content $(<1 \mathrm{wt} \%)$. Furthermore, they exhibit improved thermal stability and creep resistance up to $1400{ }^{\circ} \mathrm{C}$ [196].

As shown in Table 2, currently, other Si-based ceramic fibers (e.g., SiCO, $\mathrm{SiCNO}, \mathrm{SiCN}, \mathrm{SiBCN}$, and SiBOC) are not commercially available. Further studies are needed to realize their industrial application. More details of manufacture and the elemental composition of polymer-derived ceramic fibers can be found in review articles and books [86,150,152,196, 335-338].

\section{4 Thermal and environmental barrier coatings}

Coating is an integral part of gas-turbine engines. It is well known that the maximum temperature in the hottest part of the gas-turbine engine (gas inlet) has been dramatically boosted to unprecedented levels ( $>$ $1500{ }^{\circ} \mathrm{C}$ ) due to the introduction of thermal barrier coatings (TBCs) on the Ni-based superalloys (Fig. 6(d)). The TBCs are thin oxide-ceramic coatings $(100 \mu \mathrm{m}$ to $1 \mathrm{~mm}$ in thickness) with low thermal conductivity, which allow the engine to operate at temperatures above the melting point of the superalloys [339]. The most widely used TBCs are the atmospheric plasmasprayed 7YSZ (7 $\mathrm{wt} \%$ yttria stabilized zirconia). However, the TBC coated superalloys are approaching their temperature-capability limit, and it is not confident for the scientists and engineers whether they will be able to achieve the $>1700{ }^{\circ} \mathrm{C}$ gas inlet temperature goal or not.
Within this context, the SiC-based CMCs can provide a "quantum jump" in temperature capability [340], which is able to withstand high temperatures > $1500{ }^{\circ} \mathrm{C}$ in dry air even without TBCs. Unfortunately, in the gas turbine engines, the high-velocity, highpressure, and high-temperature gas stream contains $\sim 10$ vol\% of water vapor [339]. Under such harsh environment conditions, the CMCs are subject to active oxidation and recession owing to the formation and volatilization of $\mathrm{Si}(\mathrm{OH})_{4}$, leading to catastrophic degradation [71,89,283,341,342]. Accordingly, the SiC-based CMCs also need protective coatings, namely environmental barrier coatings (EBCs). Different from TBCs, the EBCs should be impervious (i.e., dense and crack-free) and have a good coefficient of thermal expansion (CTE) match with the CMCs in order to protect the $\mathrm{CMCs}$ from environmental degradation via blocking diffusion/ingression of oxygen/steam [340]. Of course, for the purpose of further enhancing the gas-inlet temperature of turbine engines $\left(>1700{ }^{\circ} \mathrm{C}\right)$, the thermal stability and chemical durability of EBCs must be improved as well. In addition, the EBCs must be resistant to degradation by molten calcia-magnesiaaluminosilicate (CMAS) deposits coming from ingested dust, sand, or ash as well as exhibit mechanical robustness against fracture [340]. Considering the strict requirements, the EBCs are generally multilayered ceramics with a bond-coat, inter-layer, and top-coat [343]. Furthermore, in order to meet the requirements for application at temperatures $>1700{ }^{\circ} \mathrm{C}$, a thermal insulating TBC layer is needed on the top of EBCs, forming a T/EBC coating system (Fig. 11(a)).

Preparing TBCs or EBCs is another important application of polymer-derived ceramics. Taking
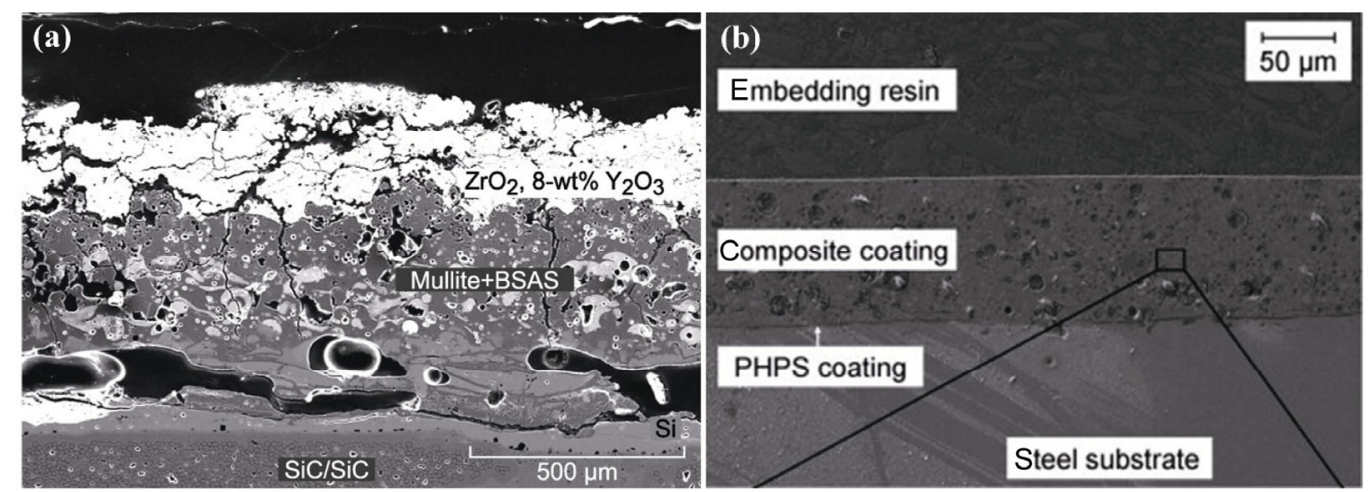

Fig. 11 (a) Typical T/EBC systems for CMCs used in gas turbine engines. Reproduced with permission from Ref. [292], (C) American Society of Civil Engineers 2013. (b) A polymer-derived EBC system consisting of a SiNO bond coat and a $\mathrm{ZrO}_{2}-\mathrm{fill}_{\mathrm{i}} \mathrm{ed}$ SiCN glass/ceramic composite coat. Reproduced with permission from Ref. [9], (C) Elsevier Ltd. 2011. 
advantage of preceramic polymers, it is very easy to prepare ceramic coatings using liquid phase deposition (e.g., dip coating, spray coating, lacquer technology, and spin coating) and subsequent pyrolysis [344]. The problems regarding thickness and isotropic shrinkage of the coatings can be solved via multiple deposition and loading active/inert fillers (Fig. 12), respectively [9,88,345]. Compared with PVD, CVD, and thermal spray methods, the PDC route possesses its superiorities including more tailorable chemical/phase compositions, lower processing temperatures $\left(<800{ }^{\circ} \mathrm{C}\right)$, lower requirements for coating equipments and low cost $[36,88]$. Particularly, the low processing temperature is important for the metal substrates with relatively low melting point [88].

Several studies with respect to preparing and testing of TBCs/EBCs using PDC route have been reported in the last years $[8,9,91,103-105,344-351]$. For instance, Günthner et al. [9] developed a well adherent, dense, and crack-free environmental barrier coating system composed of a perhydropolysilazane-derived SiNO bond coat and a $\mathrm{ZrO}_{2}$-filled polysilazane-derived glass/ceramic top coat on mild steel (Fig. 11(b)). After cyclic oxidation tests at $700{ }^{\circ} \mathrm{C}$, the coating system was undamaged and no oxidation occurred on the mild steel substrates [9]. Liu et al. [347] fabricated yttrium silicate environmental barrier coatings (EBCs) on $\mathrm{C} / \mathrm{SiC}$ composites using polysiloxanes-derived ceramic process and tested their coefficient of thermal expansion (CTE) and water-vapor resistance. The results demonstrate that the EBCs prepared from $50 \% \quad \mathrm{Y}_{2} \mathrm{O}_{3}-50 \%$ polysiloxanes can effectively protect the $\mathrm{C} / \mathrm{SiC}$ composites at $1400{ }^{\circ} \mathrm{C}$. In addition, Liu et al. [91] prepared a dense $\mathrm{SiOC}-\mathrm{BSAS} \mathrm{EBC}$ on $\mathrm{C} / \mathrm{SiC}$ composites using polysiloxane mixed with barium-strontium aluminosilicate (BSAS) fillers. The results prove that the polymer-derived SiOC-BSAS coatings are able to protect the $\mathrm{C} / \mathrm{SiC}$ composites well both in dry air and in water vapor. After being corroded in a gas flow with $50 \% \mathrm{H}_{2} \mathrm{O}$ and $50 \% \mathrm{O}_{2}$ at $1250{ }^{\circ} \mathrm{C}$, the EBC coated $\mathrm{C} / \mathrm{SiC}$ composites showed slight weight loss and high residual flexural strength. Barroso et al. [349] developed a $50 \mu \mathrm{m}$ thick TBC with high pull-off adhesion of $10 \mathrm{MPa}$, excellent thermal stability up to $1000{ }^{\circ} \mathrm{C}$, and outstanding low thermal conductivity of $0.44 \mathrm{~W} /(\mathrm{m} \cdot \mathrm{K})$. Within this TBC system, polysilazane (PHPS) derived $\mathrm{Si}_{3} \mathrm{~N}_{4}$ was used as bond-coat, and (organo)polysilazane derived $\mathrm{SiCN}$ mixed with passive YSZ and active $\mathrm{ZrSi}_{2}$ fillers were used as an insulating layer. The results indicate that the combination of the easy processability and geometry flexibility of PDC coatings with the use of commercially available preceramic polymers makes the developed processing route a promising candidate for the expansion of TBC applications. Hasemann et al. [352] prepared a SiON TBC on Mo-Si-B alloys using perhydropolysilazane as preceramic precursors and tested it cyclic oxidation resistance. The results show that the SiON coating is promising in reducing the mass loss during the initial stage of oxidation exposure at $1100{ }^{\circ} \mathrm{C}$. More details

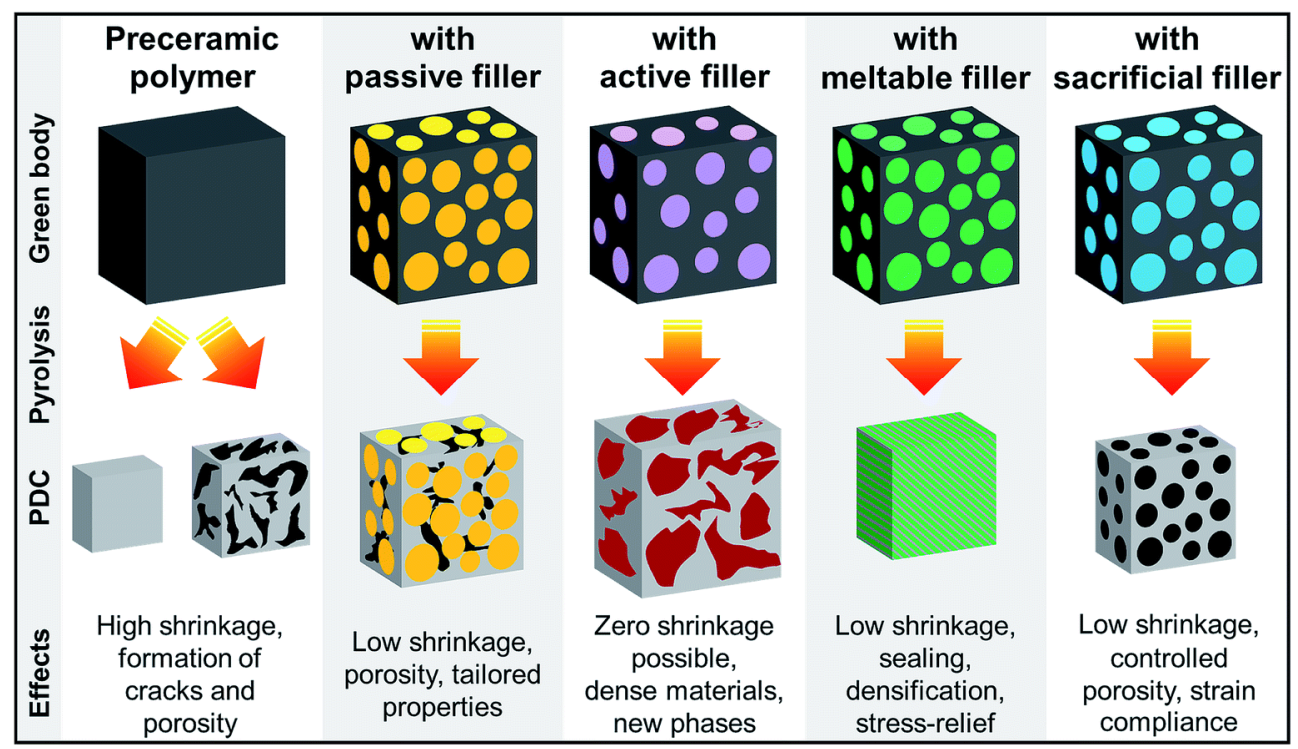

Fig. 12 Effects of different fillers on the polymer-derived ceramic coating systems. Reproduced with permission from Ref. [88], (C) The Royal Society of Chemistry 2019. 
regarding polymer-derived $\mathrm{TBCs}$ and $\mathrm{EBCs}$ are summarized in Table 3.

Currently, the polymer-derived TBCs and EBCs are still at the laboratory research stage, and the testing temperature is not high enough for the new generation gas turbine engine applications. More fundamental studies are needed to further improve their performance via enhancing their thermomechanical properties (e.g., hardness, creep resistance), thermal stabilities (with respect to crystallization and decomposition), and corrosion resistance against high-temperature water vapor as well as to tailor their thermal expansion coefficient and thermal conductivity.

\section{5 High-temperature sensors}

In situ and real-time monitoring of the temperature and dynamic pressure within the hot sections of gas turbine engines is another good way to increase their efficiency and reliability [354]. Nevertheless, currently no existing technology is able to provide online, real-time monitoring of the temperature and pressure in gas turbine engines due to the rather harsh environment. Optical-based technology is attractive due to its wireless nature. However, they lack the necessary accuracy for credible measurements and are not applicable for measurements in many important sections, such as the turbine blades, where line of sight cannot achieve [355,356]. Accordingly, new sensors with the capability of in situ and real-time monitoring the temperature and pressure in gas turbine engines are highly demanded. Because of the harsh environment in gas turbine engines, the sensors should meet some strict requirements: (1) with excellent thermal stability and chemical durability at temperatures higher than $1000{ }^{\circ} \mathrm{C}$; (2) be wireless for accessing any section in turbine engines; (3) be small or low profile without disturbing the aerodynamic flow in turbine engines, as well as (4) with high reliability [354].

PDCs are versatile materials with both interesting structural and functional properties because of their unique microstructures [35]. One good example is the piezoresistivity (i.e., the variation of the electrical resistivity caused by an applied stress) which has been firstly reported by Zhang et al. in 2008 [357]. Within this work, the amorphous $\mathrm{SiCN}$ monoliths have been found to exhibit extremely high piezoresistive coefficients (1000-4000) along both longitudinal and transverse directions, which are much higher than that of any existing ceramic materials [357]. In recent years, the piezoresistive behavior has been found in SiCNO, $\mathrm{SiCO}$, and SiAlCO ceramics as well, and the piezoresistive coefficients (also known as gauge factors) are measured to be $100-1700,145$, and $7000-16,000$, respectively [60,358]. Figure 13 presents the piezoresistivity behavior of the $\mathrm{SiCN}$ and $\mathrm{SiOC}$ at room temperature. It clearly shows that the electrical resistance of the monolithic

Table 3 Summary of polymer-derived TBC or EBC systems ( $\mathrm{PT}=$ processing temperature)

\begin{tabular}{|c|c|c|c|c|}
\hline Precursor systems & Coatings & Substrates & $\mathrm{PT}\left({ }^{\circ} \mathrm{C}\right)$ & Ref. \\
\hline Polysilazane & $\mathrm{HfO}_{2} / \mathrm{SiCN}-\mathrm{ZrO}_{2}$ & $\mathrm{Si}_{3} \mathrm{~N}_{4}$ & 1000 & {$[350]$} \\
\hline Polyhydridomethylsiloxane & $\mathrm{TiSi}_{2}-\mathrm{SiOC}$ & 316 stainless & 800 & {$[8]$} \\
\hline Perhydropolysilazane/polysilazane (Durazane 1800) & $\mathrm{Si}_{3} \mathrm{~N}_{4} / \mathrm{SiCN}-\mathrm{YSZ}-\mathrm{ZrSi}_{2}$ & Steel SISI441 & 1000 & [349] \\
\hline Polyhydromethylsiloxane & $\mathrm{SiOC}$ & 316 Stainless Steel (UNS S31600) & 800 & [105] \\
\hline Polysilazane & $\mathrm{SiCN}$ & $\begin{array}{c}\text { 13CrMo4-5 (AISI A 182)/X5CrNi18- } \\
10 \text { (AISI 304) }\end{array}$ & 700 & {$[345]$} \\
\hline Perhydropolysilazane/ABSE polycarbosilazane & $\mathrm{Si}_{3} \mathrm{~N}_{4} / \mathrm{SiCN}$ & Stainless steel (AISI 304) & 1000 & {$[346]$} \\
\hline Perhydropolysilazane & $\mathrm{SiON}$ & Mo-Si-B alloys & 800 & [352] \\
\hline $\begin{array}{l}\text { Polymethoxymethylsiloxane/hydroxy-terminated } \\
\text { linear dimethylpolysiloxane }\end{array}$ & $\mathrm{SiOC}$ & Stainless steel (\#1.4301 DIN EN 10027-2) & 1000 & {$[353]$} \\
\hline Poly(hydridomethylsiloxane) & $\mathrm{SiOC}-\mathrm{TiSi}_{2}$ & 316 Stainless Steel & 800 & {$[8]$} \\
\hline ABSE polysilazane & $\mathrm{SiCN}$ & Carbon fiber (Tenax HTA 5411 12k) & 800 & {$[344]$} \\
\hline Perhydropolysilazane/KiON HTT1800 & $\mathrm{Si}_{3} \mathrm{~N}_{4} / \mathrm{SiCN}$ & $\begin{array}{l}\text { Mild steel (13CrMo4)/stainless steel } \\
\text { (AISI 304) }\end{array}$ & 800 & {$[9]$} \\
\hline Polysiloxanes mixed $\mathrm{Y}_{2} \mathrm{O}_{3}$ & $\mathrm{Y}_{2} \mathrm{SiO}_{5} / \mathrm{Y}_{2} \mathrm{Si}_{2} \mathrm{O}_{7}$ & 2D C/SiC composites & 1400 & {$[347]$} \\
\hline $\begin{array}{l}\text { Polysiloxanes mixed with barium strontium } \\
\text { aluminosilicate (BSAS) }\end{array}$ & SiOC-BSAS & $\mathrm{C}_{\mathrm{f}} / \mathrm{SiC}$ composite & 1350 & {$[91]$} \\
\hline
\end{tabular}


$\mathrm{SiCN}$ and $\mathrm{SiOC}$ varies as a function of applied stress. The piezoresistive effect of PDCs has been proven to be dominated by the tunneling-percolation mechanism, which is owing to the presence of graphitic free carbon within the ceramic matrix of PDCs, forming a tunneling-percolation structure. Because of this unique structure, the electrical resistivity of the ceramics is sensitive to the distance between the free carbon clusters [36]. The change of distance between the free carbon clusters caused by applied stress therefore leads to a significant variation in the resistivity, resulting in a high piezoresistive coefficient [60,66,101,357-360]. Importantly, the piezoresistive behavior of PDCs can be also detected at high temperatures. Terauds et al. [60] found that the SiCNO ceramics exhibit large piezoresistive coefficients (in the range of 600-1700) at $700-1000{ }^{\circ} \mathrm{C}$, and the values depend on both the stress and temperature. The extrapolated values of the gage factor at an applied stress of $1 \mathrm{MPa}$ yield a value of 322 and 287 at 1400 and $1500{ }^{\circ} \mathrm{C}$, respectively. Based on the excellent high-temperature stability, chemical durability, and piezoresistivity, the PDCs are expected to be ideal candidates for in situ pressure

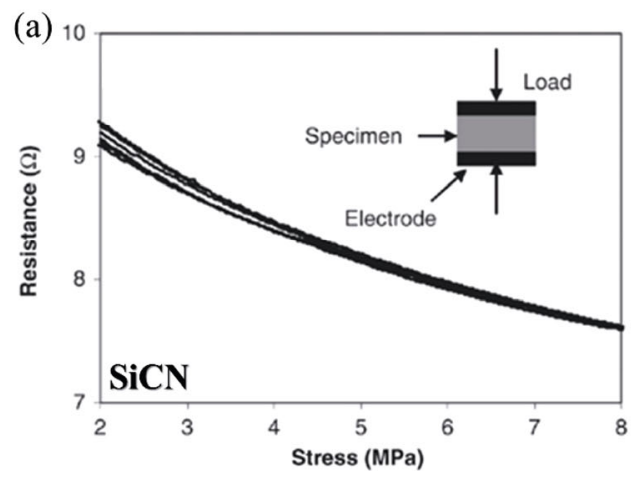

sensors used in gas turbine engines [60,68,358,361, 362]. For instance, Shao et al. [363] prepared a SiBCN ceramic pressure sensor and tested its performance using half Wheatstone bridge. The SiBCN sensor shows a giant gauge factor of 5500, and the output voltage of the packed $\mathrm{SiBCN}$ ceramic sensor changes monotonically and smoothly versus external pressure. The short response time, excellent repeatability, stability, sensitivity, and accuracy ensure its potential for pressure measurement at high temperature and harsh environments in gas turbine engines.

In addition to the pressure sensor based on piezoresistivity, the PDCs can also be used as in situ heat flux sensors [364], temperature sensors [365], and hot-wire anemometers [366] which are useful sensors for gas turbine engines. For example, Nagaiah et al. [364] designed a high-temperature heat flux sensor for gas turbine engines using polymer-derived $\mathrm{SiCN}$ ceramics. The sensor consists of two resistance temperature detectors (RTDs) made of SiAlCN, a resistive layer made of insulator-lightly doped $\mathrm{SiCN}$, and electrical leads made of conductor-heavily doped SiCN (Fig. 14). This novel sensor possesses a temperature coefficient

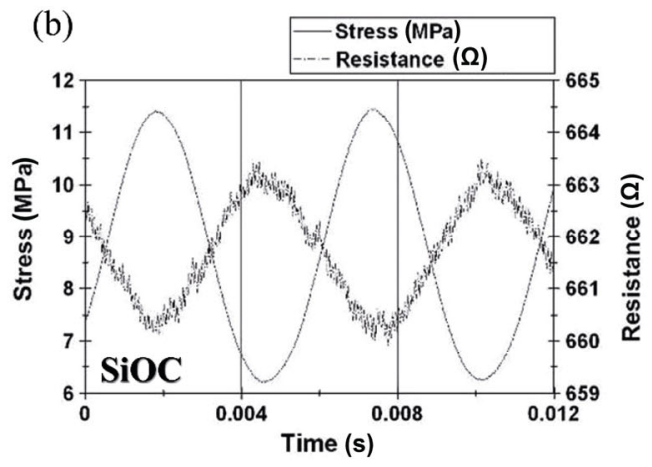

Fig. 13 Experimental proof of the piezoresistive response of (a) SiCN and (b) SiOC. Reproduced with permission from Ref. [101], (C) The American Ceramic Society 2011; Ref. [357], (c) The American Ceramic Society 2008.
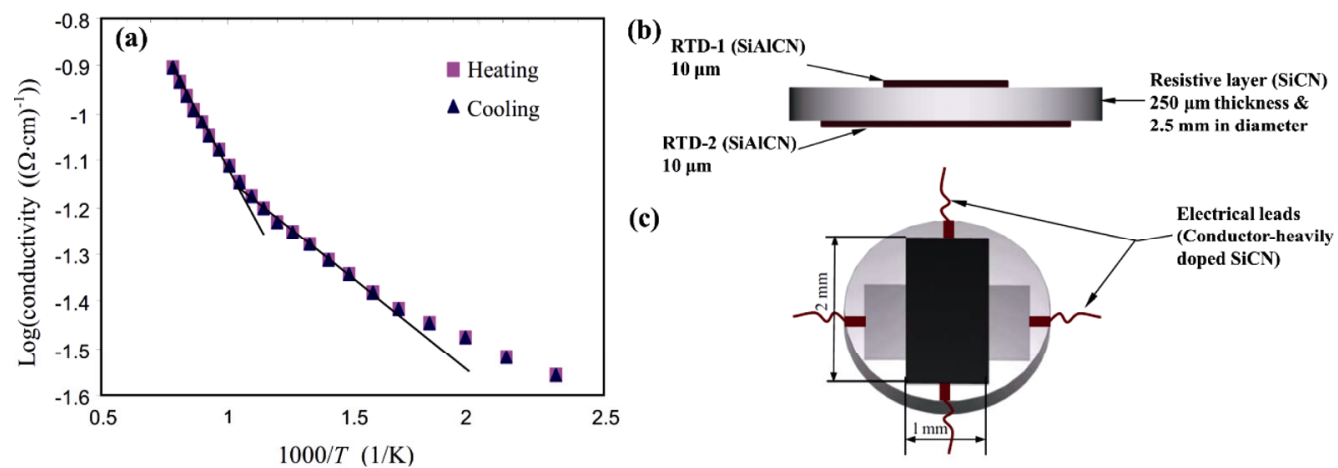

Fig. 14 (a) Electric conductivity of semiconducting SiAlCN as a function of temperature. Schematics of the proposed heat-flux sensor made of PDCs: (b) sectional view and (c) top view. Reproduced with permission from Ref. [364], (C) IOP Publishing Ltd. 2006. 
of resistance of $4000 \mathrm{ppm} /{ }^{\circ} \mathrm{C}$ and is found to perform quite satisfactorily at $1400{ }^{\circ} \mathrm{C}$ for a long time as compared to conventional heat flux sensors.

Zhao et al. [366] fabricated a temperature sensor using polymer-derived SiAlCN (Fig. 15(a)). The Pt wires are seamlessly embedded in the SiAlCN sensor head as electrodes (Fig. 15(b)). The results demonstrate that the resistance of the senor head decreases monotonically with surrounding temperatures. In actual experiments, the SiAlCN sensors exhibit good repeatability to both unidirectional and bidirectional temperature variations, and the measured data follow closely with the thermal couple measurements at temperatures up to $830{ }^{\circ} \mathrm{C}$ (Fig. 15(c)). In addition, Nagaiah et al. [367] developed a novel high-temperature MEMS hot-wire anemometer (HWA) for gas turbine environment using three types of PDC materials, namely SiAlCN, SiCN (lightly doped), and SiCN (heavily doped), which act as sensing elements (hot-wire), support prongs, and connecting leads, respectively. The results prove that PDC-based HWA can perform better than a conventional HWA in which the hot wire is made of tungsten or platinum-iridium.

As mentioned above, due to the harsh environment in the gas turbine engines, passive, wireless, and robust characteristics are highly desirable for sensors to survive. Therefore, Cheng et al. [368] fabricated a wireless pressure sensor based on a microwave evanescent-mode cavity resonator (Fig. 16(a)). The sensor is composed of a cap with a coupling aperture (Fig. 16(b)) and a cavity resonator loaded with a cylindrical post (Fig. 16(d)). On the surface of the pressure sensor cap, a patch antenna is seamlessly integrated in order to be wirelessly interrogated by the interrogation antenna (Fig. 16(c)). A PDC soft-lithography technique was developed to prepare the SiAlCN-based ceramic pressure sensor (Fig. 16(e)). The results show that the resonant frequency decreases with the increasing applied force in a quasi-linear fashion due to the reduced gap dimension, and the wireless passive pressure sensor can be used up to $800{ }^{\circ} \mathrm{C}$ owing to the robust PDC material and high- $Q$ evanescent-mode resonator structure (Figs. 16(f) and 16(g)).

Moreover, Ren et al. [144,369] proposed a novel wireless passive temperature sensor based on the temperature-dependent dielectric behavior of PDCs. The authors found that, with the increasing of temperatures from 25 to $500{ }^{\circ} \mathrm{C}$, the dielectric constant and loss tangent of the $\mathrm{SiCN}$ sample increase from 3.707 to 3.883 and from 0.0038 to 0.0213 , respectively. For the SiBCN samples, the dielectric constant and loss tangent increase from 4.817 to 5.132 and from
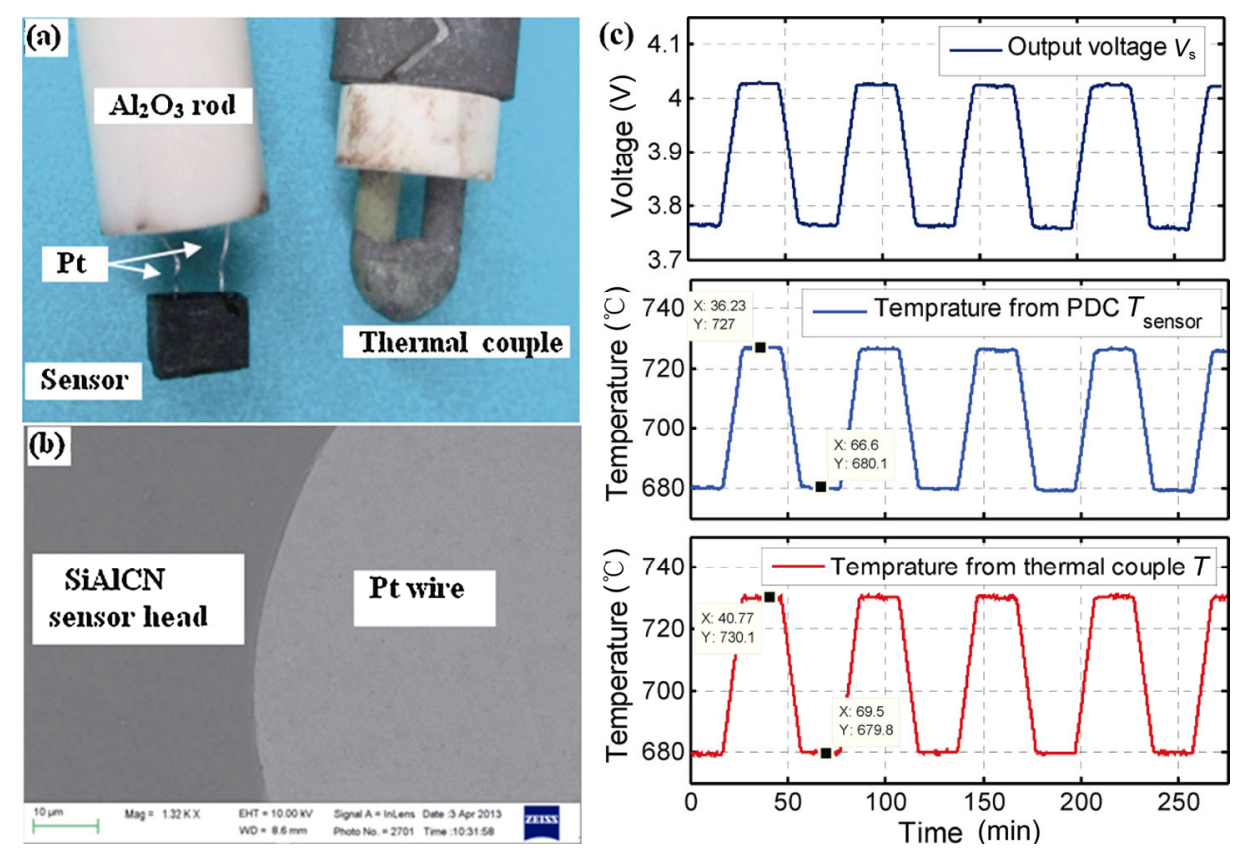

Fig. 15 (a) Photographs of a SiAlCN sensor with seamlessly embedded Pt leads (left) and a commercially available thermal couple used as reference (right); (b) SEM image showing the interface between SiAlCN and Pt leads; and (c) comparison between the temperatures measured by SiAlCN sensor and the commercial available thermal couple. Reproduced with permission from Ref. [366], (C) The Authors 2014. 


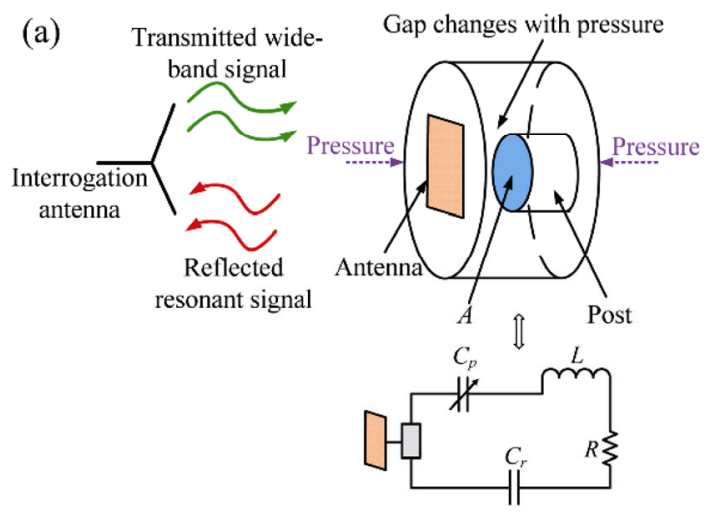

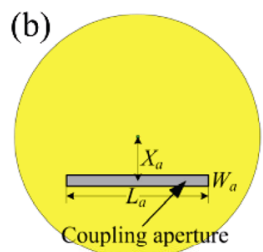

(d)

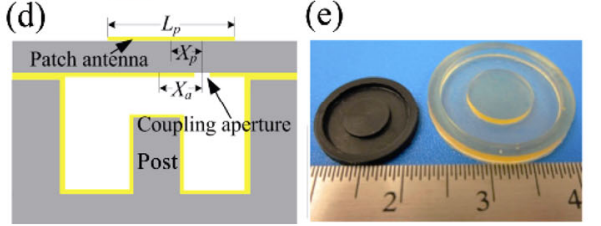

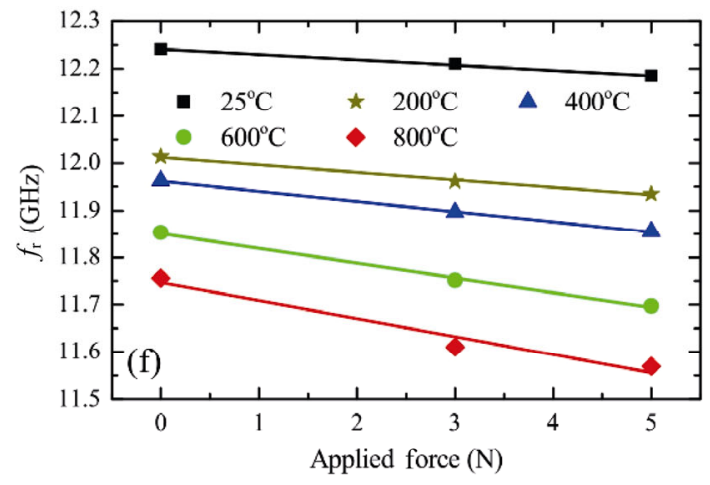

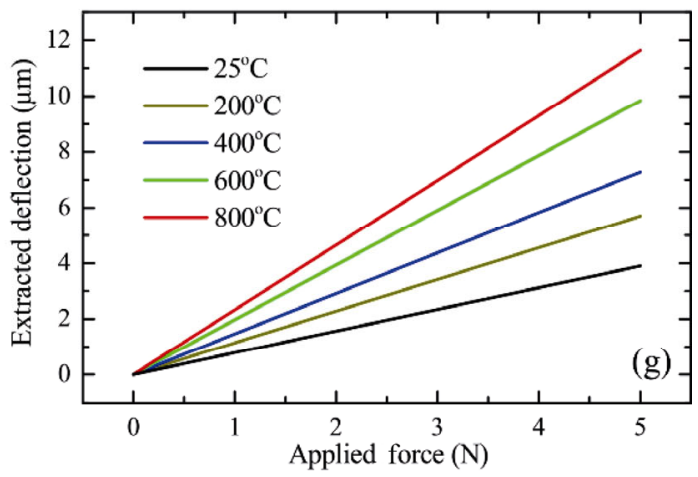

Fig. 16 (a) Schematic and circuit model of the proposed wireless pressure sensor based on an evanescent-mode cavity resonator; (b) and (c) are bottom and top views of the cap of the pressure sensor, respectively; (d) is the cut view of the patch antenna integrated pressure sensor; (e) are photographs of the polymer-derived ceramic cavity resonator before (right) and after pyrolysis (left); (f) measured resonant frequency of the polymer-derived pressure sensor as a function of the applied force at high temperatures; and $(\mathrm{g})$ extracted deflection of the pressure sensor cap as a function of the applied force at high temperatures. Reproduced with permission from Ref. [368], C Elsevier B.V. 2014.

0.0020 to 0.0186 , respectively, when the temperatures increase from 25 to $1000{ }^{\circ} \mathrm{C}$. Importantly, the experimental uncertainties for extracted the dielectric constant and loss tangent values are no more than 0.0004 and 0.0001 , respectively [369]. Based on this temperature-dependent dielectric behavior, $\mathrm{Li}$ et al. [370] developed a passive wireless polymer-derived SiCN sensor consisting of a cavity radio frequency resonator and an integrated slot antenna. The authors demonstrated that the sensor signals can be wirelessly detected at distances up to $20 \mathrm{~mm}$. Despite that the distance is still very short, this is a good start for wirelessly detected temperature in gas turbine engine using polymer derived ceramic sensors.

The studies regarding sensor applications of PDCs have been conducted for several years due to their unique microstructure, tailorable electric properties, excellent thermal stability, high chemical durability, and superior oxidation resistance. However, they are still under development and produced on a laboratory scale. It is really challenging to produce PDC sensors with precisely controllable electric properties which are of crucial importance for their practical applications. This is because the microstructure of PDCs varies with the variation of molecular structures and thermal treatment conditions. The shrinkage of the precursors during polymer-to-ceramic transformation leads to the formation of uncontrollable cracks and pores. Moreover, the carbothermal reduction reaction occurred in SiOC and $\mathrm{SiCN}$ systems at high temperature, which makes it hard to densify these ceramics. Therefore, more efforts should be made to recognize and to account for the effects of molecular structure, thermal treatment conditions, microstructure, and chemical/phase compositions on the electric properties of PDCs. A rigorous investigation of the correlations between these factors and the electric properties and performance of PDC sensors should be conducted using advanced technologies to derive a complete understanding of the origins of the high sensitivity of PDC sensors and to produce applicable PDC sensors. 


\section{Polymer-derived ceramics for electrochemical energy storage}

With the advancement of science and technology, development of electrochemical energy storage devices does not only provide us environmentally friendly solutions for driving our world but also greatly facilitates our modern life [371-379]. Among all types of electrochemical energy storage devices, lithium-ion secondary battery becomes a star in the past 30 years. Since a first lithium-based secondary battery had been invented in 1972 until its commercialization in 1990 with $\mathrm{LiCoO}_{2}$ as a positive electrode and carbon black as a negative electrode by Sony Corporation, and then until today, lithium-ion batteries have attracted a lot of attention and are nowadays widely used to power cellphones, laptops, electric vehicles, and other electric devices and in parallel have revolutionized our life [380-385]. Besides lithium-ion batteries, with the growth of application demand and the diversification of the application environment, other electrochemical energy storage and generation concepts like sodium-ion batteries [386-388], lithium sulfur batteries [389-391], supercapacitors [392-394], as well as metal-air batteries [395,396] and fuel cells [397,398] have recently gained momentum for future applications due to their respective characteristics.

All electrochemical energy storage devices are composed of electrodes, electrolytes, and separators. The performance of all those parts affects the electrochemical round-trip device efficiency. To store and release (charge/discharge) energy from a battery, three primary mobilities are involved: electronic transport in the solid state, ionic transport in the liquid and solid state, and molecular (mass) transport. The batteries used today still employ design concepts of Volta and LeClanché [401], which have been known for the last 200 years, although the electrochemical energy storage has experienced enormous transitions. The battery chemistry powering one's laptop has changed from nickel-cadmium (Ni-Cd) to nickelmetal hydride (NiMH) to lithium-ion (typically a graphitic carbon negative electrode versus a lithiated cobalt oxide positive electrode), becoming less environmentally problematic and less heavy. Lithiumion insertion materials, proposed by Whittingham in the mid-1970s as the active agent in the positive electrode [402], added the first new strategy in decades (if not centuries) to the portfolio of battery-derived portable power [403]. No perfect combination has been achieved in commercialized or about to be commercialized systems yet due to shortcomings such as electrode decomposition, formation/stability of solid-state electrolyte interface, side reactions, etc., resulting in capacity fading, instability, or safety issues. Thus, developing new multifunctional materials for electrodes, electrolytes, and electrochemical energy storages is imperative to overcome the mentioned issues [404-410]. A comparison of specific energy and specific power of different electrochemical energy storage systems is shown in Fig. 17.

In the past two decades, polymer-derived ceramics (PDCs) have been proved to be advantageous for electrochemical energy storage due to their unique chemical and thermodynamic stability, porosity structure, and decent electronic conductivity and robust, stress accommodating mechanical properties [35,411]. All physical and chemical properties of PDCs are tunable by controlling processing route and parameters or making chemical modification of precursor as demanded by the specific applications $[148,412,413]$.

PDCs have been shown to exhibit an interesting potential for energy storage devices due to their remarkable electrochemical performance. Herein, the development and application of PDCs used for electrochemical energy

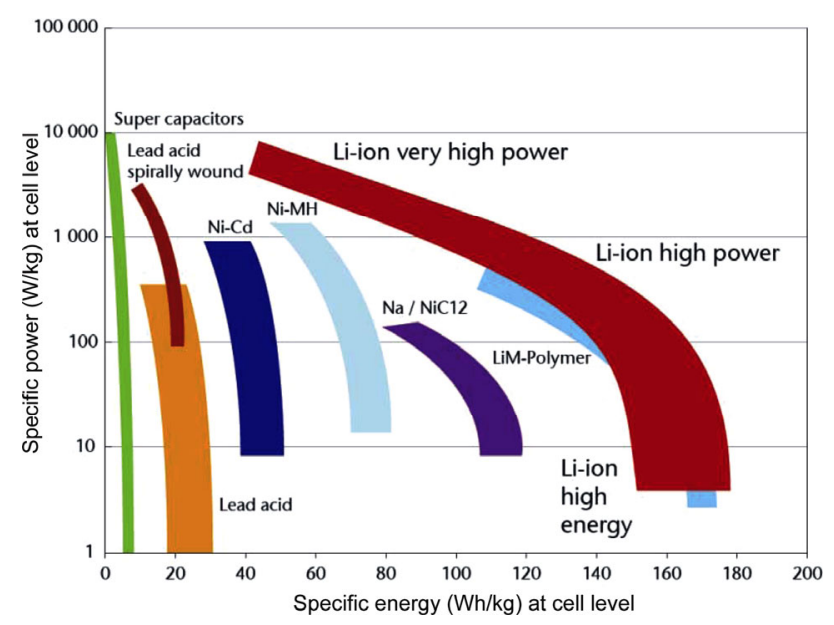

Fig. 17 Specific power versus specific energy of different electrochemical energy storage systems (note: $\mathrm{Ni}-\mathrm{Cd}=$ nickel-cadmium; $\mathrm{Ni}-\mathrm{MH}=$ nickel-metal-hydride; $\mathrm{Na} / \mathrm{NiCl} 2=$ sodium/nickel chloride; LiM-polymer $=$ lithium-metal-polymer; Li-ion = lithium ion; W/kg = watt per kilogram; $\mathrm{Wh} / \mathrm{kg}$ = watt-hour per kilogram) (source: International Energy Agency, Technology Roadmaps: Electric and Plug-in Hybrid Electric Vehicles, 2009, p. 12. (original source: Johnson Control - SAFT 2005 and 2007)). Reproduced with permission from Ref. [399], (C) ICE Publishing 2012; Ref. [400]. 
storage including lithium-ion batteries, sodium-ion batteries, lithium sulfur batteries, metal-air batteries, and supercapacitors are highlighted and discussed.

\section{1 Electrode materials in battery systems}

\subsubsection{Anode materials in lithium-ion batteries}

Lithium-ion batteries (LIBs) are widely used in all aspects of our modern life from portable electronic devices to electric vehicles and even to military and space applications due to its high energy density, high voltage, low self-discharge, and no memory effect [414]. Currently graphite with a theoretical capacity of $372 \mathrm{mAh} / \mathrm{g}$ is used as anode in the majority of commercial lithium-ion batteries. The capacity of graphite is far from meeting the demand for high performance lithium-ion batteries $[415,416]$. Lithium dendrites formed during the battery charge are considered as one of the reasons of a decay of battery electrochemical performance [417-421]. The formation of solid electrolyte interphase is another aspect that might cause the capacity fading of graphite anode. It will irreversibly consume lithium ions and increase the internal impedance of electrode. Introducing stabilizers and robust electrolytes as well as temperature treatment are the effective methods to improve to a certain extent the stability of the solid electrolyte interface (SEI) and to avoid the exfoliation of graphite layer [422-428]. Silicon is a promising candidate to replace graphite due to its extraordinary high theoretical capacity of approximate $3600 \mathrm{mAh} / \mathrm{g}$ which is almost 10 times higher as compared with a graphite anode, its low discharge potential $\left(0.5 \mathrm{~V}\right.$ versus $\left.\mathrm{Li} / \mathrm{Li}^{+}\right)$and abundance. Nevertheless, $\sim 300 \%$ volume expansion of silicon during lithiation and an accompanying phase transformation causes pulverization of the material and detachment of the electrode, thus leading to a fast fading of capacity and low coulombic efficiency. Although many solutions for enhancing the electrochemical performance of Si-based anode such as nanosizing of $\mathrm{Si}$ and Si-conductive coating composites have been addressed, from a commercial and practical point of view, only anodes with a little fraction of elemental silicon (up to $10 \mathrm{wt} \%$ ) present a stable electrochemical behavior [429-433].

Si-based PDCs materials namely SiOC and SiCN gained extensive attention as anode materials in LIBs since their unique temperature-dependent amorphous microstructure at relatively low pyrolysis temperatures (up to $1100{ }^{\circ} \mathrm{C}$ for $\mathrm{SiOC}$ and up to $1300{ }^{\circ} \mathrm{C}$ for $\mathrm{SiCN}$ ) under an inert or reactive atmosphere. Crystallization up to around $1300-1500{ }^{\circ} \mathrm{C}$ can be resisted due to the graphene-like $\mathrm{sp}^{2}$ bonded carbon network atoms located at the boundary of tetrahedral nanodomains of silicon. This character results in an excellent chemical and thermodynamic stability, elevated electrical conductivity $\left(6 \times 10^{-3} \mathrm{~S} / \mathrm{cm}\right)$, as well as robust mechanical properties. Moreover, remarkable studies have demonstrated that PDCs can reversibly accommodate $\mathrm{Li}$ in a potential range of $0-3 \mathrm{~V}$ with high electrochemical capacities up to $900 \mathrm{mAh} / \mathrm{g}$ and coulombic efficiencies over 99\% [411]. All these benefits make PDCs promising candidates for anodes in LIBs. Besides, all above properties including porosity can be easily adjusted by chemical modification of the preceramic polymer and by tunable parameters during the polymer-to-ceramic transformation [179,434-436].

Polymer-derived SiOC LIB anode was firstly reported by Wilson et al. in 1994 [438]. This work reveals that a polymer-derived SiOC pyrolyzed from siloxane polymers can reversibly intercalate lithium ions at potentials lower than $1 \mathrm{~V}$ with a specific capacity of $600 \mathrm{mAh} / \mathrm{g}$. The study of the effect of processing temperature on the cycle stability of SiOC anode demonstrates the lowest first cycle loss and

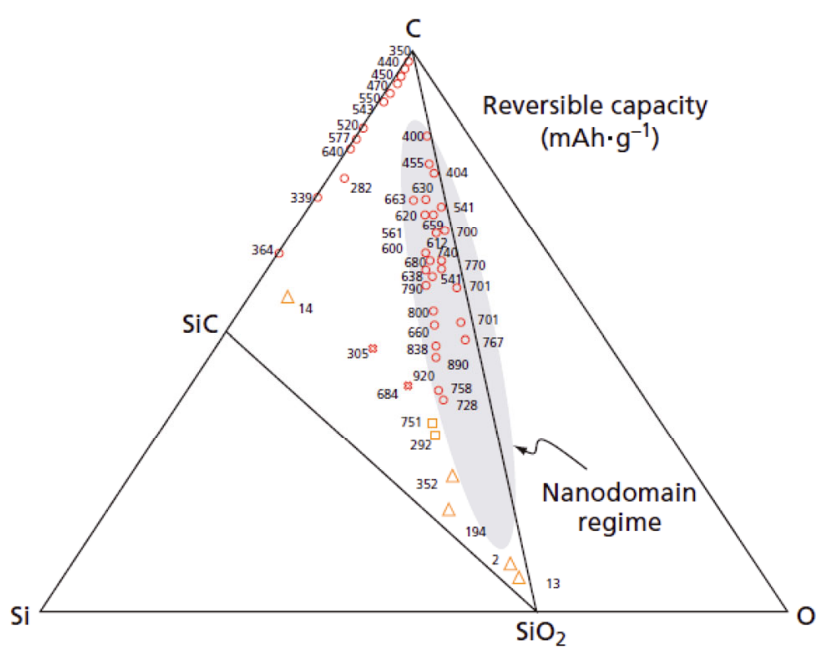

Fig. 18 SiOC compositional triangle. The numbers indicate the reversible capacity of the SiOC anode material depending on the composition. The highest capacity values are found for compositions containing mixed Si bonds (grey area) where silicon is tetrahedrally bonded to oxygen and carbon. Reproduced with permission from Ref. [399], (C) ICE Publishing 2012; Ref. [437]. 

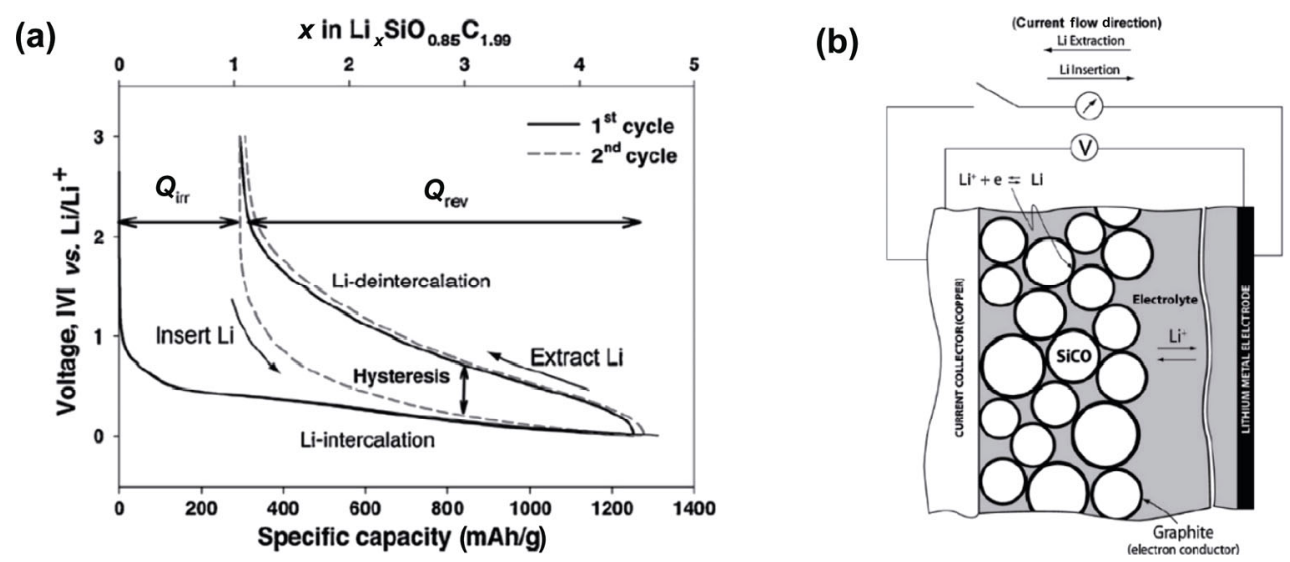

Fig. 19 (a) Insertion and extraction of lithium into polymer-derived SiOC and (b) a scheme of the microstructure of the SiOC electrode during cycling. Reproduced with permission from Ref. [444], CC Elsevier B.V. 2010.

highest reversible capacity for samples pyrolyzed at $1000{ }^{\circ} \mathrm{C}$. The further works of Dahn's group focused on the effect of the chemical composition on the electrochemical performance of more than 60 different SiOC materials, with the composition of $14 \% \mathrm{Si}$ and $80 \% \mathrm{C}$ revealing the best electrochemical performance [437]. While those works focused on the impact of the elemental composition on the electrochemical behavior, the mechanism of lithium storage and lithium transport have not been addressed in detail [439-443].

Refs. [445-447] claim that the major lithiation site is the mixed bond configuration (tetrahedrally coordinated silicon from $\mathrm{SiC}_{4}$ via $\mathrm{SiC}_{3} \mathrm{O}, \mathrm{SiC}_{2} \mathrm{O}_{2}$, and $\mathrm{SiCO}_{3}$ to $\mathrm{SiO}_{4}$ ). The reversible capacity of the specimen with mixed bonds of $\mathrm{C}, \mathrm{SiO}_{2}$, and $\mathrm{SiC}$ in SiOC compositional triangle is presented in Fig. 18. At the same time, the study of Ahn and Raj [444] describes the lithiation and delithiation process in $\mathrm{SiOC}$ as shown in Fig. 19. A hysteresis at a polarization potential between 250 and $500 \mathrm{mV}$ is demonstrated by a coulometric titration technique [444]. It is a result of kinetics and thermodynamic limitations of the diffusion of $\mathrm{Li}$ ions at the surface of electrode and electrolyte. In contrary to these findings, Fukui et al. [448,449], Graczyk-Zajac et al. [450,451], Dibandjo et al. [52], Knozowski et al. [436,452], Kaspar et al. [453,454], Wilamowska et al. [455], and Pradeep et al. [456,457] demonstrated that the carbon phase is the major Li-ion storage host site. It has been shown that lithium is accommodated in interstitial and defect sites, edges of graphene sheets, and adsorbed on the interface of graphite nano-crystallites. ${ }^{7} \mathrm{Li}$ MAS NMR (nuclear magnetic resonance) measurements were applied to confirm that the carbon phase is the host site for lithium storage by Fukui et al. [449] and Haaks et al. [458]. Sun and Zhao [459] investigated the atomistic origin of the performance of carbon-rich SiOC by first-principles theoretical approach, which demonstrates a two-step process of lithium insertion: (1) Li ions diffuse into nano-voids followed by (2) accommodation of the $\mathrm{Li}$ ions in the SiOC matrix and in the segregated carbon network. The atomistic model of SiOC and the overview of the supercell are presented in Fig. 20.

Kaspar et al. [460] investigated a polyorganosiloxanederived SiOC anode pyrolyzed at temperatures from 900 to $2000{ }^{\circ} \mathrm{C}$ and demonstrated that the reversible capacity decreases with the rise of pyrolysis temperature and formation of crystalline $\mathrm{SiC}$ at temperatures exceeding $1200{ }^{\circ} \mathrm{C}\left(660 \mathrm{mAh} / \mathrm{g}\right.$ for $900{ }^{\circ} \mathrm{C}$ to $80 \mathrm{mAh} / \mathrm{g}$ for $2000{ }^{\circ} \mathrm{C}$ ). The effect of the electrical conductivity on the capacity of SiOC was also investigated by Kaspar et al. [453], revealing that (1) a low carbon content exhibits high initially capacities but fading rapidly during cycling and (2) a carbon content beyond $20 \mathrm{wt} \%$ is beneficial for the conductivity and cycling stability.

Porous SiOC materials have also been investigated as materials for $\mathrm{Li}$-ion batterie by various researchers. Dibandjo et al. [52] made a comparison between dense and porous SiOC anodes and found that the porous sample exhibits enhanced stable electrochemical performance. Pradeep et al. [457] synthesized a linear polysiloxane cross-linked with divinylbenzene (DVB) by hydrosilylation reaction catalyzed by Pt. After pyrolysis at $1000{ }^{\circ} \mathrm{C}$ under argon, the obtained porous SiOC with $180 \mathrm{~m}^{2} / \mathrm{g}$ of specific surface area exhibits a high specific capacity over $600 \mathrm{mAh} / \mathrm{g}$ due to the porous structure providing enough fast ionic transport 


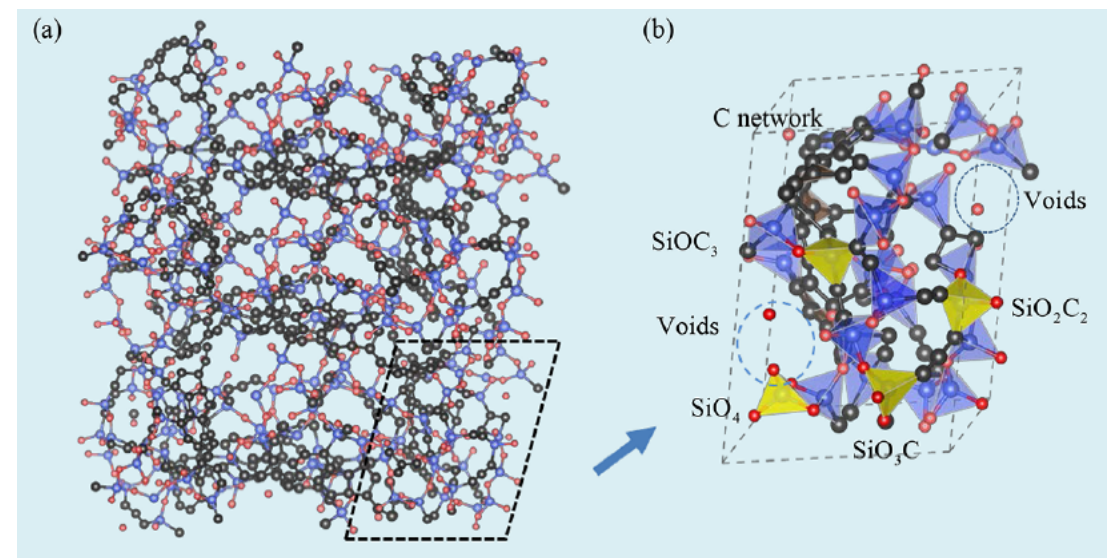

Fig. 20 Atomic model of SiOC. (a) Overview of the supercell; (b) unit cell shows a series of vertex-sharing tetrahedra (blue atoms: silicon atoms; red atoms: oxygen atoms; gray atoms: segregated carbon phase which forms the backbone of the network; blue dotted circles represent the nanovoids percolated in the lattice which contribute to the low density of the SiOC molecule). Reproduced with permission from Ref. [459], C American Chemical Society 2017.

paths and accommodating the structural changes during lithiation/delithiation. Fukui et al. [461] also developed a microporous SiOC composite material by pyrolyzing a blend of polysilane, $\left(\mathrm{Ph}_{2} \mathrm{Si}\right)_{0: 85}(\mathrm{PhSi})_{0: 15}$ (1) and polystyrene $\left(1: 1\right.$ in weight) at $1000{ }^{\circ} \mathrm{C}$, which shows a remarkable capacity of $600 \mathrm{mAh} / \mathrm{g}$ and a good cycle stability. Xia et al. [462] studied the impact of etching SiOC by $\mathrm{KOH}$ and found improved specific surface area of the material and enhanced electrochemical performance of the anode. Sang et al. [451,463] reported SiOC nanolayers wrapped 3D interconnected graphene sponge with deliberate porous mutli-layered sandwich-like structure, which shows a high initial discharge capacity $(1280 \mathrm{mAh} / \mathrm{g}$ at $0.1 \mathrm{~A} / \mathrm{g})$ and high stability $(701 \mathrm{mAh} / \mathrm{g})$ after 100 cycles due to its improved electrical conductivity, accelerated ion insertion and endowed full utilization of active sites of lithium storage.

By introducing hydrogen during pyrolysis of polysiloxane precursors, the impact of pyrolysis atmosphere on SiOC was studied by Pradeep et al. [464]. It was found that $5 \%$ of $\mathrm{H}_{2}$ admixture to the argon lead to a decreasing of the carbon content from 55.15 to $46.37 \mathrm{wt} \%$ and to an enhanced initial capacity from 568 to $704 \mathrm{mAh} / \mathrm{g}$ and coulombic efficiency from $63 \%$ to $67 \%$. Shen and Raj [465] deposited thin films anodes of SiOC on copper with around $0.5-5 \mu \mathrm{m}$ thickness which shows a capacity of $1100 \mathrm{mAh} / \mathrm{g}$ and a high efficiency of approximately $99 \%$. The highlight of this material is a facile preparation method and lower cost due to lack of binder and conductive additive. Dong et al. [466] synthesized hard SiOC microbeads by emulsifying cross-link and subsequent pyrolysis for anode and investigated its electrochemical performance. This processing approach enhanced the structural stability of the material leading to a discharge specific capacity of $805 \mathrm{mAh} / \mathrm{g}$ achieved after 300 cycles. Nitrogen-doped carbon fibers were also studied with SiOC as the matrix by Ma et al. [467]. The unique 3D conductive network and the existence of nitrogen result in improved electronic conductivity and electrochemical active sites of SiOC. Lim et al. [468] developed a novel silicone oil-derived SiOC anode by controlling free-carbon domain, which exhibits remarkable electrochemical performance including reversible capacity $(550 \mathrm{mAh} / \mathrm{g}$ at $200 \mathrm{~mA} / \mathrm{g})$, cycle stability ( $95 \%$ capacity retention after 200 cycles at $200 \mathrm{~mA} / \mathrm{g}$ ). A polymer derived SiOC integrated with graphene aerogel was prepared by Shao et al. [469] via solvent assisted infiltration. The sample comprised of 19.8 $\mathrm{wt} \%$ graphene in the SiOC matrix achieved the highest level of performance that the capacity retention was around $95 \%$ after 1000 cycles at a high current density of $1480 \mathrm{~mA} / \mathrm{g}$ and over $99 \%$ of efficiency.

Blending SiOC with high-capacity elements like silicon or tin leads to a significant improvement of the electrochemical performance of the composite electrode. Silicon oxycarbide/tin nanocomposites $(\mathrm{SiOC} / \mathrm{Sn})$ were prepared via chemical modification of polysiloxane with tin(II)acetate and subsequent pyrolysis at $1000{ }^{\circ} \mathrm{C}$ by Kaspar et al. [112]. The obtained material demonstrates high initial capacity and excellent cycle stability. Kaspar et al. [470] also studied silicon oxycarbide/ nano-silicon composites and addressed the effect of the 


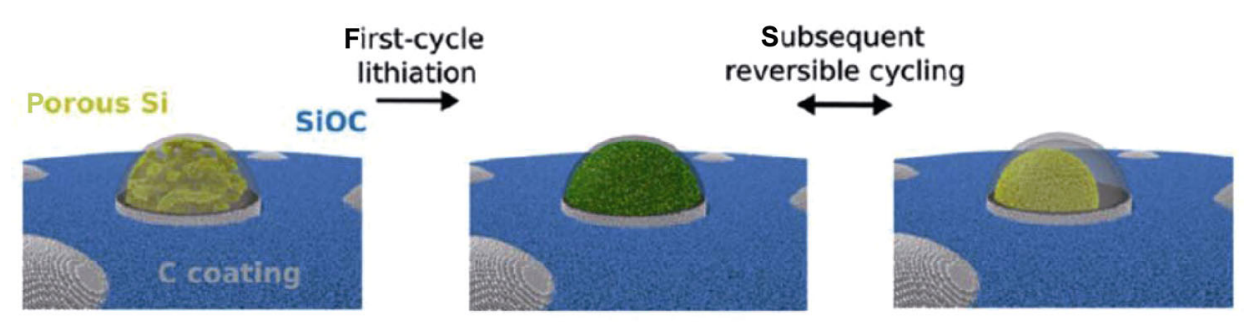

Fibers $O$ Nanoparticles by aluminothermic/magnesiothermic reduction
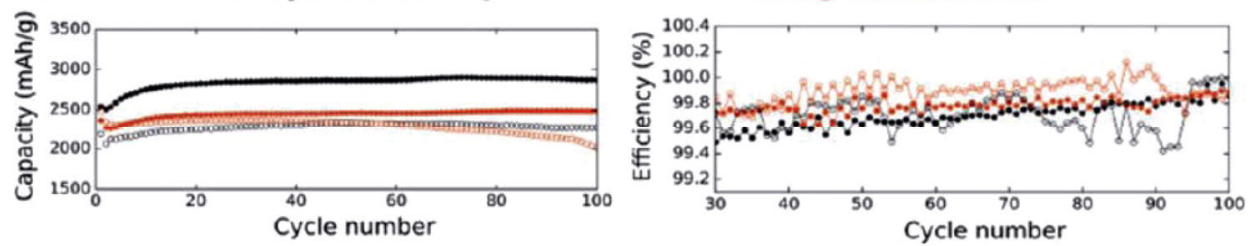

Fig. 21 Schematic diagram of mechanism of lithiation/delithiation of porous nano $\mathrm{Si}$ in a $\mathrm{C} / \mathrm{SiOC}$ matrix and its electrochemical performance. Reproduced with permission from Ref. [110], (c) American Chemical Society 2017.

silicon crystallinity on the performance of the anode. These results show that composites of SiOC and crystalline Si exhibit higher, but faster decay capacity ( $905 \mathrm{mAh} / \mathrm{g}$ of reversible capacity) while the composite of SiOC and amorphous $\mathrm{Si}$ exhibits a lower reversible capacity of $704 \mathrm{mAh} / \mathrm{g}$ but a stable cycling property up to 100 cycles, which can be explained by the microstructural integrity of the composite comprised of $\mathrm{SiOC}$ and amorphous Si. Highly porous silicon embedded into a ceramic matrix has been designed and synthesized by Vrankovic et al. [110]. As shown in Fig. 21, the prepared material achieved a capacity of $2000-3000 \mathrm{mAh} / \mathrm{g}$ normalized to the amount of $\mathrm{Si}$ and above $99.5 \%$ coulombic efficiencies as well as almost $100 \%$ capacity retention after 100 cycles. The remarkable cycle stability is attributed to the porous structure of $\mathrm{Si}$ and the uniform ceramic networks which can effectively suppress the volume expansion of silicon and provide sufficient conductive paths. Xia et al. [471] studied the effect of $\mathrm{SnCl}_{2}$ addition on the structure on the performance of SiOC anode by the synthesis of $\mathrm{Sn} / \mathrm{SiOC}$ composites with varying $\mathrm{Sn}$ content via a sol-gel process. With the rise of the Sn content, the rate capability of $\mathrm{Sn} / \mathrm{SiOC}$ composites increases first to a certain value but then decreases. A SiOC-Sb nanocomposite was fabricated by Dubey et al. [472]. The obtained material shows charge storage capacities within a range of $549-703 \mathrm{mAh} / \mathrm{g}$ under a current density of $74.4-2232 \mathrm{~mA} / \mathrm{g} .{ }^{29} \mathrm{Si}$ and ${ }^{7} \mathrm{Li} \mathrm{NMR}$ measurements demonstrate that the introduction of $\mathrm{Sb}$ in SiOC matrix decreases the amount of free $\mathrm{C}$ in the SiOC matrix, resulting in different lithium-ion storage sites.
For polymer-derived $\mathrm{SiCN}$ anode, polysilazanederived SiCN ceramics used as anode were described by Zank et al. [473] firstly in a patent in 1997 which shows that $\mathrm{SiCN}$ ceramics have reversible discharge capacities up to $560 \mathrm{mAh} / \mathrm{g}$. SiCN materials were further suggested to be applied as a solid electrolyte by Liebau-Kunzmann et al. [474]. This work demonstrates the preferential formation of $\mathrm{Li}-\mathrm{N}$ bonds in lithiation process which exhibits potential of $\mathrm{SiCN}$ for anode in LIB. Su et al. [475] investigated pure polymer-derived SiCN materials by pyrolyzing polysilylethylendiamine at $1000-1300{ }^{\circ} \mathrm{C}$. The obtained $\mathrm{SiCN}$ shows a discharge capacity of $754.9 \mathrm{mAh} / \mathrm{g}$ and an initial coulombic efficiency of $60.4 \%$. However, fast capacity fading occurred in the subsequent cycles. To solve the issue, Feng [476] applied an additional heat treatment to the SiCN material, resulting in an enhanced discharge capacity and cycle stability. Carbon-rich SiCN materials have been extensively studied by Kaspar et al. [477], Graczyk-Zajac et al. [478], and Reinold et al. [479]. Their studies reveal that the presence of a free carbon phase improved the electrochemical performance significantly, and the molecular structure of the pre-ceramic polymer affects the electrochemical performance of the final material. Liu et al. [480] found that the chemical modification with divinylbenzene (DVB) can effectively increase the carbon content which is beneficial for a higher capacity of polyorganosilazane-derived $\mathrm{SiCN}$ from 136 to $574 \mathrm{mAh} / \mathrm{g}$. Solid state NMR investigation realized by Baek et al. [481] shows that free carbon phase is a main storage site of lithium in the SiCN ceramics. Hard-carbon containing $\mathrm{SiCN}$ composites exhibiting 
an excellent performance under high current density were investigated by Wilamowska et al. [482]. Graczyk-Zajac et al. [483,484] further investigated the lithium storage mechanism of the disordered hardcarbon SiCN by Raman spectroscopy and ${ }^{7} \mathrm{Li}$ MAS NMR. This study reveals that the adsorption-like process in disordered carbon is to a significant extent responsible for lithium storage in composites and more than $33 \%$ of lithium in the hard-carbon $\mathrm{SiCN}$ is adsorbed in ionic form at the surface and in pores of the composite. Feng et al. further studied the capacity fading mechanism of SiCN by using different poly-silyl-carbodiimides as precursor. They demonstrated that stable SEI layers and abundant free carbon result in excellent electrochemical performance. The composites of $\mathrm{SiCN} /$ graphite and $\mathrm{SiCN} /$ silicon also demonstrated improved electrochemical performance if compared with pure graphite and silicon, respectively [111,479483,485]. Storch et al. [486] investigated the effect of the pyrolysis temperature on the electrochemical behavior of porous carbon-rich SiCN composite. This work shows that the sample pyrolyzed at $900{ }^{\circ} \mathrm{C}$ delivers a high initial charge capacity of $447 \mathrm{mAh} / \mathrm{g}$ and a capacity retention of $534 \mathrm{mAh} / \mathrm{g}$ after 100 cycle at a current of $72 \mathrm{~mA} / \mathrm{g}$.

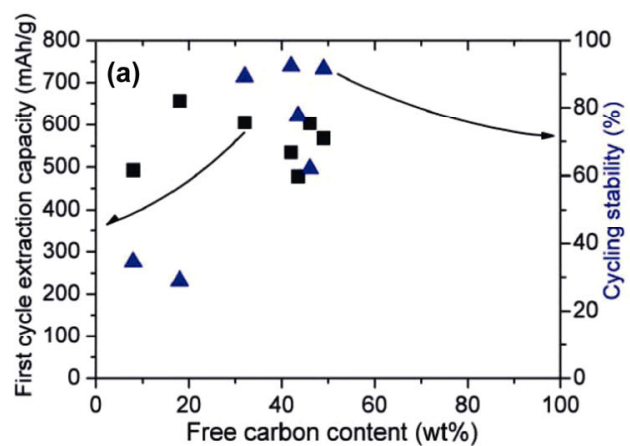

Rohrer et al. [487] addressed various approaches regarding the stabilization of silicon and tin containing anodes embedded in a SiOCN matrix. In a review of Graczyk-Zajac et al. [435], irreversible and reversible lithium storage within SiOC and $\mathrm{SiCN}$ ceramics were discussed. Their results are as follows: (1) The first cycle discharge/charge capacities of SiOC materials nearly do not depend on the amount of free carbon. On the contrary, the capacity of $\mathrm{SiCN}$ increases with the amount of carbon and reaches a threshold value at around 50\%. (2) Replacing $\mathrm{O}$ with $\mathrm{N}$ decreases the lithium storage capacity. Due to the more ionic character of $\mathrm{Si}-\mathrm{O}$ bonds, lithium is more captured by $\mathrm{O}$, which leads to a very high initial lithiation capacity even at low $\mathrm{C}$ content. (3) The more covalent character of $\mathrm{Si}-\mathrm{N}$ bonds and lower electron density on the nitrogen atom result in less capture of $\mathrm{Li}$ in the ceramic matrix if $\mathrm{O}$ is replaced by $\mathrm{N}$, thus leading to lower electrochemical performance of the anode of the LIB. Figures 22 and 23 show the dependence of the lithiation/delithiation capacity of SiOC- and SiCN-anode materials on the amount of free carbon and $\mathrm{SiOC}$ matrix or SiCN matrix, respectively. The results of this work also provide a reference for designing the optimal composition of PDC-based anode material.

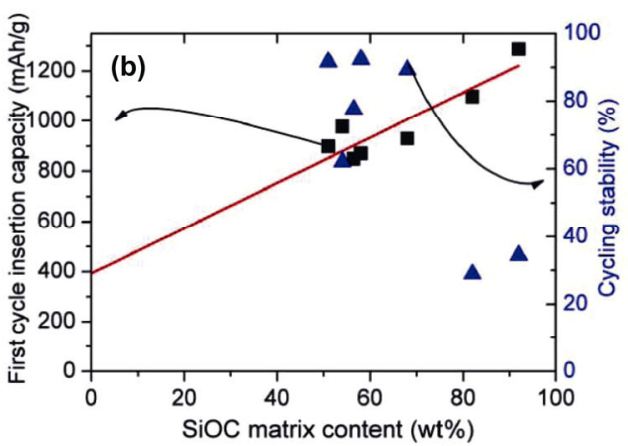

Fig. 22 Dependence of the lithiation/delithiation capacity of SiOC-derived materials on the amount of free carbon (a) and on the amount of SiOC matrix (b). Reproduced with permission from Ref. [435], C) the authors 2015.
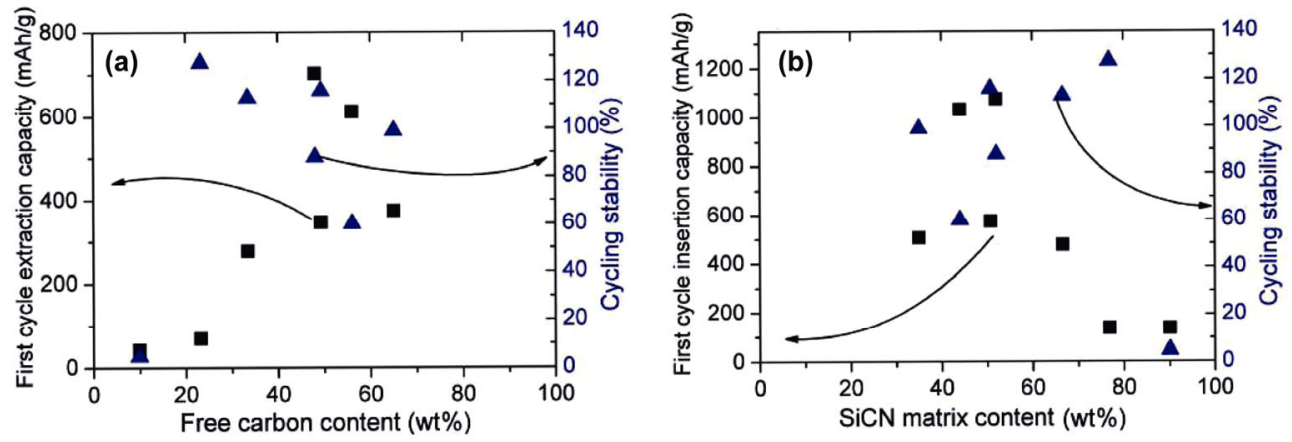

Fig. 23 Dependence of the lithiation/delithiation capacity of SiCN-derived materials on the amount of free carbon (a) and on the amount of SiCN matrix (b). Reproduced with permission from Ref. [435], C the authors 2015. 
Despite many advantages, PDC anodes reveal one important drawback, namely a low coulombic efficiency which leads to lower economic benefits compared with commercial graphite anode. Thus, PDC anode is not the mainstream research direction up to now.

\subsubsection{Cathode materials in lithium-based batteries}

$\mathrm{Li}-\mathrm{S}$ batteries are promising candidates for electrode materials for electrochemical energy storage devices due to their superior theoretical capacity of $1675 \mathrm{mAh} / \mathrm{g}$ and abundant resources as well as low cost. Nevertheless, "shuttle effect" and low conductivity of $5 \times 10^{-28} \mathrm{~S} / \mathrm{m}$ and volume expansion of $80 \%$, result in fast capacity fading and low coulombic efficiency and seriously hinder their technical application [391,488]. Anode materials with sulfur dispersed in an electrically conducting microporous SiOC and porous carbon-rich SiCN ceramic matrix exhibit decreased "shuttle effect" and enhanced electrochemical performance. Weinberger et al. [489] synthesized highly microporous submicrometric carbon spheres by etching of a sol-gel derived SiOC, which has $0.63 \mathrm{~cm}^{3} / g$ of total pore volume that can accommodate sulfur for cathode. This composite owns good cycle stability at a high current density of $500 \mathrm{~mA} / \mathrm{g}$, and the capacity retention is as high as $241 \mathrm{mAh} / \mathrm{g}$ up to 100 cycles and coulombic efficiency is close to $100 \%$ just after several cycles. The impact of the morphology of C-rich silicon carbonitride ceramic on the electrochemical performance was investigated by Qu et al. [490] via tunable pyrolysis temperature from 1000 to $1600{ }^{\circ} \mathrm{C}$. A schematic diagram of carbon-rich $\mathrm{SiCN} / \mathrm{S}$ composite anode preparation is presented in Fig. 24. Their work demonstrates that C-rich SiCN ceramic matrix exhibits improved conductivity and stable cycling property because of the abundant free carbon phase. Best electrochemical performance has been identified for the sample pyrolyzed at $1000{ }^{\circ} \mathrm{C}$ with $66 \mathrm{wt} \%$ of sulfur loading in the composite.

$\mathrm{Li}-\mathrm{Se}$ batteries are another promising candidates of high-capacity batteries due to the superior theoretical volumetric capacity of Se with $3253 \mathrm{mAh} / \mathrm{cm}^{3}$ (based on density of $4.82 \mathrm{~g} / \mathrm{cm}^{3}$ ), and their substantial electrical conductivity (20 times that of sulfur) [491]. However, inferior cycle stability and low coulombic efficiency caused by poor structural stability and sluggish lithiation reaction kinetics of a Se cathode

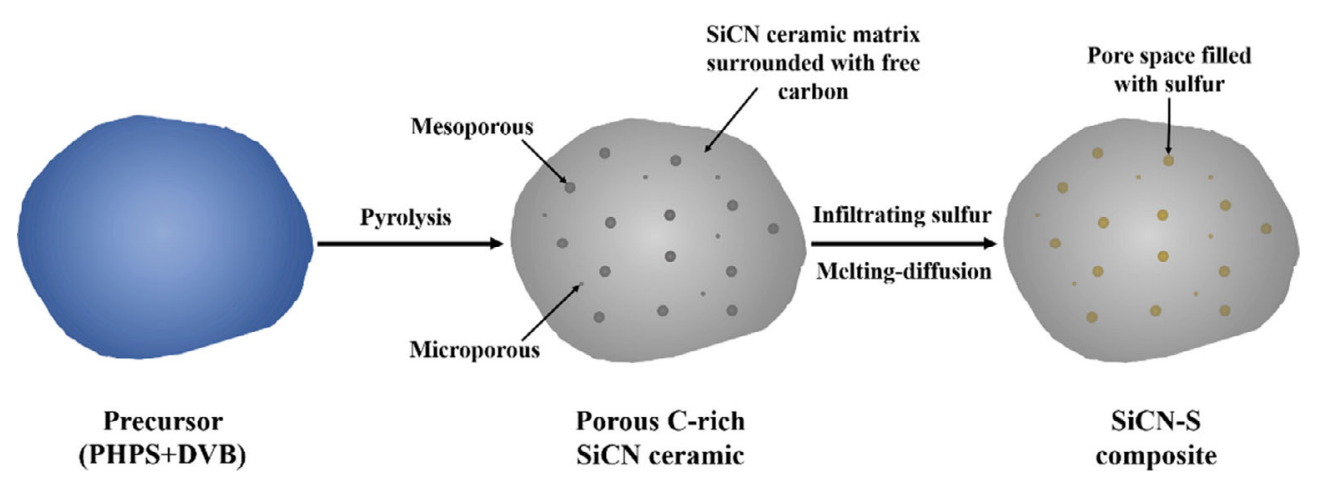

Fig. 24 Schematic diagram of carbon-rich SiCN/S cathode preparation. Reproduced with permission from Ref. [490], (C) Elsevier Ltd. 2021.

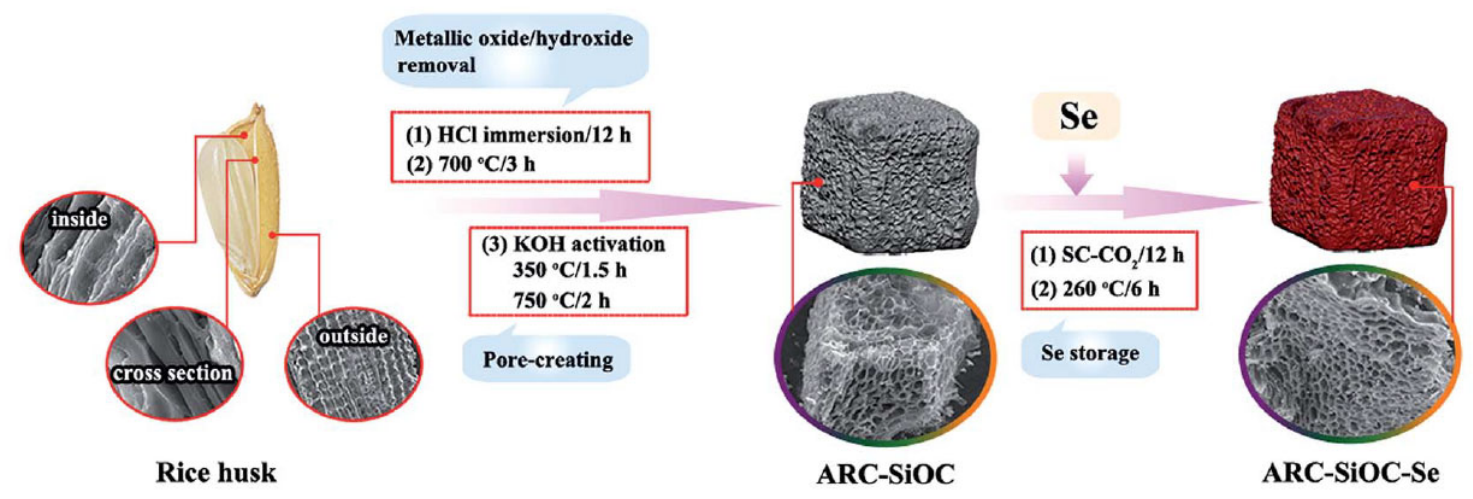

Fig. 25 Schematic of the synthesis of 3D porous SiOC/Se composite (ARC-SiOC = active rice husk carbon-SiOC matrix). Reproduced with permission from Ref. [491], C The Royal Society of Chemistry 2018. 
hamper the practical application of Se cathodes [492,493]. Fang et al. [491] developed a SiOC/Se cathode derived from rice husks by a bio-templating method with the assistance of a supercritical $\mathrm{CO}_{2}$ technique. A schematic of the synthesis of $3 \mathrm{D}$ porous $\mathrm{SiOC} / \mathrm{Se}$ composite is presented in Fig. 25. The obtained 3D porous $\mathrm{SiOC} / \mathrm{Se}$ cathode shows extremely high first areal capacity $\left(8.1 \mathrm{mAh} / \mathrm{cm}^{2}\right.$ at $\left.0.1 \mathrm{C}\right)$ with a high Se loading $\left(8 \mathrm{mg} / \mathrm{cm}^{2}\right)$ and remarkable capacity retention. The excellent properties are attributed to the unique 3D porous conductive network and SiOC units set in the porous carbon matrix, resulting in continuous electron/ion transport pathways as well as enhanced structural stability. Besides, trapping $\mathrm{Se}$ and $\mathrm{Li}_{2} \mathrm{Se}$ by strong chemical adsorption and uniform distribution of infiltrated Se were also confirmed.

\subsubsection{Anode materials in sodium-ion batteries}

Due to the high abundance and low cost of sodium, combined with its low redox potential of $-2.71 \mathrm{~V}$ $\left(\mathrm{Na}^{+} / \mathrm{Na}\right)$ versus the standard hydrogen electrode, which is only $0.3 \mathrm{~V}$ above the one of $\mathrm{Li}^{+} / \mathrm{Li}$, sodium-ion batteries (NIBs) hold much promise for large-scale energy storage application. However, NIBs are less explored than $\mathrm{Li}$-ion batteries and research for promising electrode materials is still a fundamental concern $[494,495]$.

For Li-ion batteries, graphite is the most prominent anode material, because storing Li-ions by the reversible intercalation between their basal-planes and without structural degradation is possible. For Na-ions the overall thermodynamic balance is unfavorable and sodium forms graphite intercalation compounds to only a very limited extent [496]. Alternatively, non-graphitic disordered carbons have been intensively explored as potential anodes for reversible sodium storage. Stevens and Dahn [497] studied glucose-derived hard-carbon as NIB anode, providing a high reversible storage capacity of $300 \mathrm{mAh} / \mathrm{g}$, but at relatively slow cycling current of $\mathrm{C} / 80$ with reference to $\mathrm{NaC}_{6}$ stoichiometry. Significant improvement was achieved by Wenzel et al. [498], who investigated template prepared porous carbons, providing enhanced reversible capacity of $100-130 \mathrm{mAh} / \mathrm{g}$ at higher current rates of $\mathrm{C} / 5-5 \mathrm{C}$. However, the major drawback related to most disordered carbons is their weak cycling stability, serious capacity fading upon prolonged cycling, and a low-potential sodium insertion leading to a risk of the formation of dendritic plating. So far it is assumed that storage of Na-ions within disordered carbon occurs similar to that of lithium, namely major storing sites are the edges of carbon and graphene layers, defect sites and micropores. However, this hypothesis has not been proven yet. Moreover, the experimental data $[495,499,500]$ show that no direct analogy can be drawn between the storage performances of disordered carbons with respect to these two cations. In other words, the carbonaceous materials which fail in lithium storage can appear to be stable and reversible sodium hosts, while the materials which perform very well with respect to lithium ions might not be suitable to host sodium. Until now, this problem has not been analyzed in detail yet.

In recent years, PDC materials have been widely studied for application in LIBs due to their remarkable electrochemical properties and chemical and mechanical stability. However, until now only few studies pay attention to the utilization of PDCs in NIBs. Kaspar et al. [501] studied for the first time a $\operatorname{SiOC}(\mathrm{N}) /$ hard carbon composite as anode material for NIBs with a focus on the influence of morphology of ceramic matrices on the electrochemical performance. They found a strong correlation of the electrochemical performance, porosity, and elemental composition of the $\mathrm{SiOC}(\mathrm{N})$ anode. For hard carbon of microporous nature, the addition of SiOC effectively enhanced the capacity from 44 to $201 \mathrm{mAh} / \mathrm{g}$. A Sb-embedded SiOC anode was prepared by Lee et al. [502] by a "one pot pyrolysis" process at $900{ }^{\circ} \mathrm{C}$. Owing to the existence of free carbon, the composite shows a first desodiation capacity of about $510 \mathrm{mAh} / \mathrm{g}$ and a distinguished capacity retention over $97 \%$ even after 250 cycles. Kim et al. [503] also developed a free-carbon containing $\mathrm{Sb} / \mathrm{SiOC}$ composite where the $\mathrm{Sb}$ nanoparticles are uniformly embedded in the ceramic matrix. This material yields $344.5 \mathrm{mAh} / \mathrm{g}$ of capacity retention after 150 cycles at $0.2 \mathrm{C}$ and outstanding rate properties (197.5 mAh/g at $5 \mathrm{C}$ ) due to the presence of free carbon domains. Chandra and Kim [504] produced a $\mathrm{SiCN}$ material from silicone oil as anode for NIBs. The obtained sample calcined at $900{ }^{\circ} \mathrm{C}$ exhibits a remarkable reversible capacity of $160 \mathrm{mAh} / \mathrm{g}$ at 25 $\mathrm{mA} / \mathrm{g}$ after 200 cycles and a high-rate performance. It is worth mentioning that the capacity decay of each cycle amounts only $0.09 \mathrm{mAh} / \mathrm{g}$ during 650 cycles. Chandra et al. [505] also investigated the mechanism related to $\mathrm{Na}$ ion storage in SiOCs by ex situ measurements and density functional theory simulations. 
Their work reveals that the storage of $\mathrm{Na}$ ions mainly occurs in micropores, defects, and C-rich and O-rich ceramic phases. A functionalization of $\mathrm{SiOC}$ with $\mathrm{MoS}_{2}$ is reported by Soares and Singh [117]. The $\mathrm{MoS}_{2}-\mathrm{SiOC}$ composite anode exhibits an effectively improved cycle stability over 100 cycles. Another nitrogen-doped $\mathrm{MoS}_{2} / \mathrm{SiOC}$ composite with hierarchical structure is prepared by Lim et al. [506]. Due to the enlargement of interspace and improved electronic conductivity as well as mechanical property, the hierarchical nitrogen-doped $\mathrm{MoS}_{2} / \mathrm{SiOC}$ composite achieved a facile reversible cycle of $\mathrm{Na}$ ions during the operation of the battery, namely $540.7 \mathrm{mAh} / \mathrm{g}$ of reversible capacity and almost $100 \%$ of capacity retention, also including excellent rate capability at $10 \mathrm{~A} / \mathrm{g}$. Putra et al. [507] studied SiOC-graphene composites pyrolyzed from silicone oil and demonstrated their excellent performance. They also studied the effect of fluorinated ethylene carbonate in the electrolyte on the electrochemical performance. Chandra et al. [508] proposed a new strategy that synthesizes $\mathrm{C}$ - and O-rich SiOC composites by pyrolyzing C-rich precursor under $\mathrm{H}_{2} / \mathrm{Ar}$. The obtained SiOC delivered a high reversible capacity $(234 \mathrm{mAh} / \mathrm{g}$ at $25 \mathrm{~mA} / \mathrm{g}$ ) and $160 \mathrm{mAh} / \mathrm{g}$ of reversible capacity after 140 cycles.

\subsubsection{Anode materials in potassium-ion batteries}

Practical application of potassium-ion batteries is significantly limited due to the large ionic radius of $\mathrm{K}$, which causes a low ion diffusion rate and a huge volume expansion during insertion reaction. Nevertheless, potassium-ion batteries show a high energy density in line of material abundance as well as low cost [509]. Sang et al. [510] designed and prepared bi-continuous and nano-porous carbon spheres with continuous nanocarbon matrices and interconnected nanopores by etching carbon-rich SiOC ceramics. The achieved sample shows a high first reversible capacity $(336 \mathrm{mAh} / \mathrm{g}$ at $0.1 \mathrm{~A} / \mathrm{g})$ as well as long cycle life and high-rate properties $(191 \mathrm{mAh} / \mathrm{g}$ after 2000 cycles at $0.5 \mathrm{~A} / \mathrm{g}$ ) rationalized by the interconnected nanostructure, defective nature of carbon framework, and various oxygen-containing functional groups introduced after etching.

\section{2 Electrode materials in supercapacitors}

Supercapacitors are electrochemical energy storage devices, necessary where the power requirement predominates the energy requirement. They are usually not constrained by ionic diffusion kinetics experienced in batteries and can run for a large number of cycles $\left(\sim 10^{6}\right)$ at high charge and discharge currents. Nevertheless, the energy density of supercapacitors is usually limited by a specific surface aera of the electrode materials in practical applications, whereas the rate capability is affected by the insufficient electronic conductivity of the porous electrode [511513]. Therefore, the choice of appropriate electrode materials is of importance to provide a sufficient device performance. Figure 26 shows a schematic of a supercapacitor containing porous electrode materials. Supercapacitor electrodes require high specific surface area and high electric conductivity in line with a good corrosion resistance, high temperature stability, controlled pore structure, processability and compatibility in composite materials, and a relatively low cost. All those properties can be easily obtained via effective tuning of polymer precursor of PDCs, what makes these ceramics a potential candidate for use in supercapacitors. Table 4 summarizes the electrochemical performance of various PDCs studied as electrodes in supercapacitors.

Equations (3) and (4) describe the relationship between the energy, power, and capacitance of a supercapacitor:

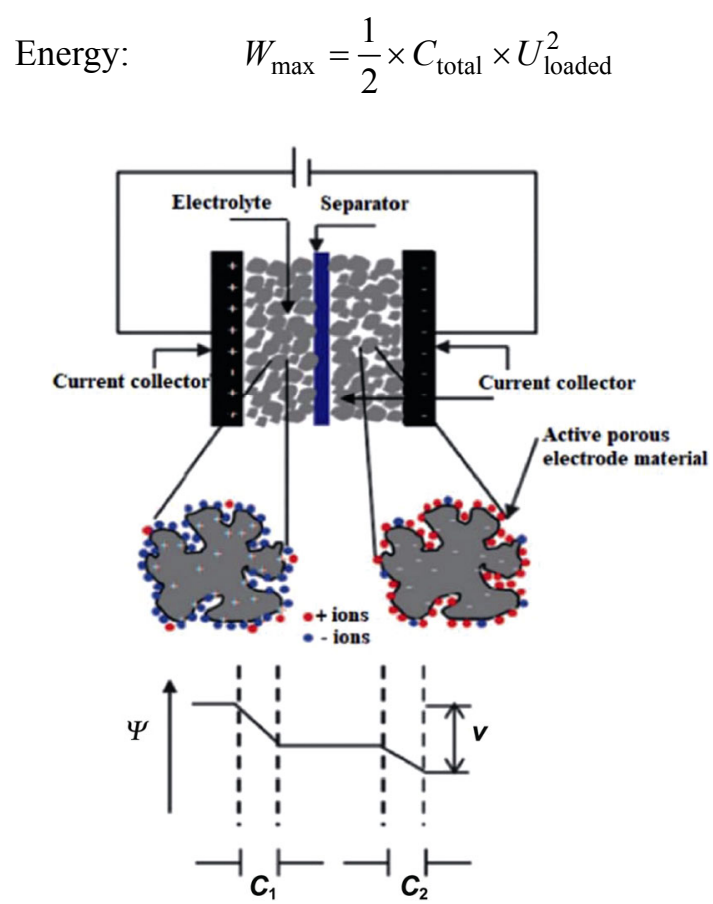

Fig. 26 Schematic of porous electrode materials used in a supercapacitor. Reproduced with permission from Ref. [392], (C) The Royal Society of Chemistry 2009. 
Table 4 Electrochemical performance of PDC electrodes used in supercapacitors

\begin{tabular}{|c|c|c|c|c|c|}
\hline Specimen & Capacitance & Power density & Specific surface area & Capacity retention & Reference \\
\hline $\mathrm{SiOC}$ & - & $156 \mathrm{~kW} / \mathrm{kg}$ & $3.2 \mathrm{~m}^{2} / \mathrm{g}$ & $90 \%(75,000$ cycles $)$ & Halim et al. [118] \\
\hline $\mathrm{SiOC}$ & $78.93 \mathrm{~F} / \mathrm{g}$ & - & - & $86 \%$ (185 cycles) & Abass et al. [514] \\
\hline $\mathrm{SiOC}$ & $16.71 \mathrm{~F} / \mathrm{g}$ & $15 \mathrm{~kW} / \mathrm{kg}$ & - & $92.8 \%$ (5000 cycles $)$ & Pazhamalai et al. [515] \\
\hline $\mathrm{SiOC}$ & $50 \mathrm{~F} / \mathrm{g}$ & - & - & $100 \%$ (2000 cycles $)$ & Mujib et al. [516] \\
\hline $\mathrm{SiOC}$ & $243.3 \mathrm{~F} / \mathrm{g}$ & - & $1376 \mathrm{~m}^{2} / \mathrm{g}$ & $87.3 \%$ ( $5 \mathrm{mV}$ of scan rate) & Kim et al. [517] \\
\hline $\mathrm{SiOC}$ & $27.2 \mathrm{mF} / \mathrm{cm}^{2}$ & $9.3 \mathrm{~kW} / \mathrm{cm}^{2}$ & - & $90 \%(1000$ cycles $)$ & Oroanyanwu et al. [518] \\
\hline $\mathrm{S}(\mathrm{B}) \mathrm{iCN}$ & $269.52 \mathrm{~F} / \mathrm{g}$ & - & - & $\begin{array}{c}124.60 \mathrm{~F} / \mathrm{g}(1000 \text { seconds test } \\
\text { at } 5 \mathrm{~A} / \mathrm{g})\end{array}$ & David et al. [119] \\
\hline $\mathrm{SiCN}$ & $188 \mathrm{mF} / \mathrm{cm}$ & - & - & $\begin{array}{c}52.23 \mathrm{mF} / \mathrm{cm}^{2}(1000 \text { cycles } \\
\left.\text { at } 5 \mathrm{~mA} / \mathrm{cm}^{2}\right)\end{array}$ & Reddy et al. [120] \\
\hline $\mathrm{SiCN}$ & $39 \mathrm{~F} / \mathrm{g}$ & - & - & Almost $100 \%$ (7000 cycles) & Moyano et al. [519] \\
\hline
\end{tabular}

Power: $\quad P_{\max }=\frac{1}{4} \times \frac{U_{\text {loaded }}^{2}}{R_{\mathrm{i}}}$

where $C_{\text {total }}$ is the total capacitance, $U_{\text {loaded }}$ is the voltage applied, and $R_{\mathrm{i}}$ is the internal DC resistance

\subsubsection{SiOC electrodes in supercapacitors}

Halim et al. [118] prepared a low-carbon SiOC composite by pyrolyzing silicone oil under argon in a temperature range from 700 to $1000{ }^{\circ} \mathrm{C}$. A pseudocapacitive behavior of the composite was confirmed by subsequent characterizations and the material demonstrated a power density of $156 \mathrm{~kW} / \mathrm{kg}$ and maintained over $90 \%$ of energy density retention after 75,000 cycles. A SiOC composite with embedded boron nitride nanotubes and reduced graphene oxide was described by Abass et al. [514]. Their material exhibits high specific capacitance of $78.93 \mathrm{~F} / \mathrm{g}$ at $1 \mathrm{~A} / \mathrm{g}$ and a great cycling retention corresponding to $86 \%$ after 185 cycles, revealing that the presence of boron nitride nanotubes in the ceramic matrix affects the free carbon phase. Pazhamalai et al. [515] studied the carbothermal preparation of SiOC lamellae by using two-dimensional siloxene sheets and alginic acid as precursors for supercapacitors. The obtained sample shows a remarkable capacitance of about $16.71 \mathrm{~F} / \mathrm{g}$ and an energy density of $20.89 \mathrm{Wh} / \mathrm{kg}$ as well as a power density of $15 \mathrm{~kW} / \mathrm{kg}$ by a voltage window of $3.0 \mathrm{~V}$ due to its lamella-like SiOC nanostructure. Mujib et al. [516] investigated the electrochemical performance of $\mathrm{SiOC}$ ceramic fiber mats as electrodes for supercapacitors. The materials were fabricated by electrospinning which show a high splendid capacitance of $50 \mathrm{~F} / \mathrm{g}$ with capacity retention around $100 \%$ after 2000 cycles. The obtained result demonstrated that higher pyrolysis temperature and longer pyrolysis time facilitate enhanced electrochemical performance. Kim et al. [517] investigated the effect of surface oxygen functional group on the performance of porous $\mathrm{SiC}$ used as supercapacitor electrode. The porous $\mathrm{SiC}$ flakes with a high surface area of $1376 \mathrm{~m}^{2} / \mathrm{g}$ were obtained by one-step carbonization of Si flakes and exhibit a high specific capacitance of $243.3 \mathrm{~F} / \mathrm{g}$ at a scan rate of $5 \mathrm{mV} / \mathrm{s}$ and $85.6 \%$ of rate performance from 5 to $500 \mathrm{mV} / \mathrm{s}$. Oroanyanwu et al. [518] studied $\mathrm{SiC} / \mathrm{SiOC} / \mathrm{C}$ nanocomposites fabricated via flash photothermal pyrolysis of cross-linked blend of polycarbosilanes and polysiloxanes. The prepared nanocomposites are thermally and oxidatively stable and show a capacitance as high as $27.2 \mathrm{mF} / \mathrm{cm}^{2}$ at a scan rate of $10 \mathrm{mV} / \mathrm{s}$ at room temperature as well as excellent stability up to 1000 cycles.

\subsubsection{SiCN electrodes in supercapacitors}

David et al. [119] synthesized a boron-doped $\mathrm{SiCN} /$ carbon nanotube/graphene composite paper by vacuum filtration and thermal reduction for using as supercapacitor electrode. The composite paper delivers a high specific capacitance of up to $269.52 \mathrm{~F} / \mathrm{g}$ at $5 \mathrm{~A} / \mathrm{g}$ and a low ohmic resistance due to the unique self-supporting structure. Reddy et al. [120] reported high-performance hierarchical SiCN nanowires (diameter: 23-37 nm) used for supercapacitors. These nanowires show a capacitance of $188 \mathrm{mF} / \mathrm{cm}$ at a current density of $5 \mathrm{~mA} / \mathrm{cm}$. Another composite with $\mathrm{SiCN}$ matrix and embedded reduced graphene oxide was studied by Moyano et al. [519]. Their work showed that the obtained composite reaches a capacitance of $39 \mathrm{~F} / \mathrm{g}$ and remains stable after 7000 cycles due to the characteristic hybrid cellular structure. Table 4 shows the electrochemical performance of electrodes prepared from PDCs used in supercapacitors. 


\subsubsection{SiOC as precursors for porous carbon as electrodes in supercapacitors}

SiOC-derived carbons from a polyphenylsilsequioxane precursor prepared by Meier et al. [520] via pyrolysis and chlorination at different temperatures have large surface areas exceeding $2000 \mathrm{~m}^{2} / \mathrm{g}$ and pore volume reaching to $1.4 \mathrm{~cm}^{3} / \mathrm{g}$, thus resulting in a considerable capacitance of $110 \mathrm{~F} / \mathrm{g}$ and stable cyclability. Duan et al. [521] reported on micro/mesoporous SiOC derived carbons fabricated by chlorination and ammonia treatment of polymethyl(phenyl)siloxane. The obtained material shows a high specific capacitance up to 148.7 $\mathrm{F} / \mathrm{g}$ as well as good capacitance retention around $94.3 \%$ after 2000 cycles at $1 \mathrm{~A} / \mathrm{g}$. Electrospinning and electrospraying were applied by Tolosa et al. [522] to form a SiOC-derived porous nano carbon as electrode for supercapacitors. Extremely high specific surface area up to $2394 \mathrm{~m}^{2} / \mathrm{g}$ was achieved, leading to a high specific capacitance of $135 \mathrm{~F} / \mathrm{g}$ at $10 \mathrm{mV} / \mathrm{s}$ and $63 \%$ of the capacitance retention at $100 \mathrm{~A} / \mathrm{g}$. Yang et al. [523] developed an ultra-high-surface-area meso-/microporous carbon by a new in-situ template method realizing an ultra-high specific surface area of $3122 \mathrm{~m}^{2} / \mathrm{g}$ and large pore volume of $2.47 \mathrm{~cm}^{3} / \mathrm{g}$. Figure 27 shows the synthesis of polysiloxane-derived highly mesoporous carbon via $\mathrm{NaOH}$ etching and activation. The fabricated material exhibits a high energy density of $42 \mathrm{Wh} / \mathrm{kg}$ at a power density of $374 \mathrm{~W} / \mathrm{kg}$ as well as an energy density retention of $21 \mathrm{Wh} / \mathrm{kg}$ at a power density of $30 \mathrm{~kW} / \mathrm{kg}$. Swain et al. [524] studied the performance of a SiOC derived nano-porous carbon hybrid with specific surface area of $1798 \mathrm{~m}^{2} / \mathrm{g}$ and the prepared material exhibits a high specific capacitance of $333 \mathrm{~F} / \mathrm{g}$. Sun et al. [525] developed a composite with $\mathrm{MnO}_{2}$ nanoneedles embedded in SiOC-derived hierarchically porous carbon by a facile hydrothermal technology for electrode material for supercapacitors. With a large specific surface area of $1749.3 \mathrm{~m}^{2} / \mathrm{g}$ and uniform distribution of $\mathrm{MnO}_{2}$ nanoneedles, the hierarchically porous carbon used as electrode delivers a high capacitance of $255.8 \mathrm{~F} / \mathrm{g}$ at $1 \mathrm{~A} / \mathrm{g}$ in a three-electrode system. When fabricating a symmetrical coin cell supercapacitor, the material exhibits a distinguished energy density $(12.6 \mathrm{Wh} / \mathrm{kg}$ at a power density of $3997.7 \mathrm{~W} / \mathrm{kg}$ ) and a remarkable capacitance retention of $92.2 \%$ after 2000 cycles [525].

\section{3 Solid electrolyte/separator materials in lithium-ion batteries}

Smith et al. [526] first synthesized a polyacrylonitrile (PAN)/polymer-derived ceramic hybrid nanofiber by combining PAN and ambient temperature-curable organopolysilazane via a single-step electrospinning process. The obtained membrane used as separator for LIBs shows excellent ionic conductivity. The composite separator with $30 \mathrm{wt} \%$ PDC has an increased ionic conductivity of $1.05 \mathrm{mS} / \mathrm{cm}$ compared to $0.29 \mathrm{mS} / \mathrm{cm}$ of pristine PAN separator and shows a stable cycling performance due to the presence of the ceramic phase on the surface of the membrane. The subsequent work of Smith et al. [527] further investigated the impact of the polymer structure and ceramic morphology on the performance of the PAN/polymer-derived ceramic hybrid nanofiber separator in LIBs. They found that the presence of tetraethyl orthosilicate (TEOS) pendant chain attached to the polysilazane (PSZ) backbone improved the interconnected amorphous networks, thus increasing electrolyte uptake and resulting in excellent cycling performance and superior ionic conductivity.

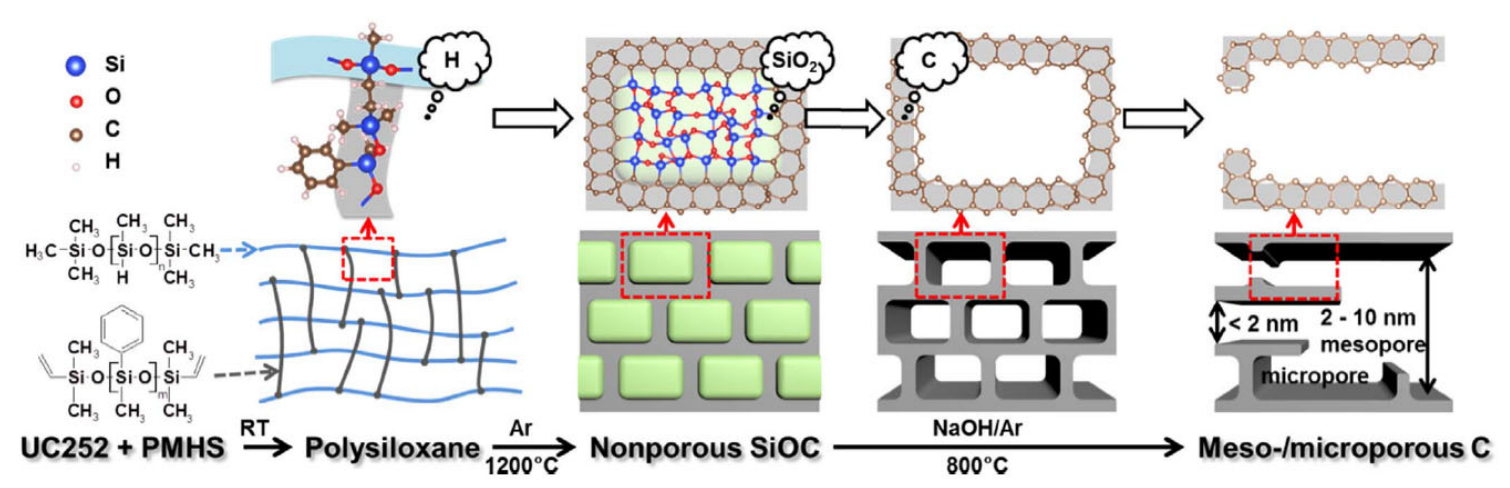

Fig. 27 Synthesis of polysiloxane-derived highly mesoporous carbon via $\mathrm{NaOH}$ etching and activation. Reproduced with permission from Ref. [523], C) Elsevier Ltd. 2017. 


\section{4 Gas diffusion layer and catalyst component in zinc-air batteries}

Cycle life of rechargeable zinc-air batteries is affected by the oxygen diffusion rate. Thus, ideal architecture of gas diffusion layer determines its electrochemical performance. However, complex manufacturing process and low oxygen gas permeability of traditional commercial gas diffusion layer hamper the performance of zinc-air batteries. Property-tailorable PDC materials offer new solutions for enhanced architecture of gas diffusion layer for zinc-air batteries. Moni et al. [528] developed a porous conductive ceramic membrane derived from poly(methyl silsesquioxane) with a bilayered structure of $390 \mu \mathrm{m}$ as well as an open porosity of $55 \%$ by a freeze tape casting technique. The obtained material was used as gas diffusion layer for zinc-air batteries. After introducing graphite and MWCNT as filler materials, a remarkable electrical conductivity of $5.59 \times 10^{-3} \mathrm{~S} / \mathrm{cm}$ was achieved. After coating with a commercial $\mathrm{Pt}-\mathrm{Ru} / \mathrm{C}$ catalyst, the as-prepared material exhibits excellent electrochemical performance due to the symmetric sponge-like structure facilitating the oxygen exchange rate and provides a short path for the kinetics.

\section{Conclusions and perspectives}

PDCs as a class of advanced ceramics with promising structural and functional properties for energy conversion and storage have received increasing attention in recent years. With respect to energy conversion systems, polymer-derived ceramic fibers are already on the market for a couple of decades. Taking advantage of the preceramic polymers, PDC approach offers solution to most of the problems associated with other processing methods for the fabrication of CMCs and T/EBCs. Moreover, several polymer-derived sensors (e.g., piezoresistive pressure sensors, temperature sensors, heat flux sensors, and hot-wire anemometers) used for in situ and real-time monitoring of the temperature/heat flux and dynamic pressure within the hot sections of gas turbine engines have been proposed and assessed. The short response time, wireless detection, excellent repeatability, stability, sensitivity, and accuracy ensure their future application in gas turbine engines. Regarding energy storage, several different PDC systems, such as SiCN,
$\mathrm{SiCO}$, and $\mathrm{SiCNO}$, as well as the composite materials consisting of a polymer-derived ceramic blended with carbon/silicon/tin have been thoroughly investigated. The PDC-based anode materials are proven to possess many desirable properties superior to or unobtainable with other materials. For instance, in addition to the tunable chemical and physical properties, the PDC-based anodes are chemically inert with respect to other battery components, able to minimize the agglomeration of lithium/sodium ions, lightweight but exhibiting excellent mechanical properties, possessing in situ formed free carbon network for electron conduction and lithium/sodium ion storage as well as showing superior exfoliation resistance. These remarkable features open a variety of new avenues regarding fundamental and applied research in the exciting fields of both PDCs and energy conversion and storage.

In the future, however, further studies in this field are still needed in order to facilitate these materials flowing out of the laboratory and into the markets. When employing the PDC approach to prepare CMCs and $\mathrm{T} / \mathrm{EBCs}$, the decomposition of preceramic polymers inevitably leads to shrinkage of the ceramic matrix and coatings during polymer-to-ceramic transformation, leading to formation of pores, voids, and micro-cracks. These defects are strongly detrimental to the thermomechanical properties and oxidation/corrosion resistance of CMCs and T/EBCs. In order to overcome this problem, further research has to be conducted from the following aspects: increasing the ceramic yield via molecular design or pyrolysis process optimization, taking multiple PIP process, introducing inert or active fillers to compensate the shrinkage as well as in conjunction with other fabricating methods, such as chemical vapor infiltration (CVI) and reactive melt infiltration (RMI). For the ceramic fibers, only a handful of ceramic fibers for use in CMCs have reached the market so far, and all of them are SiC-based fibers. Unfortunately, due to phase separation, grain growth, and carbothermal reactions, SiC-based ceramic fibers will lose their mechanical strength at high temperatures. Therefore, novel ceramic fibers with rather low oxygen content or with resistance to crystallization (e.g., $\mathrm{SiBCN}$ and novel $\mathrm{SiHfBCN}$ fibers) are highly demanded. In addition, for application in gas turbine engines, hydrothermal corrosion resistance of the Si-based fibers, CMCs, and T/EBCs at high temperatures is challenging. Thus, novel preceramic precursors should be synthesized in a bottom-up way 
or via chemical modification of commercially available precursors in order to develop new Si-based PDCs with strongly enhanced hydrothermal corrosion resistance. Furthermore, the price and technological challenge to produce polymer-derived ceramic fibers should be remarkably reduced via further innovation in order to be affordable to more commercial customers.

It is wise to produce high-temperature sensors for gas turbine engines using PDCs because of their unique microstructures, tailorable electric properties, excellent thermal stability, high chemical durability, and superior oxidation resistance. However, they are still under development and produced on a laboratory scale. Within this context, precisely controlling the electric properties and shape of proposed PDC sensors, designing and fabricating wireless sensor technology, as well as testing and calibrating methods necessitate future fundamental and applied research.

For energy storage applications, despite that superior electrochemical performance such as energy density and cycling stability can be achieved by PDC-based electrodes, some challenging issues should be solved for large-scale commercial application. For instance, compared with commercial graphite anode, the coulombic efficiency of PDC anodes used for lithium/sodium batteries is lower, which leads to lower economic benefits. In order to solve this problem, the relationship between the capacity and the free carbon content should be further clarified, with a focus on diminishing first cycle irreversible capacity. In addition, the relatively high energy-cost of material processing and voltage hysteresis also hamper the widespread use of PDCs. Controlling particle size of PDC materials and introducing free carbon and nano-porous architecture could enhance structure stability and electrochemical performance. Research of in-depth structure-propertyprocessing of PDCs for $\mathrm{Li}$ and $\mathrm{Na}$ storage, in-situ microscopy and spectroscopy characterization of the electrode/electrolyte interface of PDC electrodes should be the main research direction in the future [403]. Furthermore, the application of the PDCs as a stabilizing matrix for the anodes based on the volume-expanding elements like silicon or tin can be further developed as well.

\section{Acknowledgements}

Zhaoju Yu thanks the National Natural Science Foundation of China (Nos. 51872246 and 52061135102) for financial support. Qingbo Wen thanks the National Natural Science Foundation of China (No. 52102085) and the State Key Laboratory of Powder Metallurgy, Central South University, Changsha, China (No. 621022117). Fangmu $\mathrm{Qu}$ acknowledges the financial support by the China Scholarship Council (CSC, No. 201904910776). This review also originated from the Research Training Group at TU Darmstadt and Karlsruhe Institute of Technology (KIT) entitled "Materials Composites from Composite Materials" funded by the Deutsche Forschungsgemeinschaft (DFG, No. GRK 2561). Magdalena Graczyk-Zajac acknowledges DFG support in the frame of the project GR 4440/4-1.

\section{References}

[1] Guillon O. Advanced Ceramics for Energy Conversion and Storage. Amsterdam: Elsevier, 2020.

[2] Rao A. Sustainable energy conversion for electricity and coproducts: Principles, technologies, and equipment. Hoboken, NJ, USA: John Wiley \& Sons, Inc., 2015.

[3] Ainger F, Herbert J. The preparation of phosphorusnitrogen compounds as non-porous solids. Spec Ceram, 1960: 168-182

[4] Chantrell P, Popper P. Inorganic polymers and ceramics. Spec Ceram 1965: 67.

[5] Yajima S, Hayashi J, Omori M. Continuous silicon carbide fiber of high tensile strength. Chem Lett 1975, 4: 931-934.

[6] Yajima S, Hasegawa Y, Okamura K, et al. Development of high tensile strength silicon carbide fibre using an organosilicon polymer precursor. Nature 1978, 273: 525527.

[7] Blum YD, Platz RM, Crawford EJ. Glass strengthening by polymer-derived ceramic coatings. J Am Ceram Soc 1990, 73: $170-172$.

[8] Torrey JD, Bordia RK. Processing of polymer-derived ceramic composite coatings on steel. J Am Ceram Soc 2007, 91: 41-45.

[9] Günthner M, Schütz A, Glatzel U, et al. High performance environmental barrier coatings, Part I: Passive filler loaded SiCN system for steel. J Eur Ceram Soc 2011, 31: 3003-3010.

[10] Park CH, Joo YJ, Chung JK, et al. Morphology control of a silicon nitride thick film derived from polysilazane precursor using UV curing and IR heat treatment. Adv Appl Ceram 2017, 116: 376-382.

[11] Colombo P, Gambaryan-Roisman T, Scheffler M, et al. Conductive ceramic foams from preceramic polymers. $J$ Am Ceram Soc 2001, 84: 2265-2268.

[12] Wen Q, Xu Y, Xu B, et al. Single-source-precursor synthesis of dense $\mathrm{SiC} / \mathrm{HfC}_{x} \mathrm{~N}_{1-x}$-based ultrahigh- 
temperature ceramic nanocomposites. Nanoscale 2014, 6: 13678-13689.

[13] Wen QB, Yu ZJ, Liu XM, et al. Mechanical properties and electromagnetic shielding performance of single-sourceprecursor synthesized dense monolithic $\mathrm{SiC} / \mathrm{HfC}_{x} \mathrm{~N}_{1-x} / \mathrm{C}$ ceramic nanocomposites. J Mater Chem C 2019, 7: 10683-10693.

[14] Wen QB, Yu ZJ, Riedel R, et al. Significant improvement of high-temperature oxidation resistance of $\mathrm{HfC} / \mathrm{SiC}$ ceramic nanocomposites with the incorporation of a small amount of boron. J Eur Ceram Soc 2020, 40: 3499-3508.

[15] Wen QB, Feng Y, Yu ZJ, et al. Microwave absorption of $\mathrm{SiC} / \mathrm{HfC}_{x} \mathrm{~N}_{1-x} / \mathrm{C}$ ceramic nanocomposites with $\mathrm{HfC}_{x} \mathrm{~N}_{1-x}$ carbon core-shell particles. J Am Ceram Soc 2016, 99: 2655-2663.

[16] Klatt E, Frass A, Frieß M, et al. Mechanical and microstructural characterisation of $\mathrm{SiC}-$ and $\mathrm{SiBNC}-$ fibre reinforced CMCs manufactured via PIP method before and after exposure to air. J Eur Ceram Soc 2012, 32: 3861-3874.

[17] Poerschke DL, Braithwaite A, Park D, et al. Crystallization behavior of polymer-derived $\mathrm{Si}-\mathrm{O}-\mathrm{C}$ for ceramic matrix composite processing. Acta Mater 2018, 147: 329-341.

[18] Chawla N, Tur YK, Holmes JW, et al. High-frequency fatigue behavior of woven-fiber-fabric-reinforced polymer-derived ceramic-matrix composites. J Am Ceram Soc 2005, 81: 1221-1230.

[19] Jones R, Szweda A, Petrak D. Polymer derived ceramic matrix composites. Compos A: Appl Sci Manuf 1999, 30: 569-575.

[20] Eckel ZC, Zhou C, Martin JH, et al. Additive manufacturing of polymer-derived ceramics. Science 2016, 351: 58-62.

[21] Colombo P, Schmidt J, Franchin G, et al. Additive manufacturing techniques for fabricating complex ceramic components from preceramic polymers. $\mathrm{Am}$ Ceram Soc Bull 2017, 96: 16-23.

[22] Verbeek W. Production of shaped articles of homogeneous mixtures of silicon carbide and nitride. U.S. patent 3853 567, 1974.

[23] Verbeek W, Winter G. Formkoerper aus siliciumcarbid und verfahren zu ihrer herstellung. DE Patent 2236078, 1974.

[24] Winter G, Verbeek W, Mansmann M. Production of shaped articles of silicon carbide and silicon nitride. Google Patents, 1975. Available at https://patents.google. com/patent/US3892583A/en.

[25] Yajima S, Hayashi J, Omori M, et al. Development of a silicon carbide fibre with high tensile strength. Nature 1976, 261: 683-685.

[26] Yajima S, Okamura K, Hayashi J, et al. Synthesis of continuous $\mathrm{SiC}$ fibers with high tensile strength. $J \mathrm{Am}$ Ceram Soc 1976, 59: 324-327.

[27] Yajima S, Omori M, Hayashi J, et al. Simple synthesis of the continuous $\mathrm{SiC}$ fiber with high tensile strength. Chem Lett 1976, 5: 551-554.
[28] Takamizawa M, Kobayashi T, Hayashida A. Organoborosilicon polymer and a method for the preparation thereof. U.S. patent 4550 151, 1985.

[29] Takamizawa M, Kobayashi T, Hayashida A, et al. Method for the preparation of an inorganic fiber containing silicon, carbon, boron and nitrogen. Google Patents, 1986. Available at https://patents.google.com/patent/US4604367A/en.

[30] Greil P. Polymer derived engineering ceramics. Adv Eng Mater 2000, 2: 339-348.

[31] Riedel R, Kienzle A, Dressler W, et al. A silicoboron carbonitride ceramic stable to $2,000{ }^{\circ} \mathrm{C}$. Nature $1996, \mathbf{3 8 2}$ : 796-798.

[32] Riedel R, Passing G, Schönfelder H, et al. Synthesis of dense silicon-based ceramics at low temperatures. Nature 1992, 355: 714-717.

[33] Riedel R, Kleebe HJ, Schönfelder H, et al. A covalent micro/nano-composite resistant to high-temperature oxidation. Nature 1995, 374: 526-528.

[34] Funayama O, Nakahara H, Okoda M, et al. Conversion mechanism of polyborosilazane into silicon nitride-based ceramics. J Mater Sci 1995, 30: 410-416.

[35] Colombo P, Mera G, Riedel R, et al. Polymer-derived ceramics: 40 years of research and innovation in advanced ceramics. J Am Ceram Soc 2010, 93: 1805-1837.

[36] Wen QB, Yu ZJ, Riedel R. The fate and role of in situ formed carbon in polymer-derived ceramics. Prog Mater Sci 2020, 109: 100623.

[37] Fu SY, Zhu M, Zhu YF. Organosilicon polymer-derived ceramics: An overview. J Adv Ceram 2019, 8: 457-478.

[38] Ionescu E. Polymer-derived ceramics. In: Ceramics Science and Technology. Weinheim, Germany: Wiley-VCH Verlag GmbH \& Co. KGaA, 2014: 457-500.

[39] Su Q, King S, Li LY, et al. Microstructure-mechanical properties correlation in irradiated amorphous SiOC. Scripta Mater 2018, 146: 316-320.

[40] Stabler C, Roth F, Narisawa M, et al. High-temperature creep behavior of a SiOC glass ceramic free of segregated carbon. J Eur Ceram Soc 2016, 36: 3747-3753.

[41] Mutin PH. Control of the composition and structure of silicon oxycarbide and oxynitride glasses derived from polysiloxane precursors. J Sol Gel Sci Technol 1999, 14: 27-38.

[42] Laffon C, Flank AM, Lagarde P, et al. Study of Nicalon-based ceramic fibres and powders by EXAFS spectrometry, X-ray diffractometry and some additional methods. J Mater Sci 1989, 24: 1503-1512.

[43] Takeda M, Saeki A, Sakamoto JI, et al. Effect of hydrogen atmosphere on pyrolysis of cured polycarbosilane fibers. $J$ Am Ceram Soc 2004, 83: 1063-1069.

[44] Mera G, Riedel R, Poli F, et al. Carbon-rich SiCN ceramics derived from phenyl-containing poly(silylcarbodiimides). J Eur Ceram Soc 2009, 29: 2873-2883.

[45] Yu ZJ, Yang YJ, Mao KW, et al. Single-source-precursor synthesis and phase evolution of $\mathrm{SiC}-\mathrm{TaC}-\mathrm{C}$ ceramic nanocomposites containing core-shell structured TaC@C nanoparticles. $J$ Adv Ceram 2020, 9: 320-328. 
[46] Yu ZJ, Lv X, Lai SY, et al. $\mathrm{ZrC}-\mathrm{ZrB}_{2}-\mathrm{SiC}$ ceramic nanocomposites derived from a novel single-source precursor with high ceramic yield. J Adv Ceram 2019, 8: 112-120.

[47] Widgeon S, Mera G, Gao Y, et al. Effect of precursor on speciation and nanostructure of $\mathrm{SiBCN}$ polymer-derived ceramics. J Am Ceram Soc 2013, 96: 1651-1659.

[48] Sorarù GD, Pederiva L, Latournerie J, et al. Pyrolysis kinetics for the conversion of a polymer into an amorphous silicon oxycarbide ceramic. J Am Ceram Soc 2002, 85: 2181-2187.

[49] Peña-Alonso R, Mariotto G, Gervais C, et al. New insights on the high-temperature nanostructure evolution of $\mathrm{SiOC}$ and B-doped SiBOC polymer-derived glasses. Chem Mater 2007, 19: 5694-5702.

[50] Naviroj M, Miller SM, Colombo P, et al. Directionally aligned macroporous $\mathrm{SiOC}$ via freeze casting of preceramic polymers. J Eur Ceram Soc 2015, 35: 2225-2232.

[51] Vakifahmetoglu C, Colombo P. A direct method for the fabrication of macro-porous SiOC ceramics from preceramic polymers. Adv Eng Mater 2008, 10: 256-259.

[52] Dibandjo P, Graczyk-Zajac M, Riedel R, et al. Lithium insertion into dense and porous carbon-rich polymerderived SiOC ceramics. J Eur Ceram Soc 2012, 32: 2495-2503.

[53] Riedel R, Greiner A, Miehe G, et al. The first crystalline solids in the ternary $\mathrm{Si}-\mathrm{C}-\mathrm{N}$ system. Angew Chem Int Ed Engl 1997, 36: 603-606.

[54] Mera G, Navrotsky A, Sen S, et al. Polymer-derived SiCN and $\mathrm{SiOC}$ ceramics-structure and energetics at the nanoscale. J Mater Chem A 2013, 1: 3826.

[55] Pham T, Kim DP, Lim TW, et al. Three-dimensional SiCN ceramic microstructures via nano-stereolithography of inorganic polymer photoresists. Adv Funct Mater 2006, 16: $1235-1241$

[56] Kolb R, Fasel C, Liebau-Kunzmann V, et al. SiCN/Cceramic composite as anode material for lithium ion batteries. J Eur Ceram Soc 2006, 26: 3903-3908.

[57] Nghiem Q, Kim D, Kim DP. Synthesis of inorganicorganic diblock copolymers as a precursor of ordered mesoporous SiCN ceramic. Adv Mater 2007, 19: 2351-2354.

[58] Yu ZJ, Li F, Zhu QK. Single-source-precursor synthesis and phase evolution of $\mathrm{NbC}-\mathrm{SiC}-\mathrm{C}$ ceramic nanocomposites with core-shell structured NbC@C and SiC@C nanoparticles. Adv Powder Mater 2021, https:// doi.org/10.1016/j.apmate.2021.09.009.

[59] Chelliah NM, Singh H, Raj R, et al. Processing, microstructural evolution and strength properties of in situ magnesium matrix composites containing nano-sized polymer derived SiCNO particles. Mater Sci Eng: A 2017, 685: 429-438.

[60] Terauds K, Sanchez-Jimenez PE, Raj R, et al. Giant piezoresistivity of polymer-derived ceramics at high temperatures. J Eur Ceram Soc 2010, 30: 2203-2207.
[61] Chelliah NM, Padaikathan P, Surappa MK. Deformation mechanisms and texture evolution of in situ magnesium matrix composites containing polymer derived SiCNO dispersoids during hot compression. Mater Sci Eng: A 2018, 720: 49-59.

[62] Duan RG, Mukherjee AK. Synthesis of SiCNO nanowires through heat-treatment of polymer-functionalized singlewalled carbon nanotubes. Adv Mater 2004, 16: 11061109 .

[63] Schiavon MA, Armelin NA, Yoshida IVP. Novel poly(borosiloxane) precursors to amorphous $\mathrm{SiBCO}$ ceramics. Mater Chem Phys 2008, 112: 1047-1054.

[64] Liebau V, Hauser R, Riedel R. Amorphous SiBCO ceramics derived from novel polymeric precursors. Comptes Rendus Chimie 2004, 7: 463-469.

[65] Liao NB, Xue W, Zhou HM, et al. Molecular dynamics investigation of structure and high-temperature mechanical properties of SiBCO ceramics. J Alloys Compd 2014, 610: 45-49.

[66] Cao YJ, Gao Y, Zhao R, et al. Coupling effect of temperature and stress on the electronic behavior of amorphous SiAlCO. J Am Ceram Soc 2016, 99: 1881-1884.

[67] Cao YJ, An LN. Anomalous piezo-dielectricity of a polymer-derived amorphous silicoaluminum oxycarbide (SiAlCO). Ceram Int 2018, 44: 1467-1470.

[68] Cao YJ, Yang XP, Zhao R, et al. Giant piezoresistivity in polymer-derived amorphous SiAlCO ceramics. J Mater Sci 2016, 51: 5646-5650.

[69] Cao YJ, Yang XP, An LN. Electric conductivity and microstructure evolution of polymer-derived SiAlCO ceramics. Ceram Int 2016, 42: 4033-4038.

[70] Wang YG, Fan Y, Zhang LG, et al. Polymer-derived SiAlCN ceramics resist oxidation at $1400{ }^{\circ} \mathrm{C}$. Scripta Mater 2006, 55: 295-297.

[71] Wang YG, Fei WF, An LN. Oxidation/corrosion of polymer-derived SiAlCN ceramics in water vapor. $J \mathrm{Am}$ Ceram Soc 2006, 89: 1079-1082.

[72] Dhamne A, Xu WX, Fookes BG, et al. Polymer-ceramic conversion of liquid polyaluminasilazanes for SiAlCN ceramics. J Am Ceram Soc 2005, 88: 2415-2419.

[73] Wang YG, An LN, Fan Y, et al. Oxidation of polymer-derived SiAlCN ceramics. J Am Ceram Soc 2005, 88: $3075-3080$.

[74] Bernard S, Weinmann M, Cornu D, et al. Preparation of high-temperature stable $\mathrm{SiBCN}$ fibers from tailored single source polyborosilazanes. J Eur Ceram Soc 2005, 25: 251-256.

[75] Gao Y, Mera G, Nguyen H, et al. Processing route dramatically influencing the nanostructure of carbon-rich $\mathrm{SiCN}$ and SiBCN polymer-derived ceramics. Part I: Low temperature thermal transformation. J Eur Ceram Soc 2012, 32: 1857-1866.

[76] Zhang PF, Jia DC, Yang ZH, et al. Progress of a novel non-oxide $\mathrm{Si}-\mathrm{B}-\mathrm{C}-\mathrm{N}$ ceramic and its matrix composites. $J$ Adv Ceram 2012, 1: 157-178. 
[77] Kousaalya AB, Kumar R, Packirisamy S. Characterization of free carbon in the as-thermolyzed $\mathrm{Si}-\mathrm{B}-\mathrm{C}-\mathrm{N}$ ceramic from a polyorganoborosilazane precursor. $J$ Adv Ceram 2013, 2: 325-332.

[78] Wen QB, Yu ZJ, Xu YP, et al. $\mathrm{SiC} / \mathrm{Hf}_{y} \mathrm{Ta}_{1-y} \mathrm{C}_{x} \mathrm{~N}_{1-x} / \mathrm{C}$ ceramic nanocomposites with $\mathrm{Hf}_{y} \mathrm{Ta}_{1-y} \mathrm{C}_{x} \mathrm{~N}_{1-x}-$ carbon core-shell nanostructure and the influence of the carbon-shell thickness on electrical properties. $J$ Mater Chem C 2018, 6: 855-864.

[79] Terauds K, Raj R. Limits to the stability of the amorphous nature of polymer-derived HfSiCNO compounds. J Am Ceram Soc 2013, 96: 2117-2123.

[80] Ionescu E, Papendorf B, Kleebe HJ, et al. Phase separation of a hafnium alkoxide-modified polysilazane upon polymer-to-ceramic transformation-A case study. $J$ Eur Ceram Soc 2012, 32: 1873-1881.

[81] Yuan J, Hapis S, Breitzke H, et al. Single-sourceprecursor synthesis of hafnium-containing ultrahightemperature ceramic nanocomposites (UHTC-NCs). Inorg Chem 2014, 53: 10443-10455.

[82] Yuan J, Luan XG, Riedel R, et al. Preparation and hydrothermal corrosion behavior of $\mathrm{C}_{\mathrm{f}} / \mathrm{SiCN}$ and $\mathrm{C}_{\mathrm{f}} / \mathrm{SiHfBCN}$ ceramic matrix composites. J Eur Ceram Soc 2015, 35: 3329-3337.

[83] Luan XG, Yuan J, Wang JQ, et al. Laser ablation behavior of $\mathrm{C}_{\mathrm{f}} / \mathrm{SiHfBCN}$ ceramic matrix composites. J Eur Ceram Soc 2016, 36: 3761-3768.

[84] Yuan J, Galetz M, Luan XG, et al. High-temperature oxidation behavior of polymer-derived SiHfBCN ceramic nanocomposites. J Eur Ceram Soc 2016, 36: 3021-3028.

[85] Bill J, Aldinger F. Precursor-derived covalent ceramics. Adv Mater 1995, 7: 775-787.

[86] Flores O, Bordia RK, Nestler D, et al. Ceramic fibers based on $\mathrm{SiC}$ and $\mathrm{SiCN}$ systems: Current research, development, and commercial status. Adv Eng Mater 2014, 16: 621-636.

[87] Guo AR, Roso M, Modesti M, et al. Preceramic polymerderived SiOC fibers by electrospinning. J Appl Polym Sci 2014, 131: 39836.

[88] Barroso G, Li Q, Bordia RK, et al. Polymeric and ceramic silicon-based coatings-A review. J Mater Chem A 2019, 7: 1936-1963.

[89] Hernández-Rodríguez P, López-Honorato E. Polymer derived $\mathrm{SiC}$ environmental barrier coatings with superwetting properties. Ceram Int 2017, 43: 1128911295 .

[90] Günthner M, Wang KS, Bordia RK, et al. Conversion behaviour and resulting mechanical properties of polysilazane-based coatings. J Eur Ceram Soc 2012, 32: 1883-1892.

[91] Liu J, Zhang LT, Liu QM, et al. Polymer-derived SiOC-barium-strontium aluminosilicate coatings as an environmental barrier for $\mathrm{C} / \mathrm{SiC}$ composites. $\mathrm{J}$ Am Ceram Soc 2010, 93: 4148-4152.

[92] Yoon BH, Lee EJ, Kim HE, et al. Highly aligned porous silicon carbide ceramics by freezing polycarbosilane/ camphene solution. J Am Ceram Soc 2007, 90: 17531759.

[93] Yoon BH, Park CS, Kim HE, et al. In situ synthesis of porous silicon carbide $(\mathrm{SiC})$ ceramics decorated with $\mathrm{SiC}$ nanowires. J Am Ceram Soc 2007, 90: 3759-3766.

[94] Zhang HX, D'Angelo Nunes P, Wilhelm M, et al. Hierarchically ordered micro/meso/macroporous polymerderived ceramic monoliths fabricated by freeze-casting. $J$ Eur Ceram Soc 2016, 36: 51-58.

[95] Hanemann T, Ade M, Börner M, et al. Microstructuring of preceramic polymers. Adv Eng Mater 2002, 4: 869-873.

[96] Lee HJ, Yoon TH, Kim DP. Fabrication of microfluidic channels derived from a UV/thermally cured preceramic polymer via a soft lithographic technique. Microelectron Eng 2007, 84: 2892-2895.

[97] Martínez-Crespiera S, Ionescu E, Schlosser M, et al. Fabrication of silicon oxycarbide-based microcomponents via photolithographic and soft lithography approaches. Sens Actuat A: Phys 2011, 169: 242-249.

[98] Yang H, Deschatelets P, Brittain ST, et al. Fabrication of high performance ceramic microstructures from a polymeric precursor using soft lithography. Adv Mater 2001, 13: 54-58.

[99] Kaur S, Riedel R, Ionescu E. Pressureless fabrication of dense monolithic $\mathrm{SiC}$ ceramics from a polycarbosilane. $J$ Eur Ceram Soc 2014, 34: 3571-3578.

[100] Liu XM, Yu ZJ, Ishikawa R, et al. Single-sourceprecursor synthesis and electromagnetic properties of novel RGO-SiCN ceramic nanocomposites. J Mater Chem C 2017, 5: 7950-7960.

[101] Toma L, Kleebe HJ, Müller MM, et al. Correlation between intrinsic microstructure and piezoresistivity in a SiOC polymer-derived ceramic. J Am Ceram Soc 2012, 95: 1056-1061.

[102] Bechelany MC, Proust V, Gervais C, et al. In situ controlled growth of titanium nitride in amorphous silicon nitride: A general route toward bulk nitride nanocomposites with very high hardness. Adv Mater 2014, 26: $6548-6553$.

[103] Wang KS, Günthner M, Motz G, et al. High performance environmental barrier coatings, Part II: Active filler loaded SiOC system for superalloys. J Eur Ceram Soc 2011, 31: 3011-3020.

[104] Nguyen MD, Bang JW, Bin AS, et al. Novel polymer-derived ceramic environmental barrier coating system for carbon steel in oxidizing environments. J Eur Ceram Soc 2017, 37: 2001-2010.

[105] Wang KS, Unger J, Torrey JD, et al. Corrosion resistant polymer derived ceramic composite environmental barrier coatings. J Eur Ceram Soc 2014, 34: 3597-3606.

[106] King D, Apostolov Z, Key T, et al. Novel processing approach to polymer-derived ceramic matrix composites. Int J Appl Ceram Technol 2018, 15: 399-408.

[107] Zhao H, Chen LX, Luan XG, et al. Synthesis, pyrolysis of 
a novel liquid SiBCN ceramic precursor and its application in ceramic matrix composites. J Eur Ceram Soc 2017, 37: 1321-1329.

[108] Lewinsohn CA, Colombo P, Reimanis I, et al. Stresses occurring during joining of ceramics using preceramic polymers. J Am Ceram Soc 2001, 84: 2240-2244.

[109] Colombo P, Sglavo V, Pippel E, et al. Joining of reaction-bonded silicon carbide using a preceramic polymer. J Mater Sci 1998, 33: 2405-2412.

[110] Vrankovic D, Graczyk-Zajac M, Kalcher C, et al. Highly porous silicon embedded in a ceramic matrix: A stable high-capacity electrode for Li-ion batteries. ACS Nano 2017, 11: 11409-11416.

[111] Reinold LM, Yamada Y, Graczyk-Zajac M, et al. The influence of the pyrolysis temperature on the electrochemical behavior of carbon-rich $\mathrm{SiCN}$ polymerderived ceramics as anode materials in lithium-ion batteries. J Power Sources 2015, 282: 409-415.

[112] Kaspar J, Terzioglu C, Ionescu E, et al. Stable SiOC/Sn nanocomposite anodes for lithium-ion batteries with outstanding cycling stability. Adv Funct Mater 2014, 24: 4097-4104.

[113] Fukui H, Ohsuka H, Hino $\mathrm{T}$, et al. Influence of polystyrene/phenyl substituents in precursors on microstructures of $\mathrm{Si}-\mathrm{O}-\mathrm{C}$ composite anodes for lithium-ion batteries. J Power Sources 2011, 196: 371-378.

[114] Dahn JR, Wilson AM, Xing W, et al. Electrodes for lithium ion batteries using polysilazanes ceramic with lithium. Google Patents, 1997. Available at https://patents. google.com/patent/US5631106A/en.

[115] Seifollahi Bazarjani M, Hojamberdiev M, Morita K, et al. Visible light photocatalysis with $\mathrm{c}-\mathrm{WO}_{3-x} / \mathrm{WO}_{3} \times \mathrm{H}_{2} \mathrm{O}$ nanoheterostructures in situ formed in mesoporous polycarbosilane-siloxane polymer. J Am Chem Soc 2013, 135: 4467-4475.

[116] Kaspar J, Storch M, Schitco C, et al. SiOC(N)/hard carbon composite anodes for Na-ion batteries: Influence of morphology on the electrochemical properties. $J$ Electrochem Soc 2015, 163: A156-A162.

[117] Soares DM, Singh G. SiOC functionalization of $\mathrm{MoS}_{2}$ as a means to improve stability as sodium-ion battery anode. Nanotechnology 2020, 31: 145403.

[118] Halim M, Liu G, Ardhi REA, et al. Pseudocapacitive characteristics of low-carbon silicon oxycarbide for lithium-ion capacitors. ACS Appl Mater Interfaces 2017, 9: 20566-20576.

[119] David L, Shareef KM, Abass MA, et al. Threedimensional polymer-derived ceramic/graphene paper as a Li-ion battery and supercapacitor electrode. RSC $A d v$ 2016, 6: 53894-53902.

[120] Reddy IN, Sreedhar A, Reddy CV, et al. High performance hierarchical SiCN nanowires for efficient photocatalytic-photoelectrocatalytic and supercapacitor applications. Appl Catal B: Environ 2018, 237: 876-887.
[121] Liu XM, Yu ZJ, Ishikawa R, et al. Single-sourceprecursor derived $\mathrm{RGO} / \mathrm{CNTs}-\mathrm{SiCN}$ ceramic nanocomposite with ultra-high electromagnetic shielding effectiveness. Acta Mater 2017, 130: 83-93.

[122] Song Y, He LH, Zhang XF, et al. Highly efficient electromagnetic wave absorbing metal-free and carbonrich ceramics derived from hyperbranched polycarbosilazanes. J Phys Chem C 2017, 121: 2477424785.

[123] Zhao WY, Shao G, Jiang MJ, et al. Ultralight polymerderived ceramic aerogels with wide bandwidth and effective electromagnetic absorption properties. J Eur Ceram Soc 2017, 37: 3973-3980.

[124] Yin XW, Kong L, Zhang LT, et al. Electromagnetic properties of $\mathrm{Si}-\mathrm{C}-\mathrm{N}$ based ceramics and composites. Int Mater Rev 2014, 59: 326-355.

[125] Yu ZJ, Lv X, Mao KW, et al. Role of in situ formed free carbon on electromagnetic absorption properties of polymer-derived SiC ceramics. J Adv Ceram 2020, 9: 617-628.

[126] Liew LA, Liu YP, Luo RL, et al. Fabrication of SiCN MEMS by photopolymerization of pre-ceramic polymer. Sens Actuat A: Phys 2002, 95: 120-134.

[127] Schulz M. Polymer derived ceramics in MEMS/NEMSa review on production processes and application. $A d v$ Appl Ceram 2009, 108: 454-460.

[128] Liew LA, Saravanan RA, Bright VM, et al. Processing and characterization of silicon carbon-nitride ceramics: Application of electrical properties towards MEMS thermal actuators. Sens Actuat A: Phys 2003, 103: 171-181.

[129] Liu YP, Liew LA, Luo RL, et al. Application of microforging to SiCN MEMS fabrication. Sens Actuat A: Phys 2002, 95: 143-151.

[130] Liew LA, Bright VM, Raj R. A novel micro glow plug fabricated from polymer-derived ceramics: In situ measurement of high-temperature properties and application to ultrahigh-temperature ignition. Sens Actuat A: Phys 2003, 104: 246-262.

[131] Harshe R, Balan C, Riedel R. Amorphous Si(Al)OC ceramic from polysiloxanes: Bulk ceramic processing, crystallization behavior and applications. J Eur Ceram Soc 2004, 24: 3471-3482.

[132] Ferraioli L, Ahn D, Saha A, et al. Intensely photoluminescent pseudo-amorphous SiliconOxyCarboNitride polymer-ceramic hybrids. J Am Ceram Soc 2008, 91: 2422-2424.

[133] Shimokawa Y, Fujiwara A, Ionescu E, et al. Synthesis and characterization of luminescent properties of ceramics derived from polysilylcarbodiimides. J Ceram Soc Japan 2014, 122: 895-901.

[134] Su R, Huang ZF, Chen F, et al. Synthesis and luminescent properties of ternary $\mathrm{Si}-\mathrm{Ge}-\mathrm{N}$ nanowires. CrystEngComm 2016, 18: 8787-8793.

[135] Zhang YJ, Quaranta A, Domenico Soraru G. Synthesis 
and luminescent properties of novel $\mathrm{Eu}^{2+}$-doped silicon oxycarbide glasses. Opt Mater 2004, 24: 601-605.

[136] Cross T, Raj R, Prasad SV, et al. Mechanical and tribological behavior of polymer-derived ceramics constituted from $\operatorname{SiC}_{x} \mathrm{O}_{y} \mathrm{~N}_{z}$. J Am Ceram Soc 2006, 89: 3706-3714.

[137] Cross TJ, Raj R, Cross TJ, et al. Synthesis and tribological behavior of silicon oxycarbonitride thin films derived from poly(urea)methyl vinyl silazane. Int J Appl Ceram Technol 2006, 3: 113-126.

[138] Klaffke D, Wäsche R, Janakiraman N, et al. Tribological characterisation of siliconcarbonitride ceramics derived from preceramic polymers. Wear 2006, 260: 711-719.

[139] Li ZB, Cao YJ, He JB, et al. Mechanical and tribological performances of $\mathrm{C}-\mathrm{SiC}$ nanocomposites synthetized from polymer-derived ceramics sintered by spark plasma sintering. Ceram Int 2018, 44: 14335-14341.

[140] Alvi SA, Akhtar F. High temperature tribology of polymer derived ceramic composite coatings. Sci Rep 2018, 8: 15105.

[141] Vakifahmetoglu C, Buldu M, Karakuscu A, et al. High surface area carbonous components from emulsion derived SiOC and their gas sensing behavior. J Eur Ceram Soc 2015, 35: 4447-4452.

[142] Hu LH, Raj R. Semiconductive behavior of polymerderived SiCN ceramics for hydrogen sensing. J Am Ceram Soc 2015, 98: 1052-1055.

[143] Karakuscu A, Ponzoni A, Ayana D, et al. High carbon-high porous SiOC glasses for room temperature $\mathrm{NO}_{2}$ sensing. Procedia Eng 2014, 87: 160-163.

[144] Ren XH, Ebadi S, Chen YH, et al. High-temperature characterization of $\mathrm{SiCN}$ ceramics for wireless passive sensing applications up to $500{ }^{\circ} \mathrm{C}$. In: Proceedings of the WAMICON 2011 Conference, 2011: 1-5.

[145] Gonzalo-Juan I, Detsch R, Mathur S, et al. Synthesis and in vitro activity assessment of novel silicon oxycarbidebased bioactive glasses. Materials 2016, 9: 959.

[146] Ionescu E, Sen S, Mera G, et al. Structure, energetics and bioactivity of silicon oxycarbide-based amorphous ceramics with highly connected networks. J Eur Ceram Soc 2018, 38: 1311-1319.

[147] Gawęda M, Jeleń P, Długoń E, et al. Bioactive layers based on black glasses on titanium substrates. $J \mathrm{Am}$ Ceram Soc 2018, 101: 590-601.

[148] Riedel R, Mera G, Hauser R, et al. Silicon-based polymer-derived ceramics: Synthesis properties and applications-A review. J Ceram Soc Japan 2006, 114: 425-444.

[149] Stabler C, Ionescu E, Graczyk-Zajac M, et al. Silicon oxycarbide glasses and glass-ceramics: "All-Rounder" materials for advanced structural and functional applications. J Am Ceram Soc 2018, 101: 4817-4856.

[150] Bunsell AR, Piant A. A review of the development of three generations of small diameter silicon carbide fibres. J Mater Sci 2006, 41: 823-839.
[151] Manoj Kumar BV, Kim YW. Processing of polysiloxanederived porous ceramics: A review. Sci Technol Adv Mater 2010, 11: 044303.

[152] Miele P, Bernard S, Cornu D, et al. Recent developments in polymer-derived ceramic fibers (PDCFs): Preparation, properties and applications-A review. Soft Mater 2007, 4: 249-286.

[153] Vakifahmetoglu C, Zeydanli D, Colombo P. Porous polymer derived ceramics. Mater Sci Eng: R: Rep 2016, 106: $1-30$.

[154] Colombo P, Riedel R, Sorarù GD, et al. Polymer Derived Ceramics: From Nano-Structure to Applications. Lancaster, PA, USA: DEStech Publications, Inc., 2010.

[155] Riedel R, Bill J, Passing G. A novel carbon material derived from pyridine-borane. Adv Mater 1991, 3: 551-552.

[156] Bhat S, Lauterbach S, Dzivenko D, et al. High-pressure high-temperature behavior of polymer derived amorphous B-C-N. J Phys: Conf Ser 2014, 500: 182004.

[157] Bernard S, Miele P. Polymer-derived boron nitride: A review on the chemistry, shaping and ceramic conversion of borazine derivatives. Materials: Basel 2014, 7: 7436-7459.

[158] Lei YP, Wang YD, Song YC, et al. Novel processable precursor for $\mathrm{BN}$ by the polymer-derived ceramics route. Ceram Int 2011, 37: 3005-3009.

[159] Cornu D, Bernard S, Duperrier S, et al. Alkylaminoborazine-based precursors for the preparation of boron nitride fibers by the polymer-derived ceramics (PDCs) route. J Eur Ceram Soc 2005, 25: 111-121.

[160] Lei YP, Wang YD, Xue JG, et al. Influence of pyrolysis conditions on fabrication of polymer-derived BN fiber for wave transparent application. Compos B: Eng 2013, 51: 254-259.

[161] Salles V, Bernard S, Brioude A, et al. A new class of boron nitride fibers with tunable properties by combining an electrospinning process and the polymer-derived ceramics route. Nanoscale 2010, 2: 215-217.

[162] Gervais C, Maquet J, Babonneau F, et al. Chemically derived $\mathrm{BN}$ ceramics: Extensive ${ }^{11} \mathrm{~B}$ and ${ }^{15} \mathrm{~N}$ solid-state NMR study of a preceramic polyborazilene. Chem Mater 2001, 13: 1700-1707.

[163] Takahiro G, Hiroshi Y, Takaaki H, et al. Preparation of polyzirconoxane from zirconium oxychloride octahydrate and ethylene glycol as a precursor for zirconia ceramics. Appl Organometal Chem 2000, 14: 119-126.

[164] Li XJ, Hector AL, Owen JR, et al. Evaluation of nanocrystalline $\mathrm{Sn}_{3} \mathrm{~N}_{4}$ derived from ammonolysis of $\mathrm{Sn}\left(\mathrm{NEt}_{2}\right)_{4}$ as a negative electrode material for Li-ion and Na-ion batteries. J Mater Chem A 2016, 4: 5081-5087.

[165] Baxter DV, Chisholm MH, Gama GJ, et al. Molecular routes to metal carbides, nitrides, and oxides. 2. Studies of the ammonolysis of metal dialkylamides and hexamethyldisilylamides. Chem Mater 1996, 8: 12221228. 
[166] Kurokawa Y, Ishizaka T, Suzuki M. Preparation of refractory nitride fibers by thermal decomposition of transition metal $(\mathrm{Ti}, \mathrm{Nb})$ alkoxide-cellulose precursor gel fibers in $\mathrm{NH}_{3}$ atmosphere. J Mater Sci 2001, 36: 301-306.

[167] Thorne K, Ting SJ, Chu CJ, et al. Synthesis of TiC via polymeric titanates: The preparation of fibres and thin films. J Mater Sci 1992, 27: 4406-4414.

[168] Lang H, Seyferth D. Pyrolysis of metallocene complexes $\left(\eta \mathrm{C}_{5} \mathrm{H}_{4} \mathrm{R}\right)_{2} \mathrm{MR}$ : An organometallic route to metal carbide (MC) materials $(\mathrm{M}=\mathrm{Ti}, \mathrm{Zr}, \mathrm{Hf})$. Appl Organomet Chem 1990, 4: 599-606.

[169] Preiss H, Schierhorn E, Brzezinka KW. Synthesis of polymeric titanium and zirconium precursors and preparation of carbide fibres and films. J Mater Sci 1998, 33: 4697-4706.

[170] Tao XY, Qiu WF, Li H, et al. Synthesis of nanosized zirconium carbide from preceramic polymers by the facile one-pot reaction. Polym Adv Technol 2010, 21: 300-304.

[171] Inzenhofer K, Schmalz T, Wrackmeyer B, et al. The preparation of $\mathrm{HfC} / \mathrm{C}$ ceramics via molecular design. Dalton Trans 2011, 40: 4741-4745.

[172] Sun YN, Yang CM, Lu Y, et al. Transformation of metallic polymer precursor into nanosized $\mathrm{HfTaC}_{2}$ ceramics. Ceram Int 2020, 46: 6022-6028.

[173] Tao XY, Xiang Z, Zhou S, et al. Synthesis and characterization of a boron-containing precursor for $\mathrm{ZrB}_{2}$ ceramic. J Ceram Sci Tech 2016, 7: 107-111.

[174] Tao XY, Zhou SX, Xiang ZM, et al. Fabrication of continuous $\mathrm{ZrB}_{2}$ nanofibers derived from boroncontaining polymeric precursors. J Alloys Compd 2017, 697: 318-325.

[175] Wang $\mathrm{H}$, Chen XB, Gao B, et al. Synthesis and characterization of a novel precursor-derived $\mathrm{ZrC} / \mathrm{ZrB}_{2}$ ultra-high-temperature ceramic composite. Appl Organomet Chem 2013, 27: 79-84.

[176] Bernard S, Weinmann M, Gerstel P, et al. Boron-modified polysilazane as a novel single-source precursor for $\mathrm{SiBCN}$ ceramic fibers: Synthesis, melt-spinning, curing and ceramic conversion. J Mater Chem 2005, 15: 289.

[177] Viard A, Fonblanc D, Schmidt M, et al. Molecular chemistry and engineering of boron-modified polyorganosilazanes as new processable and functional SiBCN precursors. Chem Eur J 2017, 23: 9076-9090.

[178] Schuhmacher J, Weinmann M, Bill J, et al. Solid-state NMR studies of the preparation of $\mathrm{Si}-\mathrm{C}-\mathrm{N}$ ceramics from polysilylcarbodiimide polymers. Chem Mater 1998, 10: 3913-3922.

[179] Viard A, Fonblanc D, Lopez-Ferber D, et al. Polymer derived Si-B-C-N ceramics: 30 years of research. $A d v$ Eng Mater 2018, 20: 1800360.

[180] Peuckert M, Vaahs T, Brück M. Ceramics from organometallic polymers. Adv Mater 1990, 2: 398-404.

[181] Wynne KJ, Rice RW. Ceramics via polymer pyrolysisdagger. Annu Rev Mater Sci 1984, 14: 297-334.

[182] Jaschke B, Klingebiel U, Riedel R, et al. Cyclosilazanes and borazines: Polymer precursors to silicon- and boron-containing ceramics. Appl Organometal Chem 2000, 14: 671-685.

[183] Kroke E, Li YL, Konetschny C, et al. Silazane derived ceramics and related materials. Mater Sci Eng: R: Rep 2000, 26: 97-199.

[184] Hector AL. Synthesis and processing of silicon nitride and related materials using preceramic polymer and non-oxide sol-gel approaches. Coord Chem Rev 2016, 323: 120-137.

[185] Birot M, Pillot JP, Dunogues J. Comprehensive chemistry of polycarbosilanes, polysilazanes, and polycarbosilazanes as precursors of ceramics. Chem Rev 1995, 95: 1443-1477.

[186] Kakimoto KI, Wakai F, Bill J, et al. Synthesis of Si-C-O bulk ceramics with various chemical compositions from polycarbosilane. J Am Ceram Soc 1999, 82: 2337-2341.

[187] Su D, Li YL, An HJ, et al. Pyrolytic transformation of liquid precursors to shaped bulk ceramics. J Eur Ceram Soc 2010, 30: 1503-1511.

[188] Choong Kwet Yive NS, Corriu RJP, Leclercq D, et al. Silicon carbonitride from polymeric precursors: Thermal cross-linking and pyrolysis of oligosilazane model compounds. Chem Mater 1992, 4: 141-146.

[189] Lavedrine A, Bahloul D, Goursat P, et al. Pyrolysis of polyvinylsilazane precursors to silicon carbonitride. J Eur Ceram Soc 1991, 8: 221-227.

[190] Kaur S, Cherkashinin G, Fasel C, et al. Single-sourceprecursor synthesis of novel $\mathrm{V}_{8} \mathrm{C}_{7} / \mathrm{SiC}(\mathrm{O})$-based ceramic nanocomposites. J Eur Ceram Soc 2016, 36: 3553-3563.

[191] Wang C, Wang J, Park CB, et al. Cross-linking behavior of a polysiloxane in preceramic foam processing. J Mater Sci 2004, 39: 4913-4915.

[192] Yajima S, Hasegawa Y, Hayashi J, et al. Synthesis of continuous silicon carbide fibre with high tensile strength and high Young's modulus. J Mater Sci 1978, 13: 2569-2576.

[193] Hasegawa Y, Okamura K. Synthesis of continuous silicon carbide fibre. J Mater Sci 1983, 18: 3633-3648.

[194] Hasegawa Y. Synthesis of continuous silicon carbide fibre. J Mater Sci 1989, 24: 1177-1190.

[195] Ichikawa H, Machino F, Mitsuno S, et al. Synthesis of continuous silicon carbide fibre. J Mater Sci 1986, 21: 4352-4358.

[196] Ichikawa H. Polymer-derived ceramic fibers. Annu Rev Mater Res 2016, 46: 335-356.

[197] Laine RM, Babonneau F. Preceramic polymer routes to silicon carbide. Chem Mater 1993, 5: 260-279.

[198] Su ZM, Zhang LT, Li YC, et al. Rapid preparation of SiC fibers using a curing route of electron irradiation in a low oxygen concentration atmosphere. J Am Ceram Soc 2015, 98: 2014-2017.

[199] Cramer NB, Reddy SK, Lu H, et al. Thiol-ene photopolymerization of polymer-derived ceramic precursors. J Polym Sci A: Polym Chem 2004, 42: 1752-1757. 
[200] He WQ, Chen LX, Peng F. Coating formed by SiBCN single source precursor via UV-photopolymerization. Mater Lett 2017, 206: 121-123.

[201] Pham TA, Kim P, Kwak M, et al. Inorganic polymer photoresist for direct ceramic patterning by photolithography. Chem Commun 2007, 39: 4021-4023.

[202] Schulz M, Börner M, Göttert J, et al. Cross linking behavior of preceramic polymers effected by UV- and synchrotron radiation. Adv Eng Mater 2004, 6: 676-680.

[203] Zanchetta E, Cattaldo M, Franchin G, et al. Stereolithography of SiOC ceramic microcomponents. Adv Mater 2016, 28: 370-376.

[204] Hundley JM, Eckel ZC, Schueller E, et al. Geometric characterization of additively manufactured polymer derived ceramics. Addit Manuf 2017, 18: 95-102.

[205] Friedel T, Travitzky N, Niebling F, et al. Fabrication of polymer derived ceramic parts by selective laser curing. $J$ Eur Ceram Soc 2005, 25: 193-197.

[206] Zocca A, Gomes CM, Staude A, et al. SiOC ceramics with ordered porosity by 3D-printing of a preceramic polymer. J Mater Res 2013, 28: 2243-2252.

[207] Zocca A, Colombo P, Gomes CM, et al. Additive manufacturing of ceramics: Issues, potentialities, and opportunities. J Am Ceram Soc 2015, 98: 1983-2001.

[208] Tian XY, Zhang WG, Li DC, et al. Reaction-bonded SiC derived from resin precursors by Stereolithography. Ceram Int 2012, 38: 589-597.

[209] De Hazan Y, Penner D. SiC and SiOC ceramic articles produced by stereolithography of acrylate modified polycarbosilane systems. J Eur Ceram Soc 2017, 37: 5205-5212.

[210] Li S, Duan WY, Zhao T, et al. The fabrication of SiBCN ceramic components from preceramic polymers by digital light processing (DLP) 3D printing technology. $J$ Eur Ceram Soc 2018, 38: 4597-4603.

[211] Brinckmann SA, Patra N, Yao J, et al. Stereolithography of SiOC polymer-derived ceramics filled with $\mathrm{SiC}$ micronwhiskers. Adv Eng Mater 2018, 20: 1800593.

[212] Hasegawa Y. Si-C fiber prepared from polycarbosilane cured without oxygen. J Inorg Organomet Polym 1992, 2: 161-169.

[213] Rabe JA, Lipowitz J, Lu PP. Curing preceramic polymers by exposure to nitrogen dioxide. U.S. patent 5051215 , 1991.

[214] Hasegawa Y. New curing method for polycarbosilane with unsaturated hydrocarbons and application to thermally stable SiC fibre. Compos Sci Technol 1994, 51: 161-166.

[215] Hayashida A, Takamizawa M, Takeda Y. Preparation of hollow ceramic fibers. Google Patents, 1990. Available at https://patents.google.com/patent/US4948763A/en.

[216] Lipowitz J. Infusible preceramic polymers via plasma treatment. U.S. patent $4743662,1988$.

[217] Whinnery LL, Nichols MC, Wheeler DR, et al. Process for preparing silicon carbide foam. U.S. patent 5668 188, 1997.
[218] Perale G, Giordano C, Daniele F, et al. A novel process for the manufacture of ceramic microelectrodes for biomedical applications. Int J Appl Ceram Technol 2008, 5: 37-43.

[219] Narisawa M, Watase S, Matsukawa K, et al. White $\mathrm{Si}-\mathrm{O}-\mathrm{C}(-\mathrm{H})$ particles with photoluminescence synthesized by decarbonization reaction on polymer precursor in a hydrogen atmosphere. Bull Chem Soc Jpn 2012, 85: 724-726.

[220] Dong SM, Chollon G, Labrugere C, et al. Characterization of nearly stoichiometric SiC ceramic fibres. J Mater Sci 2001, 36: 2371-2381.

[221] Narisawa M, Funabiki F, Iwase A, et al. Effects of atmospheric composition on the molecular structure of synthesized silicon oxycarbides. J Am Ceram Soc 2015, 98: $3373-3380$.

[222] Chandra G, Martin TE. Rapid thermal process for obtaining silica coatings. E.P. patent 0462 715, 1996.

[223] Krüger U, Ullrich R. Producing a ceramic layer by spraying polymer ceramic precursor particles onto a surface comprises using a cold gas spray nozzle. Siemens AG, German, 2006.

[224] Colombo P, Martucci A, Fogato O, et al. Silicon carbide films by laser pyrolysis of polycarbosilane. J Am Ceram Soc 2001, 84: 224-226.

[225] Müller A, Herlin-Boime N, Ténégal F, et al. Comparison of $\mathrm{Si} / \mathrm{C} / \mathrm{N}$ pre-ceramics obtained by laser pyrolysis or furnace thermolysis. J Eur Ceram Soc 2003, 23: 37-46.

[226] Wilden J, Fischer G. Laser synthesis of nanostructured ceramics from liquid precursors. Appl Surf Sci 2007, 254: 1067-1072.

[227] Liu J, Qiao YL, Zhang P, et al. Synthesis of SiC ceramics from polysilazane by laser pyrolysis. Surf Coat Technol 2017, 321: 491-495.

[228] Tangermann-Gerk K, Barroso G, Weisenseel B, et al. Laser pyrolysis of an organosilazane-based glass $/ \mathrm{ZrO}_{2}$ composite coating system. Mater Des 2016, 109: 644-651.

[229] Wilden J, Bergmann JP, Schlichting S, et al. Direct laser pyrolysis of nanostructured micro components. In: Proceedings of the International Congress on Applications of Lasers \& Electro-Optic, 2006: M1103.

[230] Ma RX, Erb D, Lu K. Flash pyrolysis of polymer-derived SiOC ceramics. J Eur Ceram Soc 2018, 38: 4906-4914.

[231] Danko GA, Silberglitt R, Colombo P, et al. Comparison of microwave hybrid and conventional heating of preceramic polymers to form silicon carbide and silicon oxycarbide ceramics. J Am Ceram Soc 2004, 83: 1617-1625.

[232] Zunjarrao SC, Dyjak P, Rahman A, et al. Microwave processing of actively seeded precursor for fabrication of polymer derived ceramics. J Am Ceram Soc 2016, 99: 2260-2266.

[233] Pivin JC, Colombo P, Tonidandel M. Ion irradiation of preceramic polymer thin films. J Am Ceram Soc 1996, 79: 1967-1970. 
[234] Pivin JC, Colombo P, Sorarù GD. Comparison of ion irradiation effects in silicon-based preceramic thin films. $J$ Am Ceram Soc 2000, 83: 713-720.

[235] Pivin J, Colombo P. Ceramic coatings by ion irradiation of polycar bosilanes and polysiloxanes. Part II. Hardness and thermochemical stability. Fuel Energy Abstr 1998, 39: 303.

[236] Pivin JC, Colombo P. Ceramic coatings by ion irradiation of polycarbosilanes and polysiloxanes: Part I Conversion mechanism. J Mater Sci 1997, 32: 6163-6173.

[237] Tsukuda S, Seki S, Tagawa S, et al. Fabrication of nanowires using high-energy ion beams. J Phys Chem B 2004, 108: 3407-3409.

[238] Srivastava SK, Avasthi DK, Pivin JC. Mechanism of H release from Si-based polymers under ion irradiation. Nucl Instrum Methods Phys Res Sect B: Beam Interact Mater Atoms 2002, 191: 718-722.

[239] Pivin JC, Colombo P, Sendova-Vassileva M, et al. Ion-induced conversion of polysiloxanes and polycarbosilanes into ceramics: Mechanisms and properties. Nucl Instrum Methods Phys Res Sect B: Beam Interact Mater Atoms 1998, 141: 652-662.

[240] Kumar A, Singh F, Pivin JC, et al. Photoluminescence studies of carbon clusters formed by irradiation of Si-based polymer. Radiat Meas 2005, 40: 785-788.

[241] Liao NB, Xue W, Zhou HM, et al. Numerical investigation into the nanostructure and mechanical properties of amorphous SiBCN ceramics. RSC Adv 2013, 3: 14458

[242] Tomar V, Gan M, Kim HS. Atomistic analyses of the effect of temperature and morphology on mechanical strength of $\mathrm{Si}-\mathrm{C}-\mathrm{N}$ and $\mathrm{Si}-\mathrm{C}-\mathrm{O}$ nanocomposites. $J$ Eur Ceram Soc 2010, 30: 2223-2237.

[243] Kroll P. Searching insight into the atomistic structure of SiCO ceramics. J Mater Chem 2010, 20: 10528.

[244] Amkreutz M, Frauenheim T. Understanding precursorderived amorphous $\mathrm{Si}-\mathrm{C}-\mathrm{N}$ ceramics on the atomic scale. Phys Rev B 2002, 65: 134113.

[245] Resta N, Kohler C, Trebin HR. Molecular dynamics simulations of amorphous $\mathrm{Si}-\mathrm{C}-\mathrm{N}$ ceramics: Composition dependence of the atomic structure. J Am Ceram Soc 2003, 86: 1409-1414.

[246] Matsunaga K, Iwamoto Y. Molecular dynamics study of atomic structure and diffusion behavior in amorphous silicon nitride containing boron. J Am Ceram Soc 2004, 84: 2213-2219.

[247] Bill J, Kamphowe TW, Müller A, et al. Precursor-derived $\mathrm{Si}-(\mathrm{B}-) \mathrm{C}-\mathrm{N}$ ceramics: Thermolysis, amorphous state and crystallization. Appl Organomet Chem 2001, 15: 777793.

[248] Kleebe HJ, Turquat C, Sorarù GD. Phase separation in an SiCO glass studied by transmission electron microscopy and electron energy-loss spectroscopy. J Am Ceram Soc 2001, 84: 1073-1080.

[249] Kleebe HJ, Blum YD. SiOC ceramic with high excess free carbon. J Eur Ceram Soc 2008, 28: 1037-1042.
[250] Widgeon SJ, Sen S, Mera G, et al. ${ }^{29} \mathrm{Si}$ and ${ }^{13} \mathrm{C}$ solid-state NMR spectroscopic study of nanometer-scale structure and mass fractal characteristics of amorphous polymer derived silicon oxycarbide ceramics. Chem Mater 2010, 22: 6221-6228.

[251] Scarmi A, Sorarù GD, Raj R. The role of carbon in unexpected visco(an)elastic behavior of amorphous silicon oxycarbide above 1273 K. J Non-Cryst Solids 2005, 351: 2238-2243.

[252] Saha A, Raj R, Williamson DL. A model for the nanodomains in polymer-derived SiCO. $J$ Am Ceram Soc 2006, 89: 2188-2195.

[253] Sen S, Stebbins JF. Phase separation, clustering, and fractal characteristics in glass: A magic-angle-spinning NMR spin-lattice relaxation study. Phys Rev B 1994, 50: 822-830.

[254] Gabriel AO, Riedel R, Dressler W, et al. Thermal decomposition of poly(methylsilsesquicarbodiimide) to amorphous Si-C-N ceramics. Chem Mater 1999, 11: 412-420.

[255] Iwamoto Y, Völger W, Kroke E, et al. Crystallization behavior of amorphous silicon carbonitride ceramics derived from organometallic precursors. $J$ Am Ceram Soc 2004, 84: 2170-2178.

[256] Michelle Morcos R, Mera G, Navrotsky A, et al. Enthalpy of formation of carbon-rich polymer-derived amorphous SiCN ceramics. J Am Ceram Soc 2008, 91: 3349-3354.

[257] Mera G, Tamayo A, Nguyen H, et al. Nanodomain structure of carbon-rich silicon carbonitride polymerderived ceramics. J Am Ceram Soc 2010, 93: 1169-1175.

[258] Saha A, Raj R, Williamson DL, et al. Characterization of nanodomains in polymer-derived $\mathrm{SiCN}$ ceramics employing multiple techniques. J Am Ceram Soc 2005, 88: 232-234.

[259] Liao NB, Xue W, Zhang M. Effect of carbon content on structural and mechanical properties of $\mathrm{SiCN}$ by atomistic simulations. J Eur Ceram Soc 2012, 32: 1275-1281.

[260] Widgeon S, Mera G, Gao Y, et al. Nanostructure and energetics of carbon-rich $\mathrm{SiCN}$ ceramics derived from polysilylcarbodiimides: Role of the nanodomain interfaces. Chem Mater 2012, 24: 1181-1191.

[261] Chen YH, Yang XP, Cao YJ, et al. Quantitative study on structural evolutions and associated energetics in polysilazane-derived amorphous silicon carbonitride ceramics. Acta Mater 2014, 72: 22-31.

[262] Seitz J, Bill J, Egger N, et al. Structural investigations of $\mathrm{Si} / \mathrm{C} / \mathrm{N}$-ceramics from polysilazane precursors by nuclear magnetic resonance. J Eur Ceram Soc 1996, 16: 885-891.

[263] Traß1 S, Suttor D, Motz G, et al. Structural characterisation of silicon carbonitride ceramics derived from polymeric precursors. J Eur Ceram Soc 2000, 20: 215-225.

[264] Ionescu E, Kleebe HJ, Riedel R. Silicon-containing polymer-derived ceramic nanocomposites (PDC-NCs): 
Preparative approaches and properties. Chem Soc Rev 2012, 41: 5032.

[265] Kleebe HJ, Suttor D, Müller H, et al. Decompositioncrystallization of polymer-derived $\mathrm{Si}-\mathrm{C}-\mathrm{N}$ ceramics. $J$ Am Ceram Soc 2005, 81: 2971-2977.

[266] Kumar R, Cai Y, Gerstel P, et al. Processing, crystallization and characterization of polymer derived nano-crystalline Si-B-C-N ceramics. J Mater Sci 2006, 41: 7088-7095.

[267] Zemanová M, Lecomte E, Šajgalík P, et al. Polysilazane derived micro/nano $\mathrm{Si}_{3} \mathrm{~N}_{4} / \mathrm{SiC}$ composites. J Eur Ceram Soc 2002, 22: 2963-2968.

[268] Gasch MJ, Wan J, Mukherjee AK. Preparation of a $\mathrm{Si}_{3} \mathrm{~N}_{4} / \mathrm{SiC}$ nanocomposite by high-pressure sintering of polymer precursor derived powders. Scripta Mater 2001, 45: $1063-1068$.

[269] Xu TH, Ma QS, Chen ZH. High-temperature behavior of silicon oxycarbide glasses in air environment. Ceram Int 2011, 37: 2555-2559.

[270] Ionescu E, Papendorf B, Kleebe HJ, et al. Polymerderived silicon oxycarbide/hafnia ceramic nanocomposites. Part II: Stability toward decomposition and microstructure evolution at $T \gg 1000{ }^{\circ} \mathrm{C} . \mathrm{J} \mathrm{Am}$ Ceram Soc 2010, 93: 1783-1789.

[271] Burns GT, Taylor RB, Xu YR, et al. High-temperature chemistry of the conversion of siloxanes to silicon carbide. Chem Mater 1992, 4: 1313-1323.

[272] Le Coustumer P, Monthioux M, Oberlin A. Understanding Nicalon ${ }^{\circledR}$ fibre. J Eur Ceram Soc 1993, 11: 95-103.

[273] Jansohn P. Modern Gas Turbine Systems: High Efficiency, Low Emission, Fuel Flexible Power Generation. Woodhead Publishing, 2013.

[274] Konegger T, Torrey J, Flores O, et al. Ceramics for sustainable energy technologies with a focus on polymerderived ceramics. In: Novel Combustion Concepts for Sustainable Energy Development. Agarwal A, Pandey A, Gupta A, et al., Eds. New Delhi: Springer, 2014: 501-533.

[275] Asim N, Sopian K, Ahmadi S, et al. A review on the role of materials science in solar cells. Renew Sustain Energy Rev 2012, 16: 5834-5847.

[276] Ameri T, Khoram P, Min J, et al. Organic ternary solar cells: A review. Adv Mater 2013, 25: 4245-4266.

[277] Wright M, Uddin A. Organic-inorganic hybrid solar cells: A comparative review. Sol Energy Mater Sol Cells 2012, 107: 87-111.

[278] Hu ZH, Wang J, Ma XL, et al. A critical review on semitransparent organic solar cells. Nano Energy 2020, 78: 105376.

[279] Wang Y, Ruiz Diaz DF, Chen KS, et al. Materials, technological status, and fundamentals of PEM fuel cells -A review. Mater Today 2020, 32: 178-203.

[280] Abdalla AM, Hossain S, Azad AT, et al. Nanomaterials for solid oxide fuel cells: A review. Renew Sustain Energy Rev 2018, 82: 353-368.

[281] Majlan EH, Rohendi D, Daud WRW, et al. Electrode for proton exchange membrane fuel cells: A review. Renew Sustain Energy Rev 2018, 89: 117-134.

[282] Ren Z, Singh G. Nonoxide polymer-derived CMCs for "super" turbines. Am Ceram Soc Bull 2019, 98: 34-39.

[283] Padture NP. Advanced structural ceramics in aerospace propulsion. Nat Mater 2016, 15: 804-809.

[284] Perepezko JH. The hotter the engine, the better. Science 2009, 326: 1068-1069.

[285] Clarke DR, Oechsner M, Padture NP. Thermal-barrier coatings for more efficient gas-turbine engines. MRS Bull 2012, 37: 891-898.

[286] Information on https://www.powermag.com/anotherworld-record-for-combined-cycle-efficiency/.

[287] Spitsberg I, Steibel J. Thermal and environmental barrier coatings for $\mathrm{SiC} / \mathrm{SiC} \mathrm{CMCs}$ in aircraft engine applications. Int J Appl Ceram Tec 2004, 1: 291-301.

[288] Yu ZJ, Luan XG, Riedel R. Editorial of the special issue on ultra-high temperature ceramic matrix composites. J Eur Ceram Soc 2016, 36: 3551-3552.

[289] Ohnabe H, Masaki S, Onozuka M, et al. Potential application of ceramic matrix composites to aero-engine components. Compos A: Appl Sci Manuf 1999, 30: 489-496.

[290] Naslain RR. The design of the fibre-matrix interfacial zone in ceramic matrix composites. Compos A: Appl Sci Manuf 1998, 29: 1145-1155.

[291] Marshall DB, Cox BN. Integral textile ceramic structures. Annu Rev Mater Res 2008, 38: 425-443.

[292] Dever JA, Nathal MV, DiCarlo JA. Research on high-temperature aerospace materials at NASA Glenn research center. J Aerosp Eng 2013, 26: 500-514.

[293] Grady JE. CMC technology advancements for gas turbine engine applications. In: Proceedings of the American Ceramic Society's 10th Pacific Rim Conference on Ceramic and Glass Technology, 2013.

[294] Evans AG, Zok FW. The physics and mechanics of fibre-reinforced brittle matrix composites. J Mater Sci 1994, 29: 3857-3896.

[295] Bansal NP, Lamon J. Ceramic Matrix Composites. Hoboken, NJ, USA: John Wiley \& Sons, Inc., 2014.

[296] Kellner T. Made in rocket city: GE to mass-produce advanced space age material in the US for the first time. GE Reports, 2015. Available at https://www. designworldonline.com/ge-to-mass-produce-advanced-sp ace-age-material-in-the-u-s-for-the-first-time/.

[297] Packirisamy S, Sreejith KJ, Devapal D, et al. Polymer-derived ceramics and their space applications. In: Handbook of Advanced Ceramics and Composites. Cham: Springer International Publishing, 2020: 975-1080.

[298] Mainzer B, Lin CR, Jemmali R, et al. Characterization and application of a novel low viscosity polysilazane for the manufacture of $\mathrm{C}$ - and $\mathrm{SiC}$-fiber reinforced $\mathrm{SiCN}$ ceramic matrix composites by PIP process. J Eur Ceram Soc 2019, 39: 212-221.

[299] Song CK, Liu YS, Ye F, et al. Enhanced mechanical 
property and tunable dielectric property of $\mathrm{SiC}_{\mathrm{f}} / \mathrm{SiC}-$ SiBCN composites by CVI combined with PIP. $J A d v$ Ceram 2021, 10: 758-767.

[300] Yajima S, Hayashi J, Omori M, et al. Development of a silicon carbide fibre with high tensile strength. Nature 1976, 261: 683-685.

[301] Long X, Shao CW, Wang H, et al. Single-sourceprecursor synthesis of $\mathrm{SiBNC}-\mathrm{Zr}$ ceramic nanocomposites fibers. Ceram Int 2016, 42: 19206-19211.

[302] Nguyen VL, Proust V, Quievryn C, et al. Processing, mechanical characterization, and alkali resistance of SiliconBoronOxycarbide (SiBOC) glass fibers. $\mathrm{J} \mathrm{Am}$ Ceram Soc 2014, 97: 3143-3149.

[303] Bernard S, Cornu D, Miele P, et al. Polyborosilazanederived ceramic fibers in the $\mathrm{Si}-\mathrm{B}-\mathrm{C}-\mathrm{N}$ quaternary system for high-temperature applications. In: Proceedings of the Mechanical Properties and Performance of Engineering Ceramics and Composites: Ceramic Engineering and Science, Volume 26, 2005: 35-42.

[304] Ren Z, Singh G. Nonoxide polymer-derived CMCs for "super" turbines. Am Ceram Soc Bull 2019, 98: 34-39.

[305] Ziegler G, Richter I, Suttor D. Fiber-reinforced composites with polymer-derived matrix: Processing, matrix formation and properties. Compos A: Appl Sci Manuf 1999, 30: 411-417.

[306] Ionescu E, Linck C, Fasel C, et al. Polymer-derived $\mathrm{SiOC} / \mathrm{ZrO}_{2}$ ceramic nanocomposites with excellent hightemperature stability. J Am Ceram Soc 2010, 93: 241-250.

[307] Proust V, Bechelany MC, Ghisleni R, et al. Polymer-derived $\mathrm{Si}-\mathrm{C}-\mathrm{Ti}$ systems: From titanium nanoparticle-filled polycarbosilanes to dense monolithic multi-phase components with high hardness. J Eur Ceram Soc 2016, 36: 3671-3679.

[308] Wen QB, Luan XG, Wang L, et al. Laser ablation behavior of SiHfC-based ceramics prepared from a single-source precursor: Effects of Hf-incorporation into SiC. J Eur Ceram Soc 2019, 39: 2018-2027.

[309] Ionescu E, Bernard S, Lucas R, et al. Polymer-derived ultra-high temperature ceramics (UHTCs) and related materials. Adv Eng Mater 2019, 21: 1900269.

[310] Lee SH, Weinmann M, Aldinger F. Processing and properties of $\mathrm{C} / \mathrm{Si}-\mathrm{B}-\mathrm{C}-\mathrm{N}$ fiber-reinforced ceramic matrix composites prepared by precursor impregnation and pyrolysis. Acta Mater 2008, 56: 1529-1538.

[311] Ding Q, Ni DW, Wang Z, et al. 3D $\mathrm{C}_{\mathrm{f}} / \mathrm{SiBCN}$ composites prepared by an improved polymer infiltration and pyrolysis. J Adv Ceram 2018, 7: 266-275.

[312] Chen BW, Ding Q, Ni DW, et al. Microstructure and mechanical properties of $3 \mathrm{D} \mathrm{C}_{\mathrm{f}} / \mathrm{SiBCN}$ composites fabricated by polymer infiltration and pyrolysis. $J A d v$ Ceram 2021, 10: 28-38.

[313] Ziegler G, Richter I, Suttor D. Fiber-reinforced composites with polymer-derived matrix: Processing, matrix formation and properties. Compos A: Appl Sci Manuf 1999, 30: 411-417.
[314] Yuan Q, Chai ZF, Huang ZR, et al. A new precursor of liquid and curable polysiloxane for highly cost-efficient SiOC-based composites. Ceram Int 2019, 45: 7044-7048.

[315] Xu TH, Ma QS, Chen ZH. High-temperature behavior of $\mathrm{C}_{\mathrm{f}} / \mathrm{SiOC}$ composites in inert atmosphere. Mater Sci Eng: A 2011, 530: 266-270.

[316] Sreejith K, Rajasekhar B, Vijay V. Polymer-derived $\mathrm{C}_{\mathrm{f}} / \mathrm{SiBOC}$ ceramic matrix composites and a method of production thereof. Indian Patent Appl. No. 201841020417, 2018.

[317] Poerschke DL, Rossol MN, Zok FW. Intermediate temperature internal oxidation of a $\mathrm{SiC} / \mathrm{SiCN}$ composite with a polymer-derived matrix. J Am Ceram Soc 2016, 99: 3120-3128.

[318] Liu HT, Cheng HF, Wang J, et al. Effects of the single layer CVD $\mathrm{SiC}$ interphases on the mechanical properties of the $\mathrm{SiC}_{\mathrm{f}} / \mathrm{SiC}$ composites fabricated by PIP process. Ceram Int 2010, 36: 2033-2037.

[319] Luo Z, Zhou XG, Yu JS. Mechanical properties of SiC/SiC composites by PIP process with a new precursor at elevated temperature. Mater Sci Eng: A 2014, 607: 155-161.

[320] Wang JY, Yang ZH, Duan XM, et al. Microstructure and mechanical properties of $\mathrm{SiC}_{\mathrm{f}} / \mathrm{SiBCN}$ ceramic matrix composites. $J$ Adv Ceram 2015, 4: 31-38.

[321] Jones R, Szweda A, Petrak D. Polymer derived ceramic matrix composites. Compos A: Appl Sci Manuf 1999, 30: 569-575.

[322] Poerschke DL, Rossol MN, Zok FW. Intermediate temperature internal oxidation of a $\mathrm{SiC} / \mathrm{SiCN}$ composite with a polymer-derived matrix. J Am Ceram Soc 2016, 99: 3120-3128.

[323] Luo Z, Zhou XG, Yu JS. Mechanical properties of SiC/SiC composites by PIP process with a new precursor at elevated temperature. Mater Sci Eng: A 2014, 607: 155-161.

[324] Tian YL, Hu JD, Feng ZH, et al. Mechanical properties and high temperature failure mechanism of carbon fibers reinforced polysilazane-derived $\mathrm{SiCN}$ ceramic matrix composites via PIP process. J Eur Ceram Soc 2022, 42: 890-897.

[325] Boitier G, Chermant JL, Vicens J. Understanding the creep behavior of a $2.5 \mathrm{D} \mathrm{C}_{\mathrm{f}}-\mathrm{SiC}$ composite: II. Experimental specifications and macroscopic mechanical creep responses. Mater Sci Eng: A 2000, 289: 265-275.

[326] Zhu SJ, Mizuno M, Kagawa Y, et al. Creep and fatigue behavior in Hi-Nicalon-fiber-reinforced silicon carbide composites at high temperatures. J Am Ceram Soc 1999, 82: $117-128$.

[327] Kopeliovich D. Advances in the manufacture of ceramic matrix composites using infiltration techniques. In: Advances in Ceramic Matrix Composites. Amsterdam: Elsevier, 2014: 79-108.

[328] Kumagawa K, Yamaoka H, Shibuya M, et al. Fabrication and mechanical properties of new improved $\mathrm{Si}-\mathrm{M}-\mathrm{C}-(\mathrm{O})$ tyranno fiber. In: Proceedings of the 22nd Annual 
Conference on Composites, Advanced Ceramics, Materials, and Structures: A: Ceramic Engineering and Science Proceedings, Volume 19, 2014: 65-72.

[329] Kumagawa K, Yamaoka H, Shibuya M, et al. Thermal stability and chemical corrosion resistance of newly developed continuous $\mathrm{Si}-\mathrm{Zr}-\mathrm{C}-\mathrm{O}$ tyranno fiber. In: Proceedings of the 21st Annual Conference on Composites, Advanced Ceramics, Materials, and Structures: A: Ceramic Engineering and Science Proceedings, Volume 18, 2008: 113-118.

[330] Liu Y, Chen KZ, Dong FB, et al. Effects of hydrolysis of precursor on the structures and properties of polymer-derived SiBN ceramic fibers. Ceram Int 2018, 44: 10199-10203.

[331] Long X, Wu ZY, Shao CW, et al. High-temperature oxidation behavior of $\mathrm{SiBN}$ fibers in air. $J A d v$ Ceram 2021, 10: 768-777.

[332] Bai HW, Wen G, Huang XX, et al. Synthesis and structural characterization of SiBOC ceramic fibers derived from single-source polyborosiloxane. J Eur Ceram Soc 2011, 31: 931-940.

[333] Toreki W, Batich CD, Sacks MD, et al. Polymer-derived silicon carbide fibers with low oxygen content and improved thermomechanical stability. Compos Sci Technol 1994, 51: 145-159.

[334] Sacks MD, Morrone AA, Scheiffele GW, et al. Characterization of polymer-derived silicon carbide fibers with low oxygen content, near-stoichiometric composition, and improved thermomechanical stability. In: Ceramic Engineering and Science Proceedings. Hoboken, NJ, USA: John Wiley \& Sons, Inc., 2009: 25-35.

[335] Evans AG, Zok FW. The physics and mechanics of fibre-reinforced brittle matrix composites. J Mater Sci 1994, 29: 3857-3896.

[336] Motz G, Bordia RK. Processing, structure and properties of ceramic fibers. In: Handbook of Textile Fibre Structure. Amsterdam: Elsevier, 2009: 378-424.

[337] Viard A, Miele P, Bernard S. Polymer-derived ceramics route toward SiCN and SiBCN fibers: From chemistry of polycarbosilazanes to the design and characterization of ceramic fibers. J Ceram Soc Jpn 2016, 124: 967-980.

[338] Viard A, Fonblanc D, Lopez-Ferber D, et al. Polymer derived Si-B-C-N ceramics: 30 years of research. $A d v$ Eng Mater 2018, 20: 1800360.

[339] Padture NP, Gell M, Jordan EH. Thermal barrier coatings for gas-turbine engine applications. Science 2002, 296: 280-284.

[340] Padture NP. Environmental degradation of hightemperature protective coatings for ceramic-matrix composites in gas-turbine engines. npj Mater Degrad 2019, 3: 11 .

[341] Opila EJ. Oxidation kinetics of chemically vapordeposited silicon carbide in wet oxygen. $J$ Am Ceram Soc 1994, 77: 730-736.

[342] Luan XG, Xu XM, Wang L, et al. Self-healing enhancing tensile creep of $2 \mathrm{D}$-satin weave $\mathrm{SiC} /(\mathrm{SiC}-\mathrm{SiBCN})_{x}$ composites in wet oxygen environment. J Eur Ceram Soc 2020, 40: 3509-3519.

[343] Lee KN, Fox DS, Eldridge JI, et al. Upper temperature limit of environmental barrier coatings based on mullite and BSAS. J Am Ceram Soc 2003, 86: 1299-1306.

[344] Gadow R, Kern F. Liquid-phase coating of carbon fibers with pre-ceramic polymer precursors: Process and applications. Adv Eng Mater 2002, 4: 883-886.

[345] Schütz A, Günthner M, Motz G, et al. Characterisation of novel precursor-derived ceramic coatings with glass filler particles on steel substrates. Surf Coat Technol 2012, 207: 319-327.

[346] Günthner M, Kraus T, Dierdorf A, et al. Advanced coatings on the basis of $\mathrm{Si}(\mathrm{C}) \mathrm{N}$ precursors for protection of steel against oxidation. J Eur Ceram Soc 2009, 29: 2061-2068.

[347] Liu J, Zhang LT, Hu F, et al. Polymer-derived yttrium silicate coatings on $2 \mathrm{D} \mathrm{C} / \mathrm{SiC}$ composites. J Eur Ceram Soc 2013, 33: 433-439.

[348] Günthner M, Kraus T, Krenkel W, et al. Particle-filled PHPS silazane-based coatings on steel. Int J Appl Ceram Technol 2009, 6: 373-380.

[349] Barroso GS, Krenkel W, Motz G. Low thermal conductivity coating system for application up to $1000{ }^{\circ} \mathrm{C}$ by simple PDC processing with active and passive fillers. J Eur Ceram Soc 2015, 35: 3339-3348.

[350] Shah SR, Raj R. Multilayer design and evaluation of a high temperature environmental barrier coating for Si-based ceramics. J Am Ceram Soc 2007, 90: 516-522.

[351] Zhao G, Hu P, Zhou S, et al. Ordered silica nanoparticles grown on a three-dimensional carbon fiber architecture substrate with siliconborocarbonitride ceramic as a thermal barrier coating. ACS Appl Mater Interfaces 2016, 8: $4216-4225$.

[352] Hasemann G, Baumann T, Dieck S, et al. Polymer-derived ceramics as innovative oxidation barrier coatings for Mo-Si-B alloys. Metall Mater Trans A 2015, 46: 1455-1460.

[353] Kappa M, Kebianyor A, Scheffler M. A two-component preceramic polymer system for structured coatings on metals. Thin Solid Films 2010, 519: 301-305.

[354] Gong X, An LN, Xu CY. Wireless passive sensor development for harsh environment applications. In: Proceedings of the IEEE International Workshop on Antenna Technology, 2012: 140-143.

[355] Tregay GW, Calabrese PR,. Kaplin PL, et al. Optical fiber sensor for temperature measurement from 600 to $1900{ }^{\circ} \mathrm{C}$ in gas turbine engines. In: Proceedings of SPIE - The International Society for Optical Engineering 1589, 1991: $38-47$.

[356] Bhattacharya A, Srinivasa Rao R, Ghanashyam Krishna M. Characterization of $\mathrm{Yb}_{2} \mathrm{O}_{3}$ based optical temperature sensor for high temperature applications. Sens Actuat A: Phys 2007, 134: 348-356. 
[357] Zhang LG, Wang YS, Wei Y, et al. A silicon carbonitride ceramic with anomalously high piezoresistivity. $J \mathrm{Am}$ Ceram Soc 2008, 91: 1346-1349.

[358] Riedel R, Toma L, Janssen E, et al. Piezoresistive effect in SiOC ceramics for integrated pressure sensors. $\mathrm{J} \mathrm{Am}$ Ceram Soc 2010, 93: 920-924.

[359] Wang YS, Zhang LG, Fan Y, et al. Stress-dependent piezoresistivity of tunneling-percolation systems. J Mater Sci 2009, 44: 2814-2819.

[360] Ma BS, Wang YG. Fabrication of dense polymer-derived silicon carbonitride ceramic bulks by precursor infiltration and pyrolysis processes without losing piezoresistivity. J Am Ceram Soc 2018, 101: 2752-2759.

[361] Li N, Cao YJ, Zhao R, et al. Polymer-derived SiAlOC ceramic pressure sensor with potential for hightemperature application. Sens Actuat A: Phys 2017, 263: 174-178.

[362] Ricohermoso III E, Rosenburg F, Klug F, et al. Piezoresistive carbon-containing ceramic nanocompositesA review. Open Ceram 2021, 5: 100057.

[363] Shao G, Jiang JP, Jiang MJ, et al. Polymer-derived SiBCN ceramic pressure sensor with excellent sensing performance. J Adv Ceram 2020, 9: 374-379.

[364] Nagaiah NR, Kapat JS, An L, et al. Novel polymer derived ceramic-high temperature heat flux sensor for gas turbine environment. J Phys: Conf Ser 2006, 34: 458-463.

[365] Seo D, Jung S, Lombardo SJ, et al. Fabrication and electrical properties of polymer-derived ceramic (PDC) thin films for high-temperature heat flux sensors. Sens Actuat A: Phys 2011, 165: 250-255.

[366] Zhao R, Shao G, Cao YJ, et al. Temperature sensor made of polymer-derived ceramics for high-temperature applications. Sens Actuat A: Phys 2014, 219: 58-64.

[367] Nagaiah NR, Sleiti AK, Rodriguez S, et al. A novel design and analysis of a MEMS ceramic hot-wire anemometer for high temperature applications. J Phys: Conf Ser 2006, 34: 277-282.

[368] Cheng HT, Shao G, Ebadi S, et al. Evanescentmode-resonator-based and antenna-integrated wireless passive pressure sensors for harsh-environment applications. Sens Actuat A: Phys 2014, 220: 22-33.

[369] Ren XH, Ebadi S, Chen YH, et al. Characterization of $\mathrm{SiCN}$ ceramic material dielectric properties at high temperatures for harsh environment sensing applications. IEEE Trans Microw Theory Tech 2013, 61: 960-971.

[370] Li Y, Yu YX, San HS, et al. Wireless passive polymer-derived $\mathrm{SiCN}$ ceramic sensor with integrated resonator/antenna. Appl Phys Lett 2013, 103: 163505.

[371] Wen L, Li F, Cheng HM. Carbon nanotubes and graphene for flexible electrochemical energy storage: From materials to devices. Adv Mater 2016, 28: 4306-4337.

[372] Guo YG, Hu JS, Wan LJ. Nanostructured materials for electrochemical energy conversion and storage devices. Adv Mater 2008, 20: 2878-2887.

[373] Mai LQ, Tian XC, Xu X, et al. Nanowire electrodes for electrochemical energy storage devices. Chem Rev 2014, 114: 11828-11862.

[374] Han S, Wu DQ, Li S, et al. Porous graphene materials for advanced electrochemical energy storage and conversion devices. Adv Mater 2014, 26: 849-864.

[375] Chen KF, Song SY, Liu F, et al. Structural design of graphene for use in electrochemical energy storage devices. Chem Soc Rev 2015, 44: 6230-6257.

[376] Wang H, Yang Y, Guo L. Nature-inspired electrochemical energy-storage materials and devices. Adv Energy Mater 2017, 7: 1601709.

[377] Chen S, Qiu L, Cheng HM. Carbon-based fibers for advanced electrochemical energy storage devices. Chem Rev 2020, 120: 2811-2878.

[378] Mackanic DG, Chang TH, Huang Z, et al. Stretchable electrochemical energy storage devices. Chem Soc Rev 2020, 49: 4466-4495.

[379] Zahir N, Magri P, Luo W, et al. Recent advances on graphene quantum dots for electrochemical energy storage devices. Energy Environ Mater 2021, https://doi. org/10.1002/eem2.12167.

[380] Tarascon JM, Armand M. Issues and challenges facing rechargeable lithium batteries. Nature 2001, 414: 359367.

[381] Scrosati B, Garche J. Lithium batteries: Status, prospects and future. J Power Sources 2010, 195: 2419-2430.

[382] Bruce P, Scrosati B, Tarascon JM. Nanomaterials for rechargeable lithium batteries. Angew Chem Int Ed 2008, 47: 2930-2946.

[383] Fergus JW. Recent developments in cathode materials for lithium ion batteries. J Power Sources 2010, 195: 939-954.

[384] Ji LW, Lin Z, Alcoutlabi M, et al. Recent developments in nanostructured anode materials for rechargeable lithium-ion batteries. Energy Environ Sci 2011, 4: 2682.

[385] Zhang WJ. A review of the electrochemical performance of alloy anodes for lithium-ion batteries. J Power Sources 2011, 196: 13-24.

[386] Kim SW, Seo DH, Ma XH, et al. Electrode materials for rechargeable sodium-ion batteries: Potential alternatives to current lithium-ion batteries. Adv Energy Mater 2012, 2: 710-721.

[387] Jian ZL, Han WZ, Lu X, et al. Superior electrochemical performance and storage mechanism of $\mathrm{Na}_{3} \mathrm{~V}_{2}\left(\mathrm{PO}_{4}\right)_{3}$ cathode for room-temperature sodium-ion batteries. $A d v$ Energy Mater 2013, 3: 156-160.

[388] Sun J, Lee HW, Pasta M, et al. A phosphorene-graphene hybrid material as a high-capacity anode for sodium-ion batteries. Nat Nanotechnol 2015, 10: 980-985.

[389] Ji XL, Lee KT, Nazar LF. A highly ordered nanostructured carbon-sulphur cathode for lithium-sulphur batteries. Nat Mater 2009, 8: 500-506.

[390] Yin YX, Xin S, Guo YG, et al. Lithium-sulfur batteries: Electrochemistry, materials, and prospects. Angew Chem Int Ed 2013, 52: 13186-13200. 
[391] Manthiram A, Fu YZ, Chung SH, et al. Rechargeable lithium-sulfur batteries. Chem Rev 2014, 114: 11751-11787.

[392] Zhang LL, Zhao XS. Carbon-based materials as supercapacitor electrodes. Chem Soc Rev 2009, 38: 2520-2531.

[393] Raza W, Ali F, Raza N, et al. Recent advancements in supercapacitor technology. Nano Energy 2018, 52: 441-473.

[394] Wang Y, Shi ZQ, Huang Y, et al. Supercapacitor devices based on graphene materials. $J$ Phys Chem C 2009, 113: 13103-13107.

[395] Cheng FY, Chen J. Metal-air batteries: From oxygen reduction electrochemistry to cathode catalysts. Chem Soc Rev 2012, 41: 2172.

[396] Kim J, Gwon O, Kwon O, et al. Synergistic coupling derived cobalt oxide with nitrogenated holey twodimensional matrix as an efficient bifunctional catalyst for metal-air batteries. ACS Nano 2019, 13: 5502-5512.

[397] Steele BC, Heinzel A. Materials for fuel-cell technologies. Nature 2001, 414: 345-352.

[398] Cano ZP, Banham D, Ye SY, et al. Batteries and fuel cells for emerging electric vehicle markets. Nat Energy 2018, 3: 279-289.

[399] Bhandavat R, Pei ZJ, Singh G. Polymer-derived ceramics as anode material for rechargeable Li-ion batteries: A review. Nanomater Energy 2012, 1: 324-337.

[400] Information on https://www.iea.org/publications/ freepublications/publication/EV_PHEV_Roadmap.pdf.

[401] Thomas BR. Linden's Handbook of Batteries, 4th edn. New York: McGraw-Hill Education, 2011.

[402] Whittingham MS. Electrical energy storage and intercalation chemistry. Science 1976, 192: 1126-1127.

[403] Rolison DR, Nazar LF. Electrochemical energy storage to power the 21st century. MRS Bull 2011, 36: 486-493.

[404] Yabuuchi N, Kubota K, Dahbi M, et al. Research development on sodium-ion batteries. Chem Rev 2014, 114: 11636-11682.

[405] Fan XM, Hu GR, Zhang B, et al. Crack-free single-crystalline Ni-rich layered NCM cathode enable superior cycling performance of lithium-ion batteries. Nano Energy 2020, 70: 104450.

[406] Nayak PK, Yang LT, Brehm W, et al. From lithium-ion to sodium-ion batteries: Advantages, challenges, and surprises. Angew Chem Int Ed 2018, 57: 102-120.

[407] Li M, Lu J, Chen ZW, et al. 30 years of lithium-ion batteries. Adv Mater 2018, 30: 1800561.

[408] Liu X, Huang JQ, Zhang Q, et al. Nanostructured metal oxides and sulfides for lithium-sulfur batteries. Adv Mater 2017, 29: 1601759.

[409] Sun YT, Liu XR, Jiang YM, et al. Recent advances and challenges in divalent and multivalent metal electrodes for metal-air batteries. J Mater Chem A 2019, 7: 18183-18208.

[410] Staffell I, Scamman D, Velazquez Abad A, et al. The role of hydrogen and fuel cells in the global energy system. Energy Environ Sci 2019, 12: 463-491.
[411] Mukherjee S, Ren ZK, Singh G. Molecular polymerderived ceramics for applications in electrochemical energy storage devices. J Phys D: Appl Phys 2018, 51: 463001.

[412] Mera G, Navrotsky A, Sen S, et al. Polymer-derived SiCN and SiOC ceramics-Structure and energetics at the nanoscale. J Mater Chem A 2013, 1: 3826.

[413] Francis A. Progress in polymer-derived functional siliconbased ceramic composites for biomedical and engineering applications. Mater Res Express 2018, 5: 062003.

[414] Wu F, Maier J, Yu Y. Guidelines and trends for next-generation rechargeable lithium and lithium-ion batteries. Chem Soc Rev 2020, 49: 1569-1614.

[415] Kim T, Song WT, Son DY, et al. Lithium-ion batteries: Outlook on present, future, and hybridized technologies. $J$ Mater Chem A 2019, 7: 2942-2964.

[416] Choi JW, Aurbach D. Promise and reality of post-lithiumion batteries with high energy densities. Nat Rev Mater 2016, 1: 16013.

[417] Agubra V, Fergus J. Lithium ion battery anode aging mechanisms. Materials: Basel 2013, 6: 1310-1325.

[418] Smart MC, Ratnakumar BV. Effects of electrolyte composition on lithium plating in lithium-ion cells. $J$ Electrochem Soc 2011, 158: A379-A389.

[419] Ratnakumar BV, Smart MC. Lithium plating behavior in lithium-ion cells. ECS Trans, 2010, 25: 241-252.

[420] Bhattacharyya R, Key B, Chen HL, et al. In situ NMR observation of the formation of metallic lithium microstructures in lithium batteries. Nat Mater 2010, 9: 504-510.

[421] Honbo H, Takei K, Ishii Y, et al. Electrochemical properties and $\mathrm{Li}$ deposition morphologies of surface modified graphite after grinding. J Power Sources 2009, 189: $337-343$

[422] Markervich E, Salitra G, Levi MD, et al. Capacity fading of lithiated graphite electrodes studied by a combination of electroanalytical methods, Raman spectroscopy and SEM. J Power Sources 2005, 146: 146-150.

[423] Ning G, Haran BL, Popov BN. Capacity fade study of lithium-ion batteries cycled at high discharge rates. $J$ Power Sources 2003, 117: 160-169.

[424] Markovsky B, Rodkin A, Cohen YS, et al. The study of capacity fading processes of Li-ion batteries: Major factors that play a role. J Power Sources 2003, 119-121: 504-510.

[425] Levi MD, Wang C, Gnanaraj JS, et al. Electrochemical behavior of graphite anode at elevated temperatures in organic carbonate solutions. J Power Sources 2003, 119-121: 538-542.

[426] Gnanaraj JS, Levi MD, Levi E, et al. Comparison between the electrochemical behavior of disordered carbons and graphite electrodes in connection with their structure. $J$ Electrochem Soc 2001, 148: A525.

[427] Markovsky B, Levi MD, Aurbach D. The basic electroanalytical behavior of practical graphite-lithium 
intercalation electrodes. Electrochimica Acta 1998, 43: 2287-2304.

[428] Aurbach D, Levi MD, Levi E, et al. Common electroanalytical behavior of $\mathrm{Li}$ intercalation processes into graphite and transition metal oxides. $J$ Electrochem Soc 1998, 145: 3024-3034.

[429] Lu J, Chen ZW, Pan F, et al. High-performance anode materials for rechargeable lithium-ion batteries. Electrochem Energy Rev 2018, 1: 35-53.

[430] Feng K, Li M, Liu WW, et al. Silicon-based anodes for lithium-ion batteries: From fundamentals to practical applications. Small 2018, 14: 1702737.

[431] Zuo XX, Zhu J, Müller-Buschbaum P, et al. Silicon based lithium-ion battery anodes: A chronicle perspective review. Nano Energy 2017, 31: 113-143.

[432] Bargeron CB, Benson RC, Jette AN, et al. Oxidation of hafnium carbide in the temperature range 1400 to $2060{ }^{\circ} \mathrm{C}$. $J$ Am Ceram Soc 1993, 76: 1040-1046.

[433] Li GD, Xiong X, Huang BY, et al. Oxidized characteristic and oxidized mechanism of $\mathrm{TaC}$ coating. Chin $J$ Nonferrous 2007, 17: 360-367. (in Chinese)

[434] Mera G, Gallei M, Bernard S, et al. Ceramic nanocomposites from tailor-made preceramic polymers. Nanomaterials: Basel 2015, 5: 468-540.

[435] Graczyk-Zajac M, Reinold LM, Kaspar J, et al. New insights into understanding irreversible and reversible lithium storage within $\mathrm{SiOC}$ and $\mathrm{SiCN}$ ceramics. Nanomaterials: Basel 2015, 5: 233-245.

[436] Knozowski D, Graczyk-Zajac M, Trykowski G, et al. Silicon oxycarbide-graphite electrodes for high-power energy storage devices. Materials 2020, 13: 4302.

[437] Xing WB, Wilson AM, Eguchi K, et al. Pyrolyzed polysiloxanes for use as anode materials in lithium-ion batteries. J Electrochem Soc 1997, 144: 2410-2416.

[438] Wilson AM, Reimers JN, Fuller EW, et al. Lithium insertion in pyrolyzed siloxane polymers. Solid State Ion 1994, 74: 249-254.

[439] David L, Bhandavat R, Barrera U, et al. Polymer-derived ceramic functionalized $\mathrm{MoS}_{2}$ composite paper as a stable lithium-ion battery electrode. Sci Rep 2015, 5: 9792.

[440] Xing WB, Wilson AM, Zank G, et al. Pyrolysed pitch-polysilane blends for use as anode materials in lithium ion batteries. Solid State Ion 1997, 93: 239-244.

[441] Wilson AM, Zank G, Eguchi K, et al. Polysiloxane pyrolysis. Chem Mater 1997, 9: 1601-1606.

[442] Wilson AM, Zank G, Eguchi K, et al. Pyrolysed silicon-containing polymers as high capacity anodes for lithium-ion batteries. J Power Sources 1997, 68: 195-200.

[443] Wilson A. Pyrolysed pitch-polysilane blends for use as anode materials in lithium ion batteries II: The effect of oxygen. Solid State Ion 1997, 100: 259-266.

[444] Ahn D, Raj R. Thermodynamic measurements pertaining to the hysteretic intercalation of lithium in polymerderived silicon oxycarbide. J Power Sources 2010, 195: 3900-3906.
[445] Ahn D, Raj R. Cyclic stability and C-rate performance of amorphous silicon and carbon based anodes for electrochemical storage of lithium. J Power Sources 2011, 196: 2179-2186.

[446] Sanchez-Jimenez PE, Raj R. Lithium insertion in polymer-derived silicon oxycarbide ceramics. $\mathrm{J} \mathrm{Am}$ Ceram Soc 2010, 93: 1127-1135.

[447] Saha A, Raj R, Williamson DL. A model for the nanodomains in polymer-derived SiCO. J Am Ceram Soc 2006, 89: 2188-2195.

[448] Fukui H, Harimoto Y, Akasaka M, et al. Lithium species in electrochemically lithiated and delithiated silicon oxycarbides. ACS Appl Mater Interfaces 2014, 6: 12827-12836.

[449] Fukui H, Ohsuka H, Hino T, et al. A Si-O-C composite anode: High capability and proposed mechanism of lithium storage associated with microstructural characteristics. ACS Appl Mater Interfaces 2010, 2: 998-1008.

[450] Graczyk-Zajac M, Toma L, Fasel C, et al. Carbon-rich SiOC anodes for lithium-ion batteries: Part I. Influence of material UV-pre-treatment on high power properties. Solid State Ion 2012, 225: 522-526.

[451] Graczyk-Zajac M, Vrankovic D, Waleska P, et al. The Li-storage capacity of SiOC glasses with and without mixed silicon oxycarbide bonds. J Mater Chem A 2018, 6: 93-103.

[452] Knozowski D, Graczyk-Zając M, Vrankovic D, et al. New insights on lithium storage in silicon oxycarbide/carbon composites: Impact of microstructure on electrochemical properties. Compos B: Eng 2021, 225: 109302.

[453] Kaspar J, Graczyk-Zajac M, Choudhury S, et al. Impact of the electrical conductivity on the lithium capacity of polymer-derived silicon oxycarbide (SiOC) ceramics. Electrochimica Acta 2016, 216: 196-202.

[454] Kaspar J, Graczyk-Zajac M, Riedel R. Determination of the chemical diffusion coefficient of Li-ions in carbonrich silicon oxycarbide anodes by electro-analytical methods. Electrochimica Acta 2014, 115: 665-670.

[455] Wilamowska M, Pradeep VS, Graczyk-Zajac M, et al. Tailoring of SiOC composition as a way to better performing anodes for Li-ion batteries. Solid State Ion 2014, 260: 94-100.

[456] Pradeep VS, Graczyk-Zajac M, Riedel R, et al. New insights in to the lithium storage mechanism in polymer derived SiOC anode materials. Electrochimica Acta 2014, 119: 78-85.

[457] Pradeep VS, Ayana DG, Graczyk-Zajac M, et al. High rate capability of SiOC ceramic aerogels with tailored porosity as anode materials for Li-ion batteries. Electrochimica Acta 2015, 157: 41-45.

[458] Haaks M, Kaspar J, Franz A, et al. 7Li NMR studies of lithium ion dynamics in polymer-derived silicon oxycarbide ceramics. Solid State Ion 2016, 287: 28-35. 
[459] Sun H, Zhao KJ. Atomistic origins of high capacity and high structural stability of polymer-derived SiOC anode materials. ACS Appl Mater Interfaces 2017, 9: 35001-35009.

[460] Kaspar J, Graczyk-Zajac M, Riedel R. Lithium insertion into carbon-rich SiOC ceramics: Influence of pyrolysis temperature on electrochemical properties. J Power Sources 2013, 244: 450-455.

[461] Fukui H, Ohsuka H, Hino $\mathrm{T}$, et al. Preparation of microporous $\mathrm{Si}-\mathrm{O}-\mathrm{C}$ composite material and its lithium storage capability. Chem Lett 2009, 38: 86-87.

[462] Xia KD, Wu ZX, Xuan CJ, et al. Effect of $\mathrm{KOH}$ etching on the structure and electrochemical performance of SiOC anodes for lithium-ion batteries. Electrochimica Acta 2017, 245: 287-295.

[463] Sang ZY, Zhao ZH, Su D, et al. SiOC nanolayer wrapped $3 \mathrm{D}$ interconnected graphene sponge as a high-performance anode for lithium ion batteries. J Mater Chem A 2018, 6: 9064-9073.

[464] Pradeep VS, Graczyk-Zajac M, Wilamowska M, et al. Influence of pyrolysis atmosphere on the lithium storage properties of carbon-rich polymer derived $\mathrm{SiOC}$ ceramic anodes. Solid State Ion 2014, 262: 22-24.

[465] Shen J, Raj R. Silicon-oxycarbide based thin film anodes for lithium ion batteries. J Power Sources 2011, 196: 5945-5950.

[466] Dong BB, Han YH, Wang T, et al. Hard SiOC microbeads as a high-performance lithium-ion battery anode. ACS Appl Energy Mater 2020, 3: 10183-10191.

[467] Ma MB, Wang HJ, Li X, et al. Free-standing $\mathrm{SiOC} /$ nitrogen-doped carbon fibers with highly capacitive Li storage. J Eur Ceram Soc 2020, 40: 5238-5246.

[468] Lim H, Kim H, Kim SO, et al. Novel approach for controlling free-carbon domain in silicone oil-derived silicon oxycarbide ( $\mathrm{SiOC}$ ) as an anode material in secondary batteries. Chem Eng J 2021, 404: 126581.

[469] Shao GF, Hanaor DAH, Wang J, et al. Polymer-derived $\mathrm{SiOC}$ integrated with a graphene aerogel as a highly stable Li-ion battery anode. ACS Appl Mater Interfaces 2020, 12: 46045-46056.

[470] Kaspar J, Graczyk-Zajac M, Lauterbach S, et al. Silicon oxycarbide/nano-silicon composite anodes for Li-ion batteries: Considerable influence of nano-crystalline vs. nano-amorphous silicon embedment on the electrochemical properties. J Power Sources 2014, 269: 164-172.

[471] Xia KD, Qu L, Liu X, et al. Effect of $\mathrm{SnCl}_{2}$ addition on the structure and lithium storage performance of SiOC anodes. Appl Surf Sci 2020, 506: 144775.

[472] Dubey RJ, Sasikumar PVW, Cerboni N, et al. Silicon oxycarbide-antimony nanocomposites for high-performance Li-ion battery anodes. Nanoscale 2020, 12: 13540-13547.

[473] Zank GA, Dahn JR, Wilson AM, et al. Electrodes for lithium ion batteries using polysilazanes ceramic with lithium. U.S. Patent 5631106(A), 1997.

[474] Liebau-Kunzmann V, Fasel C, Kolb R, et al. Lithium containing silazanes as precursors for $\mathrm{SiCN}$ : $\mathrm{Li}$ ceramics-A potential material for electrochemical applications. J Eur Ceram Soc 2006, 26: 3897-3901.

[475] Su D, Li YL, Feng Y, et al. Electrochemical properties of polymer-derived $\mathrm{SiCN}$ materials as the anode in lithium ion batteries. J Am Ceram Soc 2009, 92: 2962-2968.

[476] Feng Y. Electrochemical properties of heat-treated polymer-derived $\mathrm{SiCN}$ anode for lithium ion batteries. Electrochimica Acta 2010, 55: 5860-5866.

[477] Kaspar J, Mera G, Nowak AP, et al. Electrochemical study of lithium insertion into carbon-rich polymer-derived silicon carbonitride ceramics. Electrochimica Acta 2010, 56: 174-182.

[478] Graczyk-Zajac M, Mera G, Kaspar J, et al. Electrochemical studies of carbon-rich polymer-derived $\mathrm{SiCN}$ ceramics as anode materials for lithium-ion batteries. J Eur Ceram Soc 2010, 30: 3235-3243.

[479] Reinold LM, Graczyk-Zajac M, Gao Y, et al. Carbon-rich SiCN ceramics as high capacity/high stability anode material for lithium-ion batteries. J Power Sources 2013, 236: 224-229.

[480] Liu GW, Kaspar J, Reinold LM, et al. Electrochemical performance of DVB-modified SiOC and SiCN polymer-derived negative electrodes for lithium-ion batteries. Electrochimica Acta 2013, 106: 101-108.

[481] Baek SH, Reinold LM, Graczyk-Zajac M, et al. Lithium dynamics in carbon-rich polymer-derived SiCN ceramics probed by nuclear magnetic resonance. J Power Sources 2014, 253: 342-348.

[482] Wilamowska M, Graczyk-Zajac M, Riedel R. Composite materials based on polymer-derived $\mathrm{SiCN}$ ceramic and disordered hard carbons as anodes for lithium-ion batteries. J Power Sources 2013, 244: 80-86.

[483] Graczyk-Zajac M, Wimmer M, Xu YP, et al. Lithium intercalation into disordered carbon/SiCN composite. Part 2: Raman spectroscopy and ${ }^{7} \mathrm{Li}$ MAS NMR investigation of lithium storage sites. J Solid State Electrochem 2017 , 21: 47-55.

[484] Graczyk-Zajac M, Wimmer M, Neumann C, et al. Lithium intercalation into $\mathrm{SiCN} /$ disordered carbon composite. Part 1: Influence of initial carbon porosity on cycling performance/capacity. J Solid State Electrochem 2015, 19: 2763-2769.

[485] Feng Y, Dou SM, Wei YZ, et al. Preparation and capacity-fading investigation of polymer-derived silicon carbonitride anode for lithium-ion battery. ACS Omega 2017, 2: 8075-8085.

[486] Storch M, Vrankovic D, Graczyk-Zajac M, et al. The influence of pyrolysis temperature on the electrochemical behavior of porous carbon-rich SiCN polymer-derived ceramics. Solid State Ion 2018, 315: 59-64.

[487] Rohrer J, Vrankovic D, Cupid D, et al. Si- and Sn-containing SiOCN-based nanocomposites as anode materials for lithium ion batteries: Synthesis, thermodynamic 
characterization and modeling. Int J Mater Res 2017, 108: 920-932.

[488] Ng SF, Lau MYL, Ong WJ. Lithium-sulfur battery cathode design: Tailoring metal-based nanostructures for robust polysulfide adsorption and catalytic conversion. Adv Mater 2021, https://doi.org/10.1002/adma.202008654.

[489] Weinberger M, Munding J, Lindén M, et al. Templatederived submicrometric carbon spheres for lithium-sulfur and sodium-ion battery electrodes. Energy Technol 2018, 6: $1797-1804$.

[490] Qu FM, Graczyk-Zajac M, Vrankovic D, et al. Effect of morphology of C-rich silicon carbonitride ceramic on electrochemical properties of sulfur cathode for $\mathrm{Li}-\mathrm{S}$ battery. Electrochimica Acta 2021, 384: 138265.

[491] Fang RY, Xia Y, Liang C, et al. Supercritical $\mathrm{CO}_{2}$-assisted synthesis of $3 \mathrm{D}$ porous $\mathrm{SiOC} / \mathrm{Se}$ cathode for ultrahigh areal capacity and long cycle life Li-Se batteries. J Mater Chem A 2018, 6: 24773-24782.

[492] Zeng LC, Li WH, Jiang Y, et al. Recent progress in Li-S and Li-Se batteries. Rare Met 2017, 36: 339-364.

[493] Jin J, Tian XC, Srikanth N, et al. Advances and challenges of nanostructured electrodes for Li-Se batteries. J Mater Chem A 2017, 5: 10110-10126.

[494] Vaalma C, Buchholz D, Weil M, et al. A cost and resource analysis of sodium-ion batteries. Nat Rev Mater 2018, 3: 18013.

[495] Palomares V, Serras P, Villaluenga I, et al. Na-ion batteries, recent advances and present challenges to become low cost energy storage systems. Energy Environ Sci 2012, 5: 5884.

[496] Sangster J. C-Na (carbon-sodium) system. J Phase Equilibria Diffusion 2007, 28: 571-579.

[497] Stevens DA, Dahn JR. High capacity anode materials for rechargeable sodium-ion batteries. $J$ Electrochem Soc 2000, 147: 1271.

[498] Wenzel S, Hara T, Janek J, et al. Room-temperature sodium-ion batteries: Improving the rate capability of carbon anode materials by templating strategies. Energy Environ Sci 2011, 4: 3342.

[499] Palomares V, Casas-Cabanas M, Castillo-Martínez E, et al. Update on Na-based battery materials. A growing research path. Energy Environ Sci 2013, 6: 2312.

[500] Slater MD, Kim D, Lee E, et al. Sodium-ion batteries. Adv Funct Mater 2013, 23: 947-958.

[501] Kaspar J, Storch M, Schitco C, et al. SiOC(N)/hard carbon composite anodes for Na-ion batteries: Influence of morphology on the electrochemical properties. $J$ Electrochem Soc 2015, 163: A156-A162.

[502] Lee Y, Lee KY, Choi W. One-pot synthesis of antimony-embedded silicon oxycarbide materials for high-performance sodium-ion batteries. Adv Funct Mater 2017, 27: 1702607.

[503] Kim D, Kim H, Lim H, et al. A facile control in free-carbon domain with divinylbenzene for the high- rate-performing $\mathrm{Sb} / \mathrm{SiOC}$ composite anode material in sodium-ion batteries. Int J Energy Res 2020, 44: 1147311486.

[504] Chandra C, Kim J. Silicon oxycarbide produced from silicone oil for high-performance anode material in sodium ion batteries. Chem Eng J 2018, 338: 126-136.

[505] Chandra C, Cahyadi HS, Alvin S, et al. Revealing the sodium storage mechanism in high-temperature-synthesized silicon oxycarbides. Chem Mater 2020, 32: 410-423.

[506] Lim H, Yu S, Choi W, et al. Hierarchically designed nitrogen-doped $\mathrm{MoS}_{2} /$ silicon oxycarbide nanoscale heterostructure as high-performance sodium-ion battery anode. ACS Nano 2021, 15: 7409-7420.

[507] Putra RN, Halim M, Ali G, et al. High-rate sodium insertion/extraction into silicon oxycarbide-reduced graphene oxide. New J Chem 2020, 44: 14035-14040.

[508] Chandra C, Devina W, Alvin S, et al. New strategy for increasing sodium-ion uptake in silicon oxycarbides. Chem Eng J 2021, 404: 126520.

[509] Li Z, Dong Y, Feng J, et al. Controllably enriched oxygen vacancies through polymer assistance in titanium pyrophosphate as a super anode for $\mathrm{Na} / \mathrm{K}$-ion batteries. ACS Nano 2019, 13: 9227-9236.

[510] Sang ZY, Su D, Wang JS, et al. Bi-continuous nanoporous carbon sphere derived from $\mathrm{SiOC}$ as high-performance anodes for PIBs. Chem Eng J 2020, 381: 122677.

[511] Jiang YQ, Liu JP. Definitions of pseudocapacitive materials: A brief review. Energy Environ Mater 2019, 2: 30-37.

[512] Poonam, Sharma K, Arora A, et al. Review of supercapacitors: Materials and devices. J Energy Storage 2019, 21: 801-825.

[513] Muzaffar A, Ahamed MB, Deshmukh K, et al. A review on recent advances in hybrid supercapacitors: Design, fabrication and applications. Renew Sustain Energy Rev 2019, 101: 123-145.

[514] Abass MA, Syed AA, Gervais C, et al. Synthesis and electrochemical performance of a polymer-derived silicon oxycarbide/boron nitride nanotube composite. RSC $A d v$ 2017, 7: 21576-21584.

[515] Pazhamalai $\mathrm{P}$, Krishnamoorthy $\mathrm{K}$, Sahoo S, et al. Carbothermal conversion of siloxene sheets into silicon-oxy-carbide lamellae for high-performance supercapacitors. Chem Eng J 2020, 387: 123886.

[516] Mujib SB, Cuccato R, Mukherjee S, et al. Electrospun SiOC ceramic fiber mats as freestanding electrodes for electrochemical energy storage applications. Ceram Int 2020, 46: 3565-3573.

[517] Kim M, Oh I, Kim J. Influence of surface oxygen functional group on the electrochemical behavior of porous silicon carbide based supercapacitor electrode. Electrochimica Acta 2016, 196: 357-368.

[518] Okoroanyanwu U, Bhardwaj A, Einck V, et al. Rapid preparation and electrochemical energy storage applications 
of silicon carbide and silicon oxycarbide ceramic/carbon nanocomposites derived via flash photothermal pyrolysis of organosilicon preceramic polymers. Chem Mater 2021, 33: 678-694.

[519] Moyano JJ, Mosa J, Aparicio M, et al. Strong and light cellular silicon carbonitride-Reduced graphene oxide material with enhanced electrical conductivity and capacitive response. Addit Manuf 2019, 30: 100849.

[520] Meier A, Weinberger M, Pinkert K, et al. Silicon oxycarbide-derived carbons from a polyphenylsilsequioxane precursor for supercapacitor applications. Microporous Mesoporous Mater 2014, 188: 140-148.

[521] Duan LQ, Ma QS, Mei L, et al. Fabrication and electrochemical performance of nanoporous carbon derived from silicon oxycarbide. Microporous Mesoporous Mater 2015, 202: 97-105.

[522] Tolosa A, Krüner B, Jäckel N, et al. Electrospinning and electrospraying of silicon oxycarbide-derived nanoporous carbon for supercapacitor electrodes. J Power Sources 2016, 313: 178-188.

[523] Yang J, Wu HL, Zhu M, et al. Optimized mesopores enabling enhanced rate performance in novel ultrahigh surface area meso-/microporous carbon for supercapacitors. Nano Energy 2017, 33: 453-461.

[524] Swain IP, Pati S, Behera SK. A preceramic polymer derived nanoporous carbon hybrid for supercapacitors. Chem Commun 2019, 55: 8631-8634.

[525] Sun HY, Pan JM, Yan XH, et al. $\mathrm{MnO}_{2}$ nanoneedles loaded on silicon oxycarbide-derived hierarchically porous carbon for supercapacitor electrodes with enhanced electrochemical performance. Ceram Int 2019, 45: 24802-24810.

[526] Smith SA, Park JH, Williams BP, et al. Polymer/ceramic co-continuous nanofiber membranes via room-curable organopolysilazane for improved lithium-ion battery performance. J Mater Sci 2017, 52: 3657-3669.

[527] Smith SA, Williams BP, Joo YL. Effect of polymer and ceramic morphology on the material and electrochemical properties of electrospun PAN/polymer derived ceramic composite nanofiber membranes for lithium ion battery separators. J Membr Sci 2017, 526: 315-322.

[528] Moni P, Deschamps A, Schumacher D, et al. A new silicon oxycarbide based gas diffusion layer for zinc-air batteries. J Colloid Interface Sci 2020, 577: 494-502.

Open Access This article is licensed under a Creative Commons Attribution 4.0 International License, which permits use, sharing, adaptation, distribution and reproduction in any medium or format, as long as you give appropriate credit to the original author(s) and the source, provide a link to the Creative Commons licence, and indicate if changes were made.

The images or other third party material in this article are included in the article's Creative Commons licence, unless indicated otherwise in a credit line to the material. If material is not included in the article's Creative Commons licence and your intended use is not permitted by statutory regulation or exceeds the permitted use, you will need to obtain permission directly from the copyright holder.

To view a copy of this licence, visit http://creativecommons. org/licenses/by/4.0/. 